\title{
BIOACTIVE COATINGS FOR DIRECT SKELETAL ATTACHMENT APPLICATIONS FOR LOWER LIMB PROSTHESES
}

\author{
by \\ Omar Rodríguez \\ MSc/BSc, Mechanical Engineering, Utah State University, 2010 \\ A dissertation \\ presented to Ryerson University \\ in partial fulfillment of the \\ requirements for the degree of \\ Doctor of Philosophy \\ in the Program of \\ Mechanical Engineering
}

Toronto, Ontario, Canada, 2017

COmar Rodríguez 2017 


\section{Author's Declaration}

\section{AUTHOR'S DECLARATION FOR ELECTRONIC SUBMISSION OF A DISSERTATION}

I hereby declare that I am the sole author of this dissertation. This is a true copy of the dissertation, including any required final revisions, as accepted by my examiners.

I authorize Ryerson University to lend this dissertation to other institutions or individuals for the purpose of scholarly research.

I further authorize Ryerson University to reproduce this dissertation by photocopying or by other means, in total or in part, at the request of other institutions or individuals for the purpose of scholarly research.

I understand that my dissertation may be made electronically available to the public. 


\begin{abstract}
BIOACTIVE COATINGS FOR DIRECT SKELETAL ATTACHMENT APPLICATIONS FOR LOWER LIMB PROSTHESES

Doctor of Philosophy, 2017

Omar Rodríguez

Department of Mechanical \& Industrial Engineering

Faculty of Engineering \& Architectural Science, Ryerson University
\end{abstract}

To tackle the current drawbacks with metallic implants used in direct skeletal attachment, novel bioactive glasses are considered as implant coatings in order to reduce bacterial infections and promote bone cell growth. Silica-based and borate-based glasses, with increasing amounts of titanium dioxide at the expense of either silica (for the silica-based glasses) or borate (for the borate-based glasses), respectively, were synthesized and characterized to determine the parameters that define a glass capable of inhibiting bacterial growth, stimulating cell proliferation and offering mechanical stability when enameled into a surgical alloy. The effect of substituting the glass backbone with titanium dioxide, in both glass series, is also investigated with respect to its effect on both biocompatibility and mechanical properties of the resultant glass/implant constructs.

Borate-based glasses exhibited greater processing windows compared to the silica-based glasses, making them more desirable for coating applications. They also exhibited superior performance in terms of their in vitro bioactivity and biocompatibility, over their silica-based counterparts, due to their higher solubility and greater ability to inhibit S. epidermidis and E. coli bacteria. Specifically, glass BRT0 (control borate-based glass, with no titanium incorporated) exhibited an inhibition zone against S. epidermidis of $17.5 \mathrm{~mm}$ and a mass loss of $40 \%$ after 30 days, with BRT3 (borate-based glass, with $15 \mathrm{~mol} \%$ titanium incorporated) exhibiting an 
inhibition zone against S. epidermidis of $7.6 \mathrm{~mm}$ and a mass loss of $34 \%$ after 30 days. Furthermore, borate-based glasses with greater titanium dioxide contents exhibited superior mechanical properties (e.g. bulk hardness, and critical strain energy release rates), which could be attributed to their more closely matched coefficients of thermal expansion with the titanium alloy substrate, Ti6A14V, to which they were adhered. The critical strain energy release rates in mode I for the silica-based coating/substrate system ranged from $6.2 \mathrm{~J} / \mathrm{m}^{2}$ (for SRT0, control silica-based glass with no titanium) to $12.08 \mathrm{~J} / \mathrm{m}^{2}$ (for SRT3), whereas for the borate-based systems they ranged from $10.86 \mathrm{~J} / \mathrm{m}^{2}$ (for BRT0) to $18.5 \mathrm{~J} / \mathrm{m}^{2}$ (for BRT3), with the increase for the borate-based glasses being attributed to the presence of compressive residual stresses in the coating after application. 


\section{Acknowledgements}

Firstly, I would like to thank my supervisors, Dr. Mark Towler and Dr. Marcello Papini, for giving me the opportunity to work in such an awesome research group, and for providing guidance every step of the way. I would also like to thank my family: Francisco, Marina, Ana Marina, Roberto, Octavio, María and Marianny, for always giving me their unconditional support throughout this process. My lab mates also deserve a piece of the cake for helping me out when I needed a hand and for being there to challenge me when I needed it: Adel, Mike, Li, Alireza, Saad, Faizan and Basel. Alongside my lab mates, I would like to acknowledge the help from the following Ryerson technicians: Alan Machin, Andrew Heim, Joe Amankrah, Shawn McFadden, Chao Ma, Qiang Li, Roy Churaman and Grace He. Dr. Declan Curran, Dr. Anthony Wren, Dr. Daniel Boyd and Dr. Owen Clarkin also helped me out throughout the making of this dissertation, providing technical and analytical support on some of the experiments performed.

Last, but not least, I could not have gotten to this point without the support and patience from my friends: Dulce Minaya, Michael Calcaño, Evelin Vargas, Sophy Bonnet, Filiberto Arriaga, Pedro Mateo, Vladimir Sosa, Manuel Diaz, Brian Battaglia, Steve Jones, Nevetha Yogarajah, Eduardo Duran, and Vineet Missra, to name a few.

I would like to thank the Collaborative Health Research Project fund (\#315694-DAN) for financing this research and the Ryerson University Strategic Hire program for early assistance with my stipend. Additionally, I would also like to thank Tim Keenan, Yiming Li, Ehsan Zeimaran, Qiang Li, Glenn Facey, Satoshi Hayakawa, Simon Chon, Warren Tang, Sunjeev Phul, Isaac Beniluz, Bharath Krishnan and the Malaysian Office of Higher Education High Impact Research program (HIR3/EP8) for assisting with aspects of data collection. 


\section{Dedication}

Le dedico este trabajo a mi querida abuela, Ana Iris, quien, sin quererlo, me inspiró a trabajar arduamente para conseguir lo que quiero en esta vida; a mis padres Francisco y Marina por siempre apoyarme en cada paso de mi carrera y de mi vida.

A mi sobrino Octavio también le dedico este trabajo, que sepa que aunque su tío está lejos, siempre lo tiene presente y que estos sacrificios los hago no solamente por mí, sino por él también. 


\section{Tables of Contents}

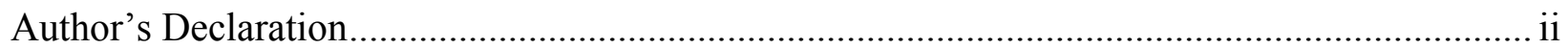

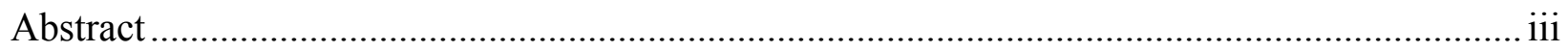

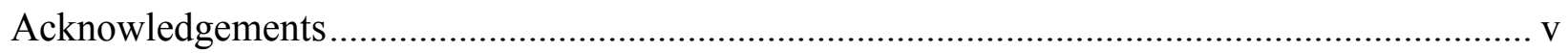

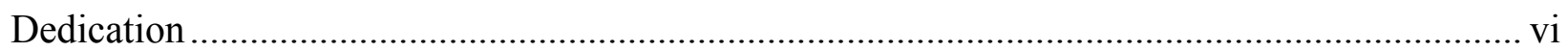

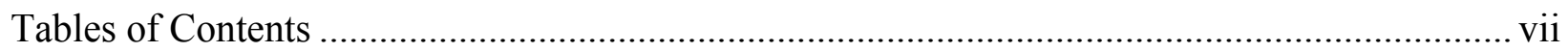

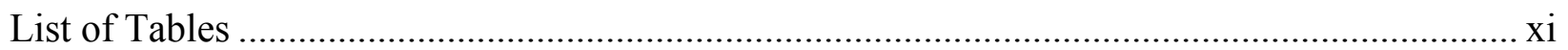

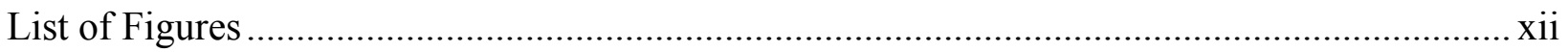

List of Abbreviations ..................................................................................................

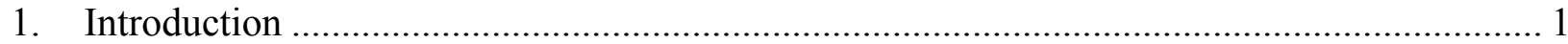

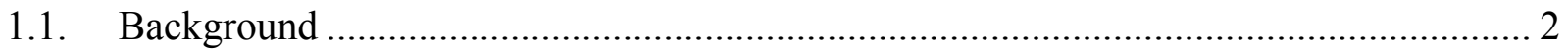

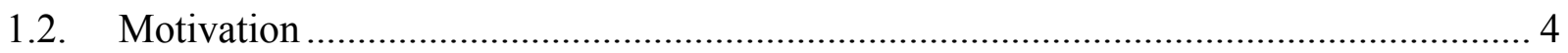

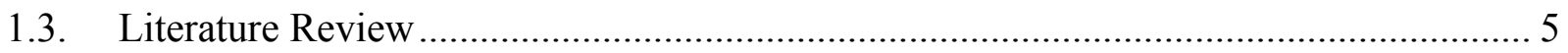

1.3.1. Osseointegration and Osseoperception ..................................................... 5

1.3.2. Metal Coating and Adhesion Measurement...................................................... 7

1.3.3. Bioactive Glasses for Coatings and Rationale for Proposed Formulations ........... 10

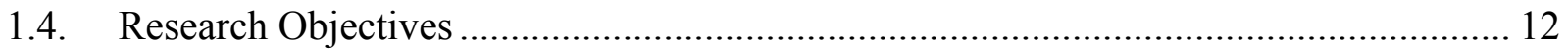

1.5. Author's Contribution in the Context of Collaboration .............................................. 14

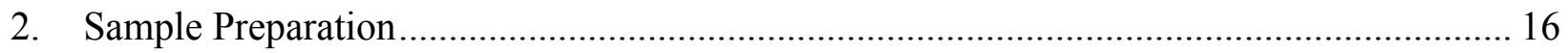

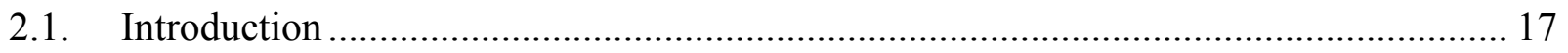

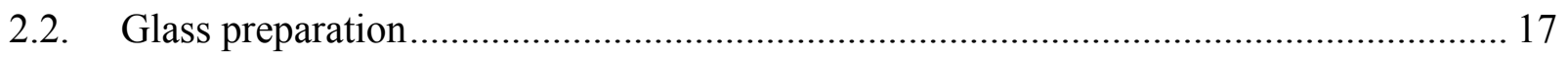

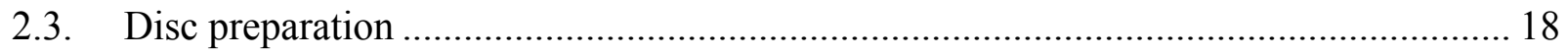

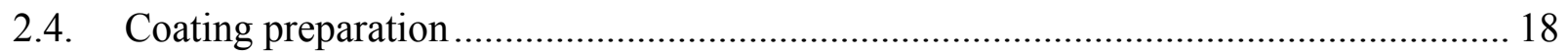

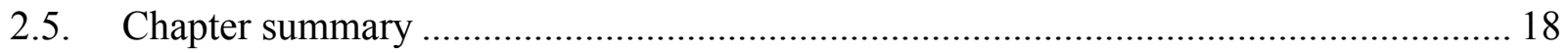


3. Characterization of Silica-based and Borate-based, Titanium-containing Bioactive Glasses

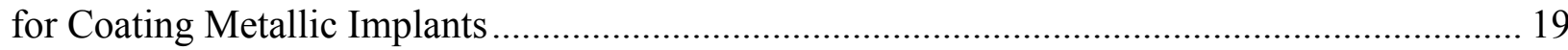

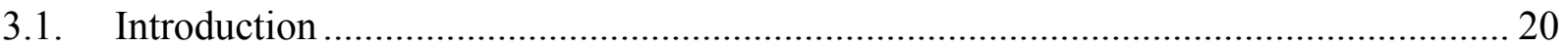

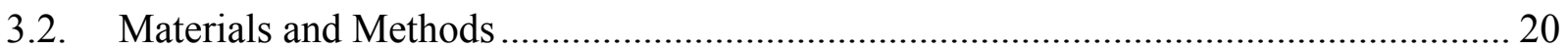

3.2.1. Glass preparation ................................................................................... 20

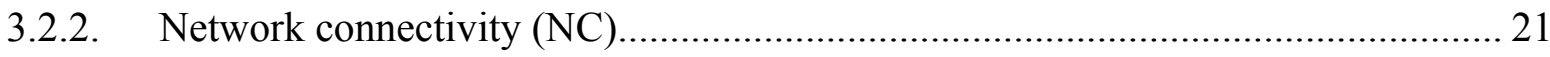

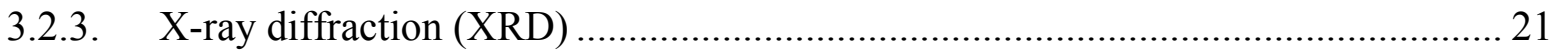

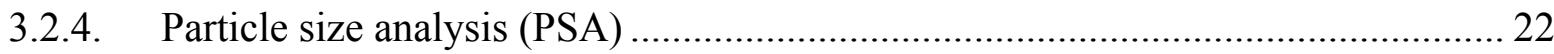

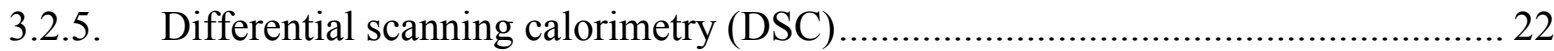

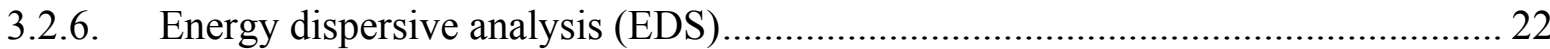

3.2.7. Fourier transform infrared (FTIR) spectroscopy ........................................... 23

3.2.8. Magic-angle spinning- Nuclear magnetic resonance spectroscopy (MAS-NMR). 23

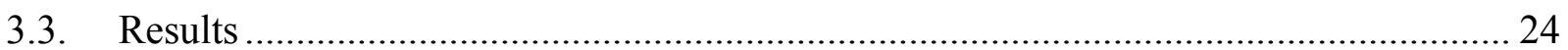

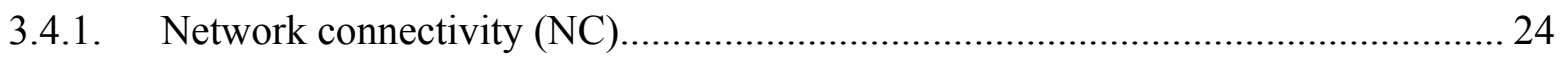

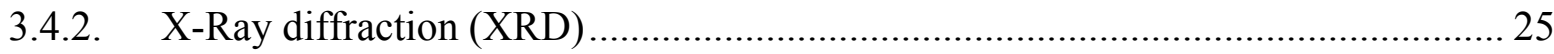

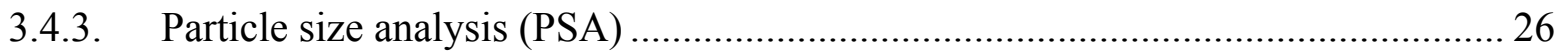

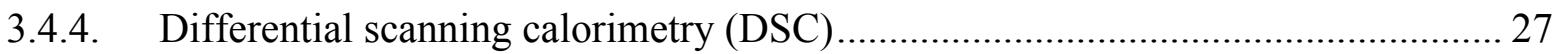

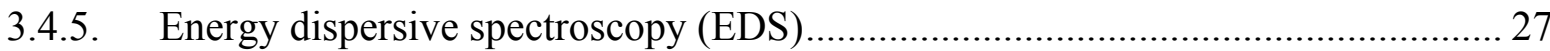

3.4.6. Fourier transform infrared (FTIR) spectroscopy ....................................... 30

3.4.7. Magic-angle spinning- Nuclear magnetic resonance spectroscopy (MAS-NMR) . 32

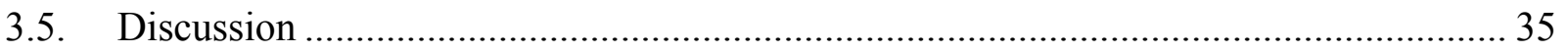

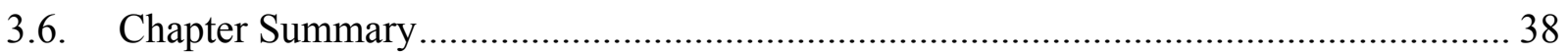

4. Biocompatibility Behavior of Titanium-containing Bioactive Glasses for Metallic Implant Coating: Solubility, Cytotoxicity and Antibacterial Analysis ............................................. 40

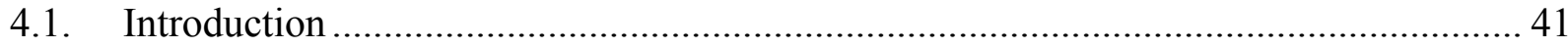

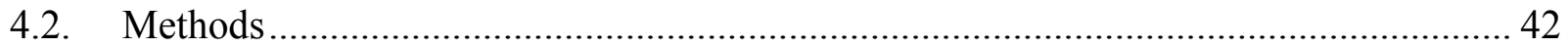




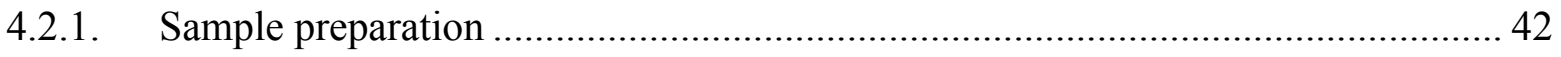

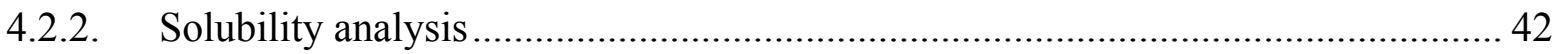

4.2.3. Ion release through Atomic Absorption Spectroscopy (AAS) ............................. 42

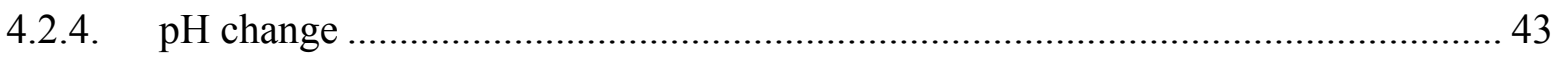

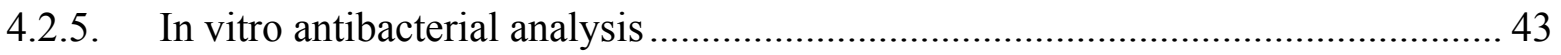

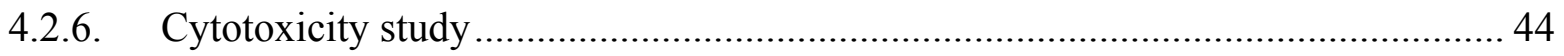

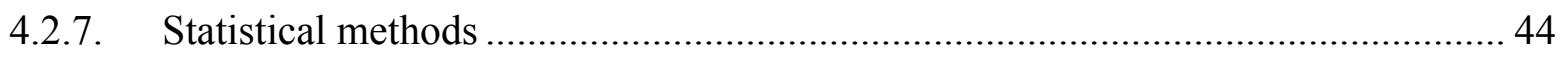

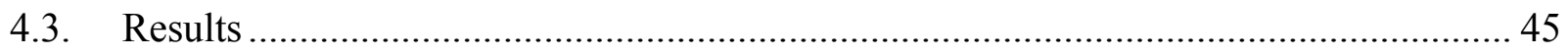

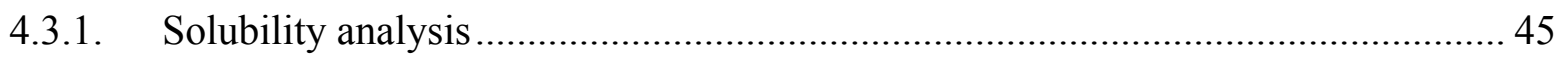

4.3.2. Ion release through Atomic Absorption Spectroscopy (AAS) ........................... 47

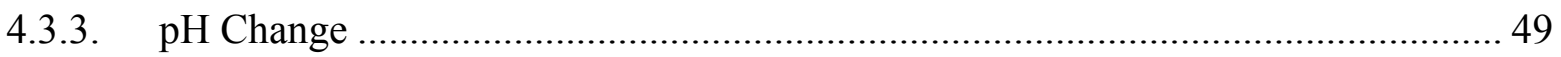

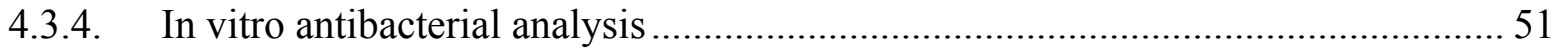

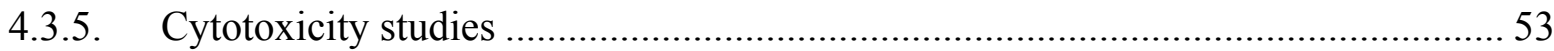

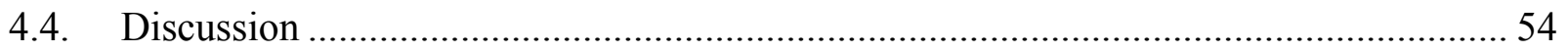

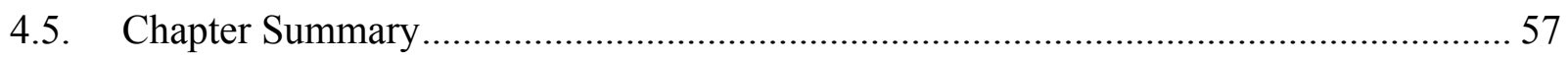

5. Silica-based and Borate-based, Titanium-containing Bioactive Coatings Characterization: strain energy release rate, residual stresses, hardness and thermal expansion.......................... 59

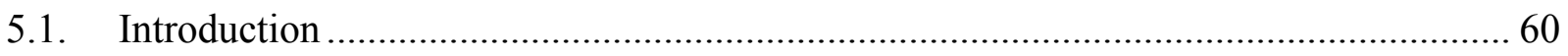

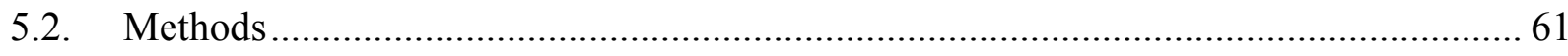

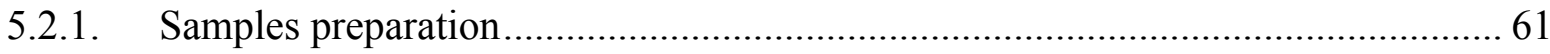

5.2.2. Coefficient of thermal expansion (CTE) measurement by Linear Dilatometry ..... 61

5.2.3. Residual Stress and Strain Analysis............................................................. 62

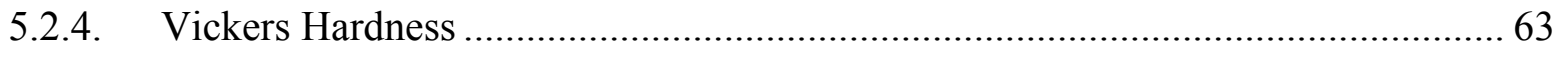

5.2.5. Coating Bulk Mode I Strain Energy Release Rate Using Vickers Indentation ...... 63

5.2.6. Coating/Substrate System Mode I Strain Energy Release Rate.......................... 65 


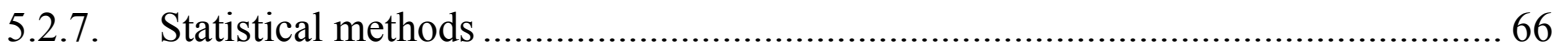

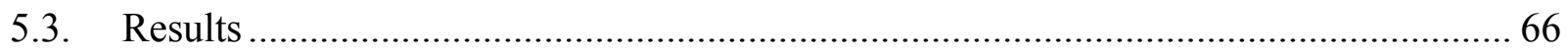

5.3.1. Coefficient of thermal expansion (CTE) measurement by Linear Dilatometry ..... 66

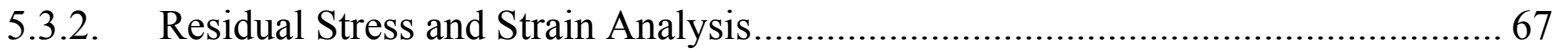

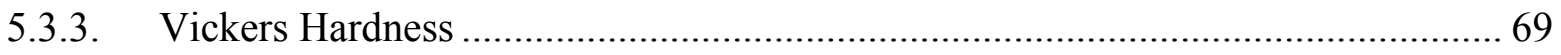

5.3.4. Bulk Mode I Critical Strain Energy Release Rate Using Vickers Indentation ....... 69

5.3.5. Coating/ Substrate System Mode I Critical Strain Energy Release Rate............... 71

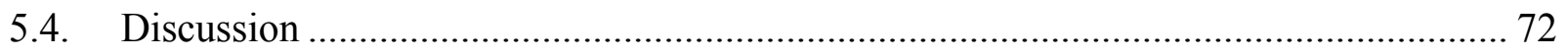

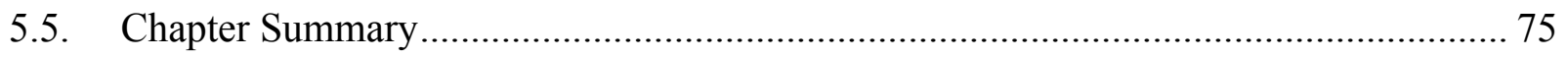

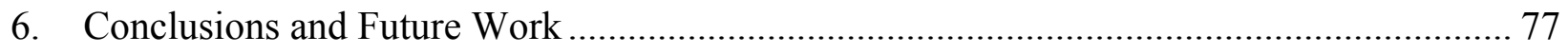

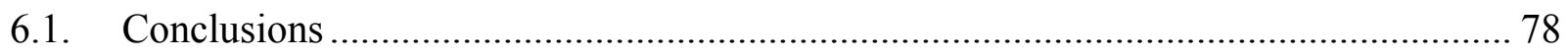

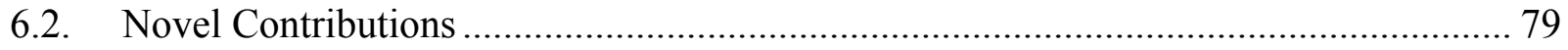

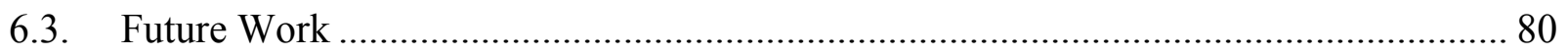

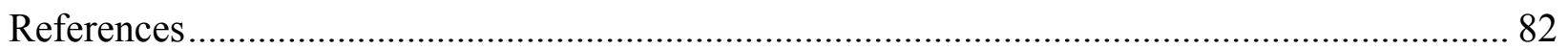




\section{List of Tables}

- Table 2.1. Glass formulations (mol\%) .................................................................. 17

- Table 2.2. Glass transition, crystallization and coating temperatures............................ 18

- Table 3.1. Network connectivity for the silica-based glasses (left) and for the borate-

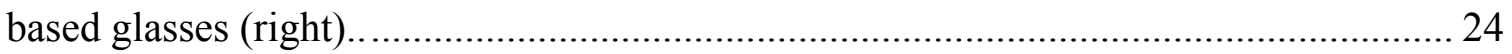

- Table 3.2. Particle size distribution for silica-based and borate-based glass series......... 26

- Table 3.3. DSC results for silica and borate-based glass series. .................................. 27

- Table 3.4. Compositional analysis from EDS (mol\%) with standard deviation for the silicate-based glasses. Values in parentheses represent target values............................. 28

- Table 3.5. Compositional analysis from EDS (mol\%) with standard deviation for the borate-based glasses. Values in parentheses represent target values............................ 28

- Table 3.6. Infrared (IR) peak assignment for silica-based and borate-based glass spectra. 


\section{List of Figures}

- Figure 1.1. Socket attachment [10] (left) and direct skeletal attachment [11] (right)

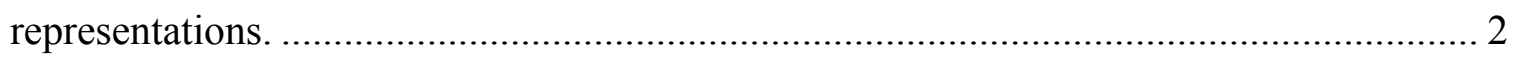

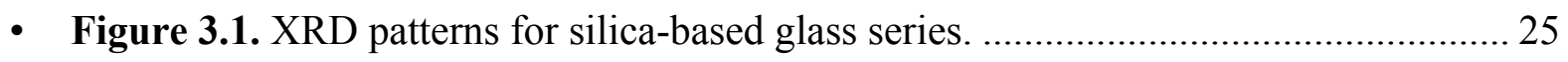

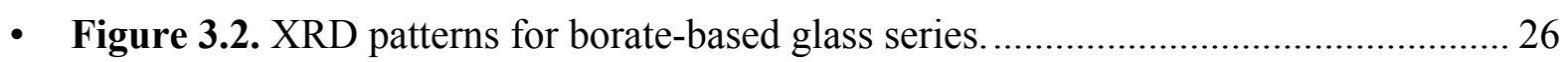

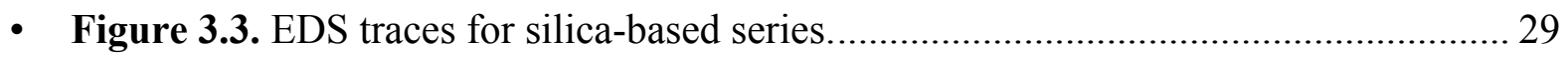

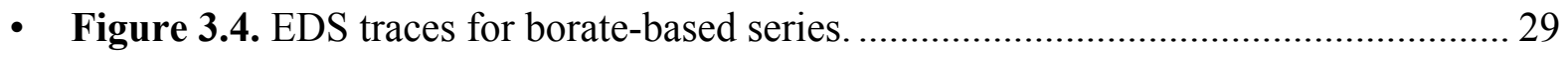

- Figure 3.5. FTIR Transmittance spectra for silica-based glasses. ..................................... 31

- Figure 3.6. FTIR Transmittance spectra for borate-based glasses.................................... 32

- Figure 3.7. ${ }^{29} \mathrm{Si}$ Chemical shift for the silica-based glass series. ....................................... 33

- Figure 3.8. ${ }^{31} \mathrm{P}$ Chemical shift for the silica-based glass series. ....................................... 34

- Figure 3.9. ${ }^{11} \mathrm{~B}$ Chemical shift for the borate-based glass series. .................................... 34

- Figure 3.10. ${ }^{31} \mathrm{P}$ Chemical shift for the borate-based glass series.................................... 35

- Figure 4.1. Solubility study for SRT glass series $(n=3)$. Scatter bars indicate one standard deviation from the mean. Stars and bars show statistical significance $(p<0.05)$.

- Figure 4.2. Solubility study for BRT glass series $(n=3)$. Scatter bars indicate one standard deviation from the mean. Stars and bars show statistical significance $(p<0.05)$.

- Figure 4.3. $\mathrm{Zn}^{2+}$ release from SRT glass series $(n=3)$. Scatter bars indicate one standard deviation from the mean. Stars and bars show statistical significance $(p<0.05)$.

- Figure 4.4. $\mathrm{Zn}^{2+}$ release from BRT glass series $(n=3)$. Scatter bars indicate one standard deviation from the mean. Stars and bars show statistical significance $(p<0.05)$ 48 
- $\quad$ Figure 4.5. $\mathrm{Ti}^{4+}$ release from SRT glass series $(n=3)$. Scatter bars indicate one standard deviation from the mean. Stars and bars show statistical significance $(p<0.05)$ 48

- $\quad$ Figure 4.6. $\mathrm{Ti}^{4+}$ release from BRT glass series $(n=3)$. Scatter bars indicate one standard deviation from the mean. Stars and bars show statistical significance $(p<0.05)$

- $\quad$ Figure 4.7. $\mathrm{pH}$ Measurements for SRT glass series $(n=3)$. Scatter bars indicate one standard deviation from the mean. Stars and bars show statistical significance $(p<0.05)$.

- Figure 4.8. $\mathrm{pH}$ Measurements for BRT glass series $(n=3)$. Scatter bars indicate one standard deviation from the mean. Stars and bars show statistical significance $(p<0.05)$.

- $\quad$ Figure 4.9. Inhibition zones (in $\mathrm{mm})$ for $S$. epidermidis for SRT glasses $(n=3)$. Scatter bars indicate one standard deviation from the mean. No significant difference was found at each time incubation time $(p<0.05)$. 52

- $\quad$ Figure 4.10. Inhibition zones (in $\mathrm{mm}$ ) for S. epidermidis for BRT glasses $(n=3)$. Scatter bars indicate one standard deviation from the mean. Stars and bars show statistical significance $(p<0.05)$ 52

- Figure 4.11. Inhibition zones (in $\mathrm{mm})$ for $E$. coli for BRT glasses $(n=3)$. Scatter bars indicate one standard deviation from the mean. Stars and bars show statistical significance $(p<0.05)$. 53

- Figure 4.12. MTT cytotoxicity assay results $(n=3)$. Scatter bars indicate one standard deviation from the mean. Stars and bars show statistical significance $(p<0.05)$. 54 
- Figure 5.1. Schematic depiction of the cracks emanating from a Vickers indent. $a$ is the half of the diameter length of the dent, and $c$ is the crack length measured from the center of the indent. 64

- Figure 5.2. Bilayer double cantilever beam specimens. All units in millimeters. Gray materials represent the titanium alloy substrates, black material represents the glass, and white material represents the epoxy. 66

- Figure 5.3. CTE for the SRT and BRT glasses, plotted along with the CTE of Ti6Al4V as reference $(n=3)$. Scatter bars indicate one standard deviation from the mean. 67

- Figure 5.4. Residual strain at the substrate/coating interface using the SRT and BRT glasses as coating $(n=3)$. Scatter bars indicate one standard deviation from the mean.. 68

- Figure 5.5. Residual stresses experienced in the glass coating at the coating/substrate interface using the SRT and BRT glasses as coating $(n=3)$. Scatter bars indicate one standard deviation from the mean 68

- Figure 5.6. Vickers hardness for the SRT and BRT glasses $(n=3)$. Scatter bars indicate one standard deviation from the mean. Stars and bars show statistical significance $(p<$ $0.05)$ 69

- Figure 5.7. Bulk Mode I critical strain energy release rates for the SRT and BRT glasses $(n=3)$. The $\mathrm{G}_{\mathrm{IC}}$ values for Fused silica glass and Pyrex obtained from the literature [109, 110] are also shown for reference. Scatter bars indicate one standard deviation from the mean. Stars and bars show statistical significance $(p<0.05)$. 70

- Figure 5.8. SEM of a Vickers indent on SRT0 with the emanating cracks. The average half diameter and crack length are $54.8 \mu \mathrm{m}$ and $187.9 \mu \mathrm{m}$, respectively. 71 
- Figure 5.9. Mode I critical strain energy release rates for the coating/substrate systems with SRT and BRT glasses ( $n=3$ /sample, 3 samples per glass). Scatter bars indicate one standard deviation from the mean. Stars and bars show statistical significance $(p<0.05)$. 


\section{List of Abbreviations}

- AAS: Atomic Absorption Spectroscopy

- $\mathbf{B}_{2} \mathbf{O}_{3}$ : Boron oxide

- BO: Bridging oxygen

- CaO: Calcium oxide

- CTE: Coefficient of Thermal Expansion

- DCB: Double-cantilever beam

- DSA: Direct Skeletal Attachment

- DSC: Differential Scanning Calorimetry

- $\quad$ E. coli: Escherichia coli

- FTIR: Fourier Transform Infrared Spectroscopy

- $\boldsymbol{G}_{\boldsymbol{I} \boldsymbol{C}}$ : Mode I Critical Strain Energy Release Rate

- ICDD: International Centre for Diffraction Data

- MAS-NMR: Magic-Angle Spinning - Nuclear Magnetic Resonance Spectroscopy

- $\quad \mathrm{Na}_{2} \mathrm{O}$ : Sodium oxide

- NBO: Non-bridging oxygen

- NBS: Number of bridging species

- NC: Network Connectivity

- $\quad \mathbf{P}_{2} \mathbf{O}_{5}$ : Phosphorus pentoxide

- PSA: Particle Size Analysis

- S. epidermidis: Staphylococcus epidermidis

- $\mathbf{S i O}_{2}$ : Silica 
- $\mathbf{T}_{\text {coat }}$ : Coating temperature

- $\mathbf{T}_{\mathbf{g}}$ : Glass Transition temperature

- $\mathbf{T i O}_{2}$ : Titanium dioxide

- $\mathbf{T}_{\mathbf{x}}$ : Crystallization temperature

- VIF: Vickers indentation fracture

- XRD: X-ray Diffraction Spectroscopy

- ZnO: Zinc oxide

- $\Delta T$ : Processing temperature 
1. Introduction 


\subsection{Background}

In the field of prosthetics, two technologies for attaching the residual limb and the prosthetic implant are widely utilized: socket attachment and direct skeletal (or bone-anchored) attachment [1]. Socket attachment is the most common method [2], with designs already established for below, through or above-knee amputations $[3,4,5,6]$. In general, socket attachment consists of wrapping the prosthetic limb around the residual limb, with the prosthesis serving as the socket for the residual limb, with quadrilateral and ischial containment sockets being the most noteworthy technologies [7]. Compared to socket attachment, direct skeletal attachment (DSA) is a relatively new technology, where an implant is attached directly to the patient's bone at the residual limb. Upon healing, the implant in DSA serves as the attachment mechanism between the prosthesis and the body [1]. In achieving osseointegration, the implant is permanently connected to the bone, resulting in high force and moment interaction between the prosthesis and the body [8]. DSA technology offers an advantage over socket technology through a reduction in skin-related complications and residual limb constraints within the socket, as a result of the limited direct contact between the prosthetic implant and the skin [9].
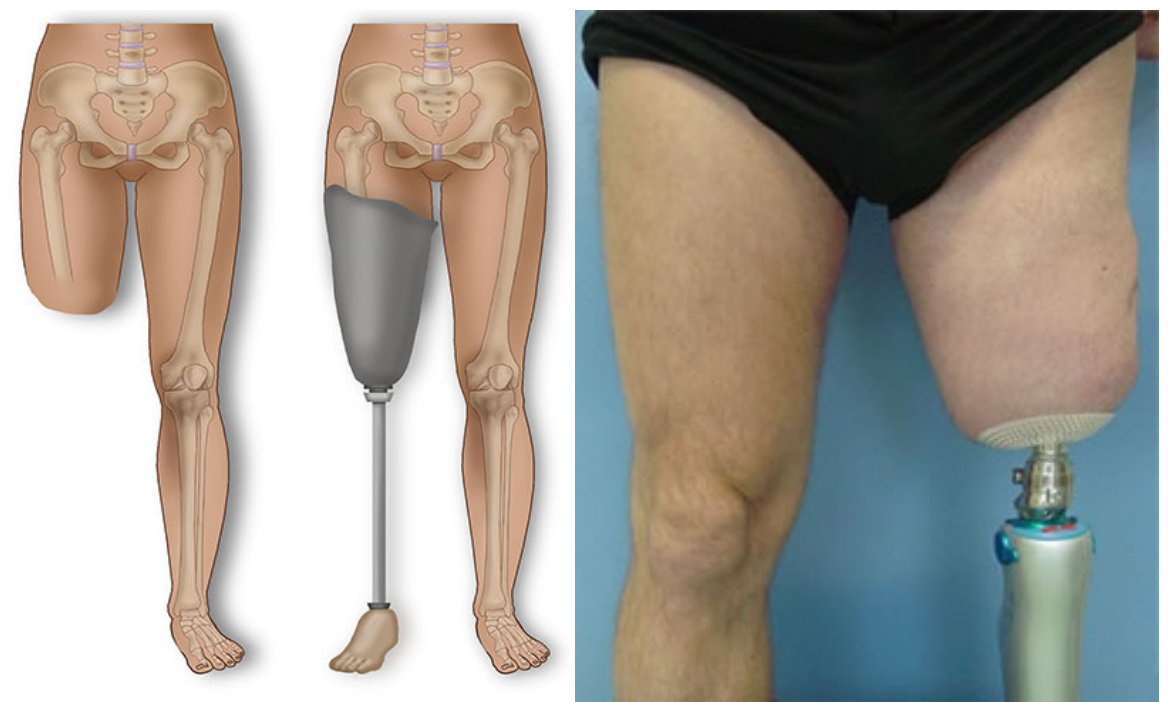

Figure 1.1. Socket attachment [10] (left) and direct skeletal attachment [11] (right) representations. 
Titanium has become one of the preferred implant materials due to its ability to create a permanent bond to bone via osseointegration $[12,13]$. It is this characteristic that has also made DSA devices more favorable than socket attachments for prosthetics. However, there are concerns regarding DSA including potential infection, skin irritation and breakdown, implant failure and risk of a broken bone in the residual $\operatorname{limb}[14,15,16,17,18]$. Addressing these concerns will aid in shifting the current paradigm from socket attachment towards DSA.

It is important to understand the overall mechanics of the DSA system, as loads that may negatively affect the residual limb bone may occur in this situation [18]. This places a patient at risk of requiring additional treatment if the bone weakens or fractures due to incomplete osseointegration or to detrimental bone remodeling induced by stress shielding [19]. Different approaches have been taken toward improving the patient's experience with DSA, including modifying the implant surface by chemical etching with hydrochloric and/or sulfuric acid, sandblasting, titanium plasma-spraying, hydroxylapatite (HA) plasma-spraying or coating the implant with either a titanium dioxide $\left(\mathrm{TiO}_{2}\right)$ layer through anodic oxidation or with a bioactive glass $[9,20,21,22]$. HA coatings have been used for over 20 years in such applications, exploiting its ability to promote bone ingrowth [23, 24, 25]; yet there are concerns with HA use as it has no mechanism to retard bacterial or biofilm colonization at the implant site. Coatings have also been produced based on chlorhexidine and silicone with ammonia couplings [26, 27], but these have little clinical applicability due to erosion of the compounds as they migrate to the surface. Of all the approaches above, coating with bioactive glasses have showed encouraging results [20].

The use of bioactive materials in orthopedic surgery has proliferated since the development of Hench's 45S5 Bioglass ${ }^{\circledR}$ in the 1960s [28] due to its favorable interaction with 
living tissue. Bioglass ${ }^{\circledR}$ was the first synthetic material to chemically adhere to both hard and soft tissue [28]. Although Hench acknowledged that Bioglass ${ }^{\circledR}$ is unsuitable as a coating [29], he developed criteria for an optimal bone replacement material [30], which included that "the material should resorb at the same rate that bone is regenerated, with byproducts that are beneficial and easily excreted by the body so that bone will restore to a healthy state".

\subsection{Motivation}

DSA has been evaluated versus socket attachment to assess the feasibility of these two technologies, concluding that DSA provides the amputees with a better overall experience [2]. Hagberg et al. compared the hip range of motion for two groups of patients: those with socket prostheses (43 patients (32 male subjects), with an average age of 51 years) and those with boneanchored prostheses (20 patients (15 male subjects), with an average age of 46 years). $37 \%$ (16) of the patients with socket prostheses experienced restricted hip motion in all directions, and 44\% (19) from the same group expressed discomfort while sitting. No patient using boneanchored prostheses experienced restricted hip motion, nor did they express discomfort while sitting. These results evidence the advantage of DSA over socket attachment, providing a justification to further improve on this technology.

As bioactive glasses influence genetic expression, differentiation and cell proliferation by the release of ions $[31,32,33,34]$, engineering control of the biological response via dissolution products creates an opportunity for innovation. The proposed compositions are expected to provide superior performance as they are expected to inhibit bacterial growth due to the addition of zinc, while the absence of aluminum minimizes the possibility of the coating causing toxicity 
in surrounding tissues. Furthermore, incorporating titanium in the glass compositions is expected to enhance osseointegration $[12,13,35]$.

Furthermore, evaluating the ability of using borate-based bioactive glasses for coating purposes will tackle the fact that silicate-based glasses possess a significantly different coefficient of thermal expansion compared to metallic implants (e.g. Ti6Al4V, with $10.6 \times 10^{-6} /{ }^{\circ} \mathrm{C}$ in the range of $0-650^{\circ} \mathrm{C}$ [36] versus $45 \mathrm{~S} 5$, with $17.0 \times 10^{-6} /{ }^{\circ} \mathrm{C}$, in the range of $0-500^{\circ} \mathrm{C}[37], \sim 60 \%$ difference), which plays a detrimental role as the coating fissures around the implant due to the mismatch in contraction when the coating/implant assembly is taken from the high coating temperatures to room temperature.

\subsection{Literature Review}

\subsubsection{Osseointegration and Osseoperception}

Titanium has facilitated the securing of implants into the maxilla and mandible by stimulating direct bone apposition to the implant surface [38]. Denser bones, such as the anterior mandible, exhibit better osseointegration than less dense bones, such as the posterior maxilla [39], given that denser bones provide greater bone/implant interface area [38].

At the beginning of the 1950s, Leventhal tested the fixation of titanium screws into the femora of rats [40]. He described how the screws were progressively more attached to the bone, until such a point that the screws were so firmly attached that attempting to remove them resulted in breaking the femur. This was the first indication of the osseointegrative behavior of titanium. Towards the end of the 1950s, researchers evaluated the process for modifying a rabbit's ear chamber, by attaching a titanium implant with central canal and transverse opening to the ear bone, allowing for the bone and vessels to grow into the chamber [41]. Upon experiencing the 
successful integration of these elements, the researchers expanded to test with dental prostheses, which further proved the reliability of titanium-based implants.

Patients with osseointegrated implants have also exhibited what has been termed osseoperception; the capacity to identify tactile thresholds transmitted through the prostheses [12]; this was first observed on dental implant patients who demonstrated a level of functional capacity equal to that of individuals with reduced dentition of the same extension as in the osseointegration group [42]. A study was performed to evaluate the level of osseoperception between patients with osseointegrated prostheses and those with socket-attached prostheses [43]. Testing was performed on 13 patients with transfemoral, transtibial, transradial and transhumeral prostheses, where test patients with same gender and similar age and amputation levels were compared across the two groups. The study consisted of applying small vibrations to different fingers or toes, as applicable, and testing the perception of the patient to the stimuli. It was concluded that patients with osseointegrated prostheses were able to reliably detect vibration pulses through their prostheses, whereas socket prostheses users did not exhibit this ability.

Beneficial as the osseointegration process appears to be, it is worth noting that applications requiring only temporary fixation should avoid the use of titanium, since it may require fracturing the bone to which it is attached during the removal process. In prosthetics, this may seldom be the case; however, precautions have to be taken during the design of the implant and its attachment as improper design may result in discomfort for the amputee, requiring the change or removal of the overall prosthesis, which may pose complexity if an osseointegrated prosthesis was used. 


\subsubsection{Metal Coating and Adhesion Measurement}

Coatings can enhance a metal's ability to resist corrosion and wear, and to increase their adhesion and wettability. Metals have been determined suitable as implants due to their mechanical properties, though they can be rejected by the body due to unwanted chemical reactions at the interface between the metal and living tissue. For this reason, an additional property is required for these coatings: that they serve as a suitable biological interface between implant and tissue. Ceramics and glasses have been developed for the purpose of providing a barrier for the implant against bacterial colonization. Several practical coating methods will be discussed, focusing on their suitability for steel, titanium and titanium alloys.

Of the accepted coating techniques, enameling is one of the most widely used. Chen et al. [44] described the coating of $1 \mathrm{Cr} 11 \mathrm{Ni} 2 \mathrm{~W} 2 \mathrm{MoV}$ martensitic stainless steel samples with an ethanol-based suspension of $\mathrm{SiO}_{2}-\mathrm{Al}_{2} \mathrm{O}_{3}-\mathrm{ZnO}-\mathrm{CaO}-\mathrm{ZrO}_{2}-\mathrm{TiO}_{2}-\mathrm{B}_{2} \mathrm{O}_{3}-\mathrm{Na}_{2} \mathrm{O}-\mathrm{KNO}_{3}$ glass. The suspension was sprayed on to the steel samples at room temperature, then dried at $250^{\circ} \mathrm{C}$ for 15 mins. Ultimately, the assembly was heat-treated at $870^{\circ} \mathrm{C}$ for $3 \mathrm{~min}$, the temperature being sufficiently higher than the softening point to allow for the coating to flow on the substrate. The authors observed that low firing temperatures and short sintering times did not help the glass to spread along the substrate, resulting in a porous coat.

The enameling technique with an ethanol-based suspension applied to titanium alloy Ti6Al4V has also been investigated by Pavon et al. [45]. The authors used two glass formulations based on the composition $\mathrm{SiO}_{2}-\mathrm{CaO}-\mathrm{Na}_{2} \mathrm{O}-\mathrm{MgO}-\mathrm{P}_{2} \mathrm{O}_{5}-\mathrm{K}_{2} \mathrm{O}$, with $\mathrm{SiO}_{2}$ contents of $61.1 \mathrm{~mol} \%$ and $64.1 \mathrm{~mol} \%$, to evaluate their effectiveness as coating materials. The substrates were polished with diamond paste then ultrasonically cleaned in an acetone-ethanol bath. Upon application of the suspension on the substrates, the assemblies were air-dried at $75^{\circ} \mathrm{C}$ overnight, 
fired at temperatures ranging from $800^{\circ} \mathrm{C}$ to $820^{\circ} \mathrm{C}$, and quenched in air. The glass coating with $61.1 \mathrm{~mol} \%$ of $\mathrm{SiO}_{2}$ exhibited higher stress distribution compared to the $64.1 \mathrm{~mol} \%$ formulation, which the authors attributed to a greater thermal expansion mismatch between the glass and the substrate. Lotfibakhshaiesh et al. [46] evaluated a different glass formulation $\left(\mathrm{SiO}_{2}-\mathrm{P}_{2} \mathrm{O}_{5}-\mathrm{CaO}-\right.$ SrO- $-\mathrm{Na}_{2} \mathrm{O}-\mathrm{K}_{2} \mathrm{O}-\mathrm{MgO}-\mathrm{ZnO}$, changing the molecular percentage of calcium and strontium oxide) for coating Ti6Al4V through an analogous process to that of Pavon et al. [45], with the exception that the firing environment used by Pavon et al. was air, whereas Lotfibakhshaiesh et al. used a vacuum environment. Successful coating was reported by Lotfibakhshaiesh et al., proving that complete substitution of calcium oxide for strontium oxide favors crystallization due to a smaller processing window.

Enameling techniques have also been investigated using isopropanol instead of ethanol. Sola et al. [47] tested bioactive glass compositions $\left(\mathrm{Na}_{2} \mathrm{O}-\mathrm{K}_{2} \mathrm{O}-\mathrm{CaO}-\mathrm{P}_{2} \mathrm{O}_{5}-\mathrm{SiO}_{2}\right)$ suspended in isopropanol and then deposited on Ti6Al4V substrates. The authors investigated different heating profiles to determine the best coating process, using a temperature ramp to heat up the samples and including an isothermal stage for $1 \mathrm{hr}$ at the maximum temperature, as this overall heating schedule allowed for optimum coverage.

Mehdipoura et al. [48] evaluated the effect of different processing parameters during electrophoretic deposition of a $\mathrm{SiO}_{2}-\mathrm{P}_{2} \mathrm{O}_{5}-\mathrm{CaO}-\mathrm{MgO}$ glass on to $316 \mathrm{~L}$ stainless steel. Prior to coating, the steel substrates were washed with distilled water, rinsed, then degreased by ultrasonic cleaning in acetone for $10 \mathrm{~min}$, and then dried. A triethanolamine-ethanol-glass suspension was elaborated, then by means of electrophoretic deposition, applied to the substrate at constant voltages of $30 \mathrm{Vcm}^{-2}, 60 \mathrm{Vcm}^{-2}$ and $90 \mathrm{Vcm}^{-2}$. Adhesion was enhanced by sintering 
the assembly at $800^{\circ} \mathrm{C}$. It was determined that porosity and surface cracks increased with processing voltage, with the best coating quality achieved at $30 \mathrm{Vcm}^{-2}$.

Schrooten and Helsen [49] used a reactive plasma spraying technique for coating Ti6Al4V titanium alloy with a $\mathrm{SiO}_{2}-\mathrm{Na}_{2} \mathrm{O}-\mathrm{P}_{2} \mathrm{O}_{5}-\mathrm{CaF}_{2}$ glass. The substrates were coated with a $50 \mu \mathrm{m}$-layer of the bioactive glass. Substrate-coat adhesion was measured, and found to be sufficient for load-bearing applications (greater than $48 \mathrm{MPa}$ in shear and greater than $84 \mathrm{MPa}$ in tension). The authors found that adhesion strength was dependent upon the inherent strength of the glass itself: a higher strength bioactive glass was more strongly bonded to the titanium alloy.

In order to measure adhesion, indentation-based measurement methods allow a quick and qualitative measurement $[37,50,51,52]$. Such tests can quantify fracture toughness of the material by the direct measurements of cracking after indentation $[53,54,55,56,57,58,59]$. A common example is the Vickers indentation fracture (VIF) test, which measures the lengths of the cracks emanating from the indents. This technique was first developed by Lawn et al. [53], under the assumption that such cracks were created due to tensile stresses that form during unloading. Anstis et al. [54] validated Lawn's model for several ceramics and glasses by comparing the fracture toughness obtained from the VIF test with the ones obtained from standard fracture tests. Later, Laugier [59] showed that indentation crack geometry in glasses and ceramics were different and claimed that Lawn's model required modification when used for evaluating ceramic toughness, and therefore developed a new model that described the indentation cracking in ceramics more realistically. 


\subsubsection{Bioactive Glasses for Coatings and Rationale for Proposed}

\section{Formulations}

The potential of bioactive glasses in coating applications was first postulated with the development of Hench's 45S5 Bioglass ${ }^{\circledR}$ in the 1960s [28]. Bioglass ${ }^{\circledR}$ was the first synthetic material to chemically adhere to both hard and soft tissue [28]. In situ degradation of such materials makes them desirable for clinical applications owing to the release of ions into the physiological environment, which can promote antibacterial behavior, bone formation and growth, and tissue healing [31, 60,61]. Although bioactive glasses have been employed for coating metals $[44,47,37,62]$, these compositions have all, to date, contained aluminum [44, 37], which is associated with defective bone mineralization and neurotoxicity [63]. Other compositions have been deficient in zinc $[47,62,37]$, an antibacterial component $[60,64,65]$ known to aid the healing process by inhibiting the growth of bacteria, including caries-related bacteria Streptococcus mutans [66]. Although virtually all materials facilitate bacterial ingress which can lead to biofilm formation, bacteria attach less readily to glass [67], providing a rationale for a glass-based solution to bacterial colonization of surgical implants.

The current dissertation considers two distinct glass series, one based on silica $\left(\mathrm{SiO}_{2}\right)$ and one on borate $\left(\mathrm{B}_{2} \mathrm{O}_{3}\right)$, with increasing amounts of titanium dioxide $\left(\mathrm{TiO}_{2}\right)$ incorporated at the expense of the silicate or borate component, respectively. $\mathrm{B}_{2} \mathrm{O}_{3}$ has been shown to reduce the coefficient of thermal expansion (CTE) of glasses [68] so that borate glasses have CTEs closer to that of the surgical metals (typically Ti6Al4V, with a CTE of $9.5 \times 10^{-6} /{ }^{\circ} \mathrm{C}$ in the range of 0 $\left.315^{\circ} \mathrm{C}[69]\right)$. Processing such glasses for coating applications (e.g., through enameling [47, 70], plasma spraying [49] or electrophoretic deposition [48]) requires heat treatment at temperatures high enough to allow for the glass to react with the substrate surface thus creating a chemical 
bond $[71,72]$. Once the bond has formed and the assembly is cooled, the difference in CTE between the glass and metal will induce residual stresses, causing cracks to appear in the glass or at the glass/substrate interface. For this reason, a borate-based glass series is proposed, to evaluate the effect of $\mathrm{B}_{2} \mathrm{O}_{3}$ on its coating capability by means of a reduced CTE compared to silica-based glasses, which means that residual stresses at the glass-substrate interface would be reduced since both components would be subjected to comparable amounts of shrinkage during the cool off stage of enameling. A silica-based glass series is also proposed, with a composition analogous to that of the borate-based glass series, to allow for the evaluation of the effect of $\mathrm{B}_{2} \mathrm{O}_{3}$ versus $\mathrm{SiO}_{2}$ on resultant properties of the coating. Additionally, $\mathrm{TiO}_{2}$ is incorporated in these glasses as it helps promote a more stable chemical bond when coating such a glass onto Ti6Al4V [68]. Titanium has also been incorporated in bioactive glasses: for phosphate glasses, the addition of $\mathrm{TiO}_{2}$ has been associated with an increase in the crystallization temperature due to titanium acting as a network former with $\mathrm{Ti}^{4+}$ crosslinking phosphate units in these glasses and therefore impending crystallization [73]; in silicate glasses, $\mathrm{TiO}_{2}$ has been shown to enter the glass network as a glass modifier by increasing the concentration of non-bridging oxygen in the glass structure, depolymerizing the silicate network [74].

Limited literature is currently available on the effect of $\mathrm{TiO}_{2}$ inclusion in borate-based glass structures. Calcium oxide $(\mathrm{CaO})$ and phosphorus pentoxide $\left(\mathrm{P}_{2} \mathrm{O}_{5}\right)$ are also incorporated into the glasses as $\mathrm{Ca}$ and $\mathrm{P}$ are the main elements in the inorganic phase of bone, facilitating bone formation and resorption [75]. Sodium oxide $\left(\mathrm{Na}_{2} \mathrm{O}\right)$ is included in the formulation as it has been proven to reduce the glass transition and crystallization temperature [76], facilitating lower enameling temperatures, thus reducing the risk of $\alpha$ to $\beta$ transformation of the titanium substrate, a transformation which can hinder corrosion resistance [69]. 


\subsection{Research Objectives}

The objectives of this research are to:

- Design, synthesize and subsequently characterize novel titanium-containing bioactive glasses, based on both silica and borate backbones, for the coating of metallic implants for medical applications:

O X-ray diffraction will be performed on all glasses to determine where an amorphous composition is achieved and if crystal phase formation occurs during the glass firing, annealing and sintering process.

- Differential scanning calorimetry will be performed to determine thermal characteristics of the novel glasses, including glass transition $\left(T_{g}\right)$ and crystallization temperature $\left(\mathrm{T}_{\mathrm{x}}\right)$.

○ Energy dispersive spectroscopy will be employed to examine the glasses composition.

- Fourier transform infrared spectroscopy and Magic-angle spinning - Nuclear magnetic resonance will provide information about the chemical bonds in each glass.

- Investigate and assess the bioactivity and biocompatibility behavior of the fired glasses in vitro:

- Solubility and ion release profile studies will be conducted to examine the timedependent behavior of the bioactive glasses immersed in deionized water. Solubility studies will determine how mass changes as a function of incubation 
time, while ion release profiles will determine which ions are released and in which amounts from the glass into the incubation medium.

$\circ \mathrm{pH}$ changes of the deionized water when exposed to the glass compositions will be studied to understand how glass degradation will affect the environment once it is placed inside the body.

○ To support the antibacterial claim, in vitro antibacterial analysis will be undertaken to test the ability of the proposed glasses to inhibit the growth of bacteria at the implantation site.

- Cytotoxicity studies will be conducted to determine in vitro bioactivity of the glasses by culturing appropriate cells on the bioactive glass then evaluating its proliferation.

- Measure and quantify mechanical characteristics of the bioactive glasses as coating materials:

- Coating the titanium alloys through enameling with ethanol will be achieved with both silicate- and borate-based glasses on a titanium alloy Ti6Al4V substrate.

- In order to achieve proper coating of the metals (i.e., no visible cracks or delamination on the coating), the coating must have a coefficient of thermal expansion comparable to that of the substrate. If this is not true, then the coating may fracture as it cools due to the mismatched thermal expansion coefficient. Determining CTE will facilitate the design of coatings with suitable thermal expansion. 
- Upon coating, due to the mismatch in CTE, residual stresses and strains will be produced within the glass; these stresses and strains will be computed to assess the effect of the coating process on the glass.

○ The hardness of each glass will be measured using a Vickers indenter. This measurement will provide insight on the glass ability to withstand plastic deformation.

- Strain energy release rate in mode I (opening) will measure the ability for cracks to propagate through the bioactive coating or along the coating/substrate interface. Higher quality glass will require a greater amount of energy to propagate cracks, reducing the chances for failure of the implant in the body. Strain energy release rate will be measure both for the bulk glass and for the glass coating/Ti alloy substrate system.

\subsection{Author's Contribution in the Context of Collaboration}

All proposed glasses were prepared and fired by the author; the majority of the glass discs and coatings used for the evaluations in this dissertation were also prepared by the author.

For the glass characterization work, presented in Chapter 3, particle size and Fourier Transform Infrared (FTIR) spectrometer samples were performed and analyzed by the author; network connectivity calculations were also carried out by the author; the remaining tests (x-ray diffraction, differential scanning calorimetry, energy dispersive spectroscopy and magic-angle spinning/nuclear magnetic resonance) were collected by trained personnel and the collected data was analyzed by the author. 
For the biocompatibility work, presented in Chapter 4, the data for all but the cytotoxicity studies was collected and analyzed by the author; the cytotoxicity studies data was collected by trained personnel, with the data analyzed by the author.

For the mechanical characterization work, presented in Chapter 5, coefficient of thermal expansion measurement was conducted by trained personnel, with the data being analyzed by the author; the residual stress and strain analysis and Vickers indentation tests were carried out and analyzed by the author, and the bulk and coating strain energy release rate data was partially collected by the author, with the bulk strain energy release rate data being collected and analyzed by a colleague, and the coating strain energy release rate data being analyzed by the author. 
2. Sample Preparation 


\subsection{Introduction}

In this chapter, the procedures for manufacturing the glasses are presented, as well as the procedure for coating them onto metals and the discs used in evaluating the biocompatibility, bioactivity and mechanical properties of the glasses. The nomenclature for the glasses used throughout this dissertation is also introduced in this chapter.

\subsection{Glass preparation}

The glass compositions and nomenclatures are reported in $\mathrm{Table}^{2.1} . \mathrm{TiO}_{2}$ was added at the expense of $\mathrm{SiO}_{2}$ for the SRT series and at the expense of $\mathrm{B}_{2} \mathrm{O}_{3}$ for the BRT series. One batch of each glass was prepared by weighing out appropriate amounts of analytical grade reagents (Fisher Scientific, Ottawa, ON, Canada \& Sigma-Aldrich, Oakville, ON, Canada), firing (1400$1500{ }^{\circ} \mathrm{C}$ for $1 \mathrm{~h}$ for the silica-based glasses, $1200{ }^{\circ} \mathrm{C}$ for $1 \mathrm{~h}$ for borate-based glasses) in silica crucibles, and shock quenching in water. The resulting frit was then ball-milled and sieved to retrieve glass particulates $\leq 20 \mu \mathrm{m}$.

Table 2.1. Glass formulations (mol\%).

\begin{tabular}{|c|c|c|c|c|c|c|c|c|c|c|}
\cline { 2 - 13 } \multicolumn{1}{c|}{} & \multicolumn{4}{c|}{ Silica-based glass } & \multicolumn{5}{c|}{ Borate-based glasses } \\
\hline Reagent & SRT0 & SRT1 & SRT2 & SRT3 & SRT4 & BRT0 & BRT1 & BRT2 & BRT3 & BRT4 \\
\hline TiO $_{2}$ & 0 & 5 & 10 & 15 & 20 & 0 & 5 & 10 & 15 & 20 \\
\hline $\mathbf{S i O}_{2}$ & 52 & 47 & 42 & 37 & 32 & 0 & 0 & 0 & 0 & 0 \\
\hline $\mathbf{B}_{2} \mathbf{O}_{3}$ & 0 & 0 & 0 & 0 & 0 & 52 & 47 & 42 & 37 & 32 \\
\hline $\mathbf{C a O}$ & 12 & 12 & 12 & 12 & 12 & 12 & 12 & 12 & 12 & 12 \\
\hline $\mathbf{P}_{2} \mathbf{O}_{\mathbf{5}}$ & 6 & 6 & 6 & 6 & 6 & 6 & 6 & 6 & 6 & 6 \\
\hline $\mathbf{N a}_{\mathbf{2}} \mathbf{O}$ & 14 & 14 & 14 & 14 & 14 & 14 & 14 & 14 & 14 & 14 \\
\hline $\mathbf{Z n O}$ & 16 & 16 & 16 & 16 & 16 & 16 & 16 & 16 & 16 & 16 \\
\hline
\end{tabular}




\subsection{Disc preparation}

Approximately $200 \mathrm{mg}$ of each glass were pressed using a hydraulic press with pressure ranging between 2,500 - 3,000 psi. The pressed discs were then heat treated to promote the coalescence of glass particles and create a solid body.

\subsection{Coating preparation}

Ti6A14V substrate samples were degreased and cleaned in ethanol prior to coating. For each glass formulation, a suspension of the glass powder in ethanol (ratio of 5:1, ethanol to glass mass) was deposited on the substrates. Afterwards, the coatings were allowed to air-dry for 30 min, then fired at temperatures $\left(T_{\text {coat }}\right)$ ranging between the glass transition temperature $\left(T_{g}\right)$ and the crystallization temperature $\left(\mathrm{T}_{\mathrm{x}}\right)$ of each glass (Table 2.2), for 15 minutes.

Table 2.2. Glass transition, crystallization and coating temperatures.

\begin{tabular}{|l|c|c|c|}
\cline { 2 - 4 } \multicolumn{1}{c|}{} & $\mathrm{T}_{\mathrm{g}}\left({ }^{\circ} \mathrm{C}\right)$ & $\mathrm{T}_{\mathrm{x}}\left({ }^{\circ} \mathrm{C}\right)$ & $\mathrm{T}_{\text {coat }}\left({ }^{\circ} \mathrm{C}\right)$ \\
\hline SRT0 & 619 & 735 & 650 \\
\hline SRT1 & 592 & 670 & 630 \\
\hline SRT2 & 596 & 650 & 625 \\
\hline SRT3 & 610 & 705 & 640 \\
\hline SRT4 & 636 & 710 & 675 \\
\hline
\end{tabular}

\begin{tabular}{|l|c|c|c|}
\cline { 2 - 4 } \multicolumn{1}{c|}{} & $\mathrm{T}_{\mathrm{g}}\left({ }^{\circ} \mathrm{C}\right)$ & $\mathrm{T}_{\mathrm{x}}\left({ }^{\circ} \mathrm{C}\right)$ & $\mathrm{T}_{\text {coat }}\left({ }^{\circ} \mathrm{C}\right)$ \\
\hline BRT0 & 521 & 603 & 520 \\
\hline BRT1 & 530 & 625 & 550 \\
\hline BRT2 & 520 & 670 & 595 \\
\hline BRT3 & 523 & 633 & 550 \\
\hline BRT4 & 528 & 625 & 575 \\
\hline
\end{tabular}

\subsection{Chapter summary}

The preceding procedures described were used as the preparatory stage in the next chapters. The glass preparation procedure was required for Chapters 3 through 5; glass discs were required for Chapter 4 and 5 (biocompatibility and mechanical characterization, respectively), and coating preparation was only required for Chapter 5 . 
3. Characterization of Silica-based and Borate-based, Titaniumcontaining Bioactive Glasses for Coating Metallic Implants 
The work presented in this chapter [77] is based on the peer-reviewed, published paper:

Rodriguez, O., Curran, D.J., Papini, M., Placek, L.M., Wren, A.W., Schemitsch, E.H., Zalzal, P. and Towler, M.R., 2016. Characterization of silica-based and borate-based, titaniumcontaining bioactive glasses for coating metallic implants. Journal of Non-Crystalline Solids, 433, pp.95-102.

\subsection{Introduction}

This chapter outlines the characterization of two novel bioactive glass series, a silicabased glass series and a borate-based glass series that contain increasing amounts of titanium oxide $\left(\mathrm{TiO}_{2}\right)$. Titanium is employed to exploit its osseointegrative capability at the interface of the metallic implant and the bone. $\mathrm{TiO}_{2}$ was added in increments of $5 \mathrm{~mol} \%$ up to $20 \mathrm{~mol} \%$. Characterization techniques included energy dispersive spectroscopy (EDS), x-ray diffraction (XRD), differential scanning calorimetry (DSC), Fourier transform infrared (FTIR) spectroscopy, particle size analysis (PSA) and magic-angle spinning-nuclear magnetic resonance (MAS-NMR).

\subsection{Materials and Methods}

\subsubsection{Glass preparation}

Glass preparation for this work was done as per Section 2.2. All glass compositions were evaluated. 


\subsubsection{Network connectivity (NC)}

Network connectivity (NC) provides information on the ability for a glass to degrade and interact with the surrounding tissues [78]. Network connectivity for the proposed formulations were calculated using Eq. 3.1:

$$
N C=\frac{B O-N B O}{N B S}
$$

where $B O$ is the number of bridging oxygens, $N B O$ the number of non-bridging oxygens and $N B S$ the total number of bridging species. As network formers, $2 \mathrm{BO}$ are contributed to the glass network per $\mathrm{SiO}_{2}$ and $\mathrm{B}_{2} \mathrm{O}_{3}$ in each $\mathrm{Q}^{2}$ unit; as network modifiers, $2 \mathrm{NBO}$ are contributed per $\mathrm{Ca}^{2+}$ and 1 NBO per $\mathrm{Na}^{+}$. As for $\mathrm{P}_{2} \mathrm{O}_{5}$, recent work by $\mathrm{Hill}[79,80,81]$ provided insight on the role of phosphates in the glass network, demonstrating its role as an orthophosphate $\mathrm{Q}^{0}$ (glass modifier) in a $\mathrm{SiO}_{2}-\mathrm{P}_{2} \mathrm{O}_{5}-\mathrm{CaO}-\mathrm{Na}_{2} \mathrm{O}$ series. Supported by this work, $\mathrm{P}_{2} \mathrm{O}_{5}$ may only be considered as a glass modifier, with $3 \mathrm{NBO}$ per $\mathrm{PO}_{4}{ }^{3-}$, and supporting data will be gathered through ${ }^{31} \mathrm{P}$ MAS-NMR. As for $\mathrm{ZnO}$ and $\mathrm{TiO}_{2}$, these reagents behave as network intermediates; therefore, in considering $\mathrm{ZnO}$ as a glass former $1 \mathrm{BO}$ is added, and $2 \mathrm{BO}$ are added for $\mathrm{TiO}_{2}$. Considering these reagents as modifiers, $2 \mathrm{NBO}$ are contributed per $\mathrm{Zn}^{2+}$ and per $\mathrm{TiO}_{6}{ }^{2-}$.

\subsubsection{X-ray diffraction (XRD)}

X-ray diffraction (XRD) was performed to confirm that an amorphous state was achieved for all fired materials. Samples were analyzed over the range of $20^{\circ} \leq 2 \theta \leq 80^{\circ}$, with a step size of $0.05^{\circ}$ using a PANalytical X-ray diffractometer (PANalytical, QC, Canada). CuKa (1.54 $\AA$ ) anode was employed, with a generator voltage of $30 \mathrm{kV}$ and a tube current of $10 \mathrm{~mA}$. Crystalline 
phases were identified using the International Centre for Diffraction Data (ICDD) standard diffraction patterns.

\subsubsection{Particle size analysis (PSA)}

After grinding and sieving of the glass, particle size analysis (PSA) was undertaken to retrieve the average particle size of the glass powder. Particle size analysis was achieved using a BeckmanCoulter Multisizer 4 Particle size analyzer (BeckmanCoulter, Fullerton, CA, USA). Three powder samples per glass were evaluated in the range of $2 \mu \mathrm{m}-60 \mu \mathrm{m}$. Results were

analyzed by Multisizer 4 software, with means and standard deviations based on counting statistics of 30,000 particles per measurement.

\subsubsection{Differential scanning calorimetry (DSC)}

A combined differential scanning calorimetry-thermogravimetric analyzer (DSC-TGA) (SDT 2960 Simultaneous DSC-TGA, TA Instruments, DE, USA) was used to measure the glass transition temperature $\left(\mathrm{T}_{\mathrm{g}}\right)$ and crystallization temperature $\left(\mathrm{T}_{\mathrm{x}}\right)$ for both glass series. A heating rate of $20^{\circ} \mathrm{C} \min ^{-1}$ was employed using an air atmosphere with alumina in a matched platinum crucible as a reference. Sample measurements were carried out every 6 sec between $20^{\circ} \mathrm{C}$ and $850^{\circ} \mathrm{C}$.

\subsubsection{Energy dispersive analysis (EDS)}

Samples were analyzed using a JEOL JSM-6380LV Scanning Electron Microscopy equipped with an energy dispersive spectrometer (JEOL, Peabody, MA, USA). Compositional analysis was performed with beam energy of $20.0 \mathrm{keV}$. EDS results were acquired using Oxford 
EDS Aztec software, with standard deviations provided by the software based on counting statistics.

\subsubsection{Fourier transform infrared (FTIR) spectroscopy}

Silica-based and borate-based ground glass $(\leq 20 \mu \mathrm{m})$ was used for this technique in ambient air $\left(23 \pm 1{ }^{\circ} \mathrm{C}\right)$. The spectra were collected using a PerkinElmer Spectrum One IR (PerkinElmer, Waltham, MA, USA). Analysis was performed in the wavenumber ranging from $600 \mathrm{~cm}^{-1}$ to $4000 \mathrm{~cm}^{-1}$ with a spectral resolution of $4 \mathrm{~cm}^{-1}$.

\subsubsection{Magic-angle spinning- Nuclear magnetic resonance spectroscopy (MAS-NMR)}

For the silica-based series, ${ }^{29} \mathrm{Si}$ and ${ }^{31} \mathrm{P}$ MAS-NMR spectra was acquired with high power cw ${ }^{1} \mathrm{H}$ decoupling on a Bruker AVANCE III $200 \mathrm{MHz}$ NMR spectrometer (Bruker Corporation, Billerica, MA, USA) equipped with a 7-mm CPMAS probe. The MAS rate was $4.5 \mathrm{kHz}$ for ${ }^{29} \mathrm{Si}$ and $5 \mathrm{kHz}$ for ${ }^{31} \mathrm{P}$. The pulse time and recycle delay were $4 \mu \mathrm{sec}$ and $60 \mathrm{sec}$, respectively, for the ${ }^{29} \mathrm{Si}$ MAS-NMR, and $3.25 \mu \mathrm{sec}$ and $60 \mathrm{sec}$, respectively, for the ${ }^{31}$ P MAS-NMR. For the boratebased series, ${ }^{11} \mathrm{~B}$ and ${ }^{31} \mathrm{P}$ MAS-NMR experiments was carried out on an Agilent DD2 $500 \mathrm{MHz}$ NMR spectrometer (Agilent Technologies, Inc., Santa Clara, CA, USA) at the magnetic field of 11.7 Tesla. A zirconia rotor with a diameter of $3.2 \mathrm{~mm}$ was used for ${ }^{11} \mathrm{~B}$ and ${ }^{31} \mathrm{P}$ MAS-NMR measurements. Direct polarization ${ }^{11} \mathrm{~B}$ and ${ }^{31} \mathrm{P}$ MAS-NMR spectra was taken at $160.3 \mathrm{MHz}$ and 202.3 MHz, respectively, with $0.725 \mu$ sec pulse length ( $\pi / 8$-pulse angle) and $5 \mathrm{sec}$ recycle delay for ${ }^{11} \mathrm{~B}$ MAS-NMR, and with $2.8 \mu$ sec pulse length ( $\pi / 2$-pulse angle) and $120 \mathrm{sec}$ recycle delay for ${ }^{31} \mathrm{P}$ MAS-NMR. 
${ }^{29} \mathrm{Si}$ chemical shifts were referenced externally to the $-\mathrm{Si}\left(\mathrm{CH}_{3}\right)$ resonance of tetrakis trimethylsilyl silane $\left[\left(\mathrm{CH}_{3}\right)_{3} \mathrm{Si}\right]_{4} \mathrm{Si}$, which was assigned a chemical shift of -9.9 ppm with respect to tetramethyl silane $\mathrm{C}_{4} \mathrm{H}_{12} \mathrm{Si}$ at $0 \mathrm{ppm} .{ }^{31} \mathrm{P}$ chemical shifts were referenced externally to ammonium dihydrogen phosphate $\mathrm{NH}_{4} \mathrm{H}_{2} \mathrm{PO}_{4}$, which was assigned a chemical shift of $0.81 \mathrm{ppm}$ for the silica-based glasses (1.0 ppm for the borate-based glasses) with respect to $85 \%$ phosphoric acid $\mathrm{H}_{3} \mathrm{PO}_{4}$ at 0 ppm. ${ }^{11} \mathrm{~B}$ chemical shifts were referenced externally to boric acid $\mathrm{H}_{3} \mathrm{BO}_{3}$ saturated aqueous solution, which was assigned a chemical shift of -19.49 ppm with respect to boron trifluoride etherate $\left(\mathrm{C}_{2} \mathrm{H}_{5}\right)_{2} \mathrm{O} \cdot \mathrm{BF}_{3}$ at 0 ppm.

\subsection{Results}

\subsubsection{Network connectivity (NC)}

Table 3.1 lists the network connectivity calculations for the fired glass formulations. For both glass series, the addition of $\mathrm{TiO}_{2}$ contributing to $\mathrm{BO}$ did not alter significantly the network connectivity regardless of $\mathrm{ZnO}$ contribution of $\mathrm{BO}$ or $\mathrm{NBO}$. In considering the contribution of $\mathrm{TiO}_{2}$ of $\mathrm{NBO}$ in the form of $\mathrm{TiO}_{6}{ }^{2-}$, network connectivity decreased as $\mathrm{TiO}_{2}$ is increased, with lower connectivity achieved as $\mathrm{ZnO}$ contributed to $\mathrm{NBO}$ as network modifier $\mathrm{Zn}^{2+}$.

Table 3.1. Network connectivity for the silica-based glasses (left) and for the borate-based glasses (right). FF refers to $\mathrm{TiO}_{2}$ and $\mathrm{ZnO}$ as a glass formers; FM refers to $\mathrm{TiO}_{2}$ as a glass former and $\mathrm{ZnO}$ as a glass modifier; $\mathrm{MF}$ refers to $\mathrm{TiO}_{2}$ as a glass modifier and $\mathrm{ZnO}$ as a glass former; and $\mathrm{MM}$ refers to $\mathrm{TiO}_{2}$ and $\mathrm{ZnO}$ as glass modifiers.

\begin{tabular}{|c|c|c|c|c|}
\cline { 2 - 5 } \multicolumn{1}{c|}{} & FF & FM & MM & MF \\
\hline SRT0 & 2.47 & 2.04 & 2.04 & 2.27 \\
\hline SRT1 & 2.44 & 2.04 & 1.62 & 1.97 \\
\hline SRT2 & 2.41 & 2.03 & 1.10 & 1.62 \\
\hline SRT3 & 2.39 & 2.03 & 0.43 & 1.21 \\
\hline SRT4 & 2.36 & 2.03 & -0.44 & 0.71 \\
\hline
\end{tabular}

\begin{tabular}{|c|c|c|c|c|}
\cline { 2 - 5 } \multicolumn{1}{c|}{} & FF & FM & MM & MF \\
\hline BRT0 & 2.27 & 2.02 & 2.02 & 2.42 \\
\hline BRT1 & 2.27 & 2.02 & 1.81 & 2.27 \\
\hline BRT2 & 2.27 & 2.02 & 1.55 & 2.1 \\
\hline BRT3 & 2.27 & 2.02 & 1.22 & 1.89 \\
\hline BRT4 & 2.27 & 2.02 & 0.78 & 1.63 \\
\hline
\end{tabular}




\subsubsection{X-Ray diffraction (XRD)}

Crystallinity of the fired glasses was evaluated using XRD. The results are shown in Fig. 3.1 for the silica-based series and in Fig. 3.2 for the borate-based series. Results for SRT3 indicate no formation of crystal phases during the firing process; however, SRT0, SRT1, SRT2 and SRT4 exhibit sharp peaks, confirming the presence of some crystallinity in these glasses. XRD traces were compared to the ICDD and the phase identified as Sodium Calcium Phosphate Silicate $\mathrm{Na}_{2} \mathrm{Ca}_{4}\left(\mathrm{PO}_{4}\right) \mathrm{SiO}_{4}$ (Ref. 00-033-1229) in all cases. In the case of the borate-based series, glasses with up to $5 \mathrm{~mol} \% \mathrm{TiO}_{2}$ exhibited no crystal formation; however, at $10 \mathrm{~mol} \% \mathrm{TiO}_{2}$ peaks are observed, becoming more pronounced at 15 and $20 \mathrm{~mol} \% \mathrm{TiO}_{2}$; partial crystal phase of Titanium Oxide, $\mathrm{TiO}_{2}$ (Ref. 01-071-0650) was found in BRT2, BRT3 and BRT4.

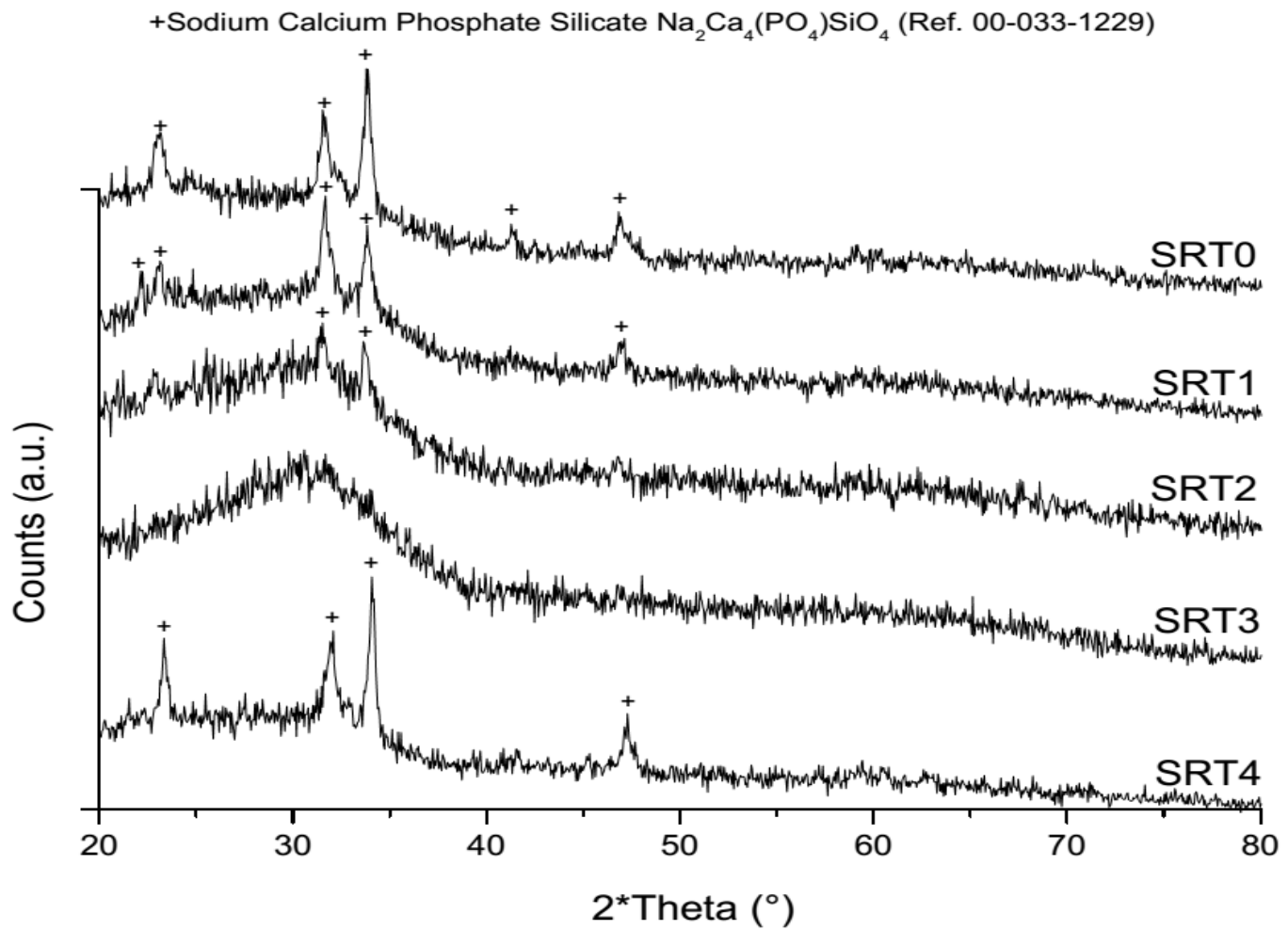

Figure 3.1. XRD patterns for silica-based glass series. 


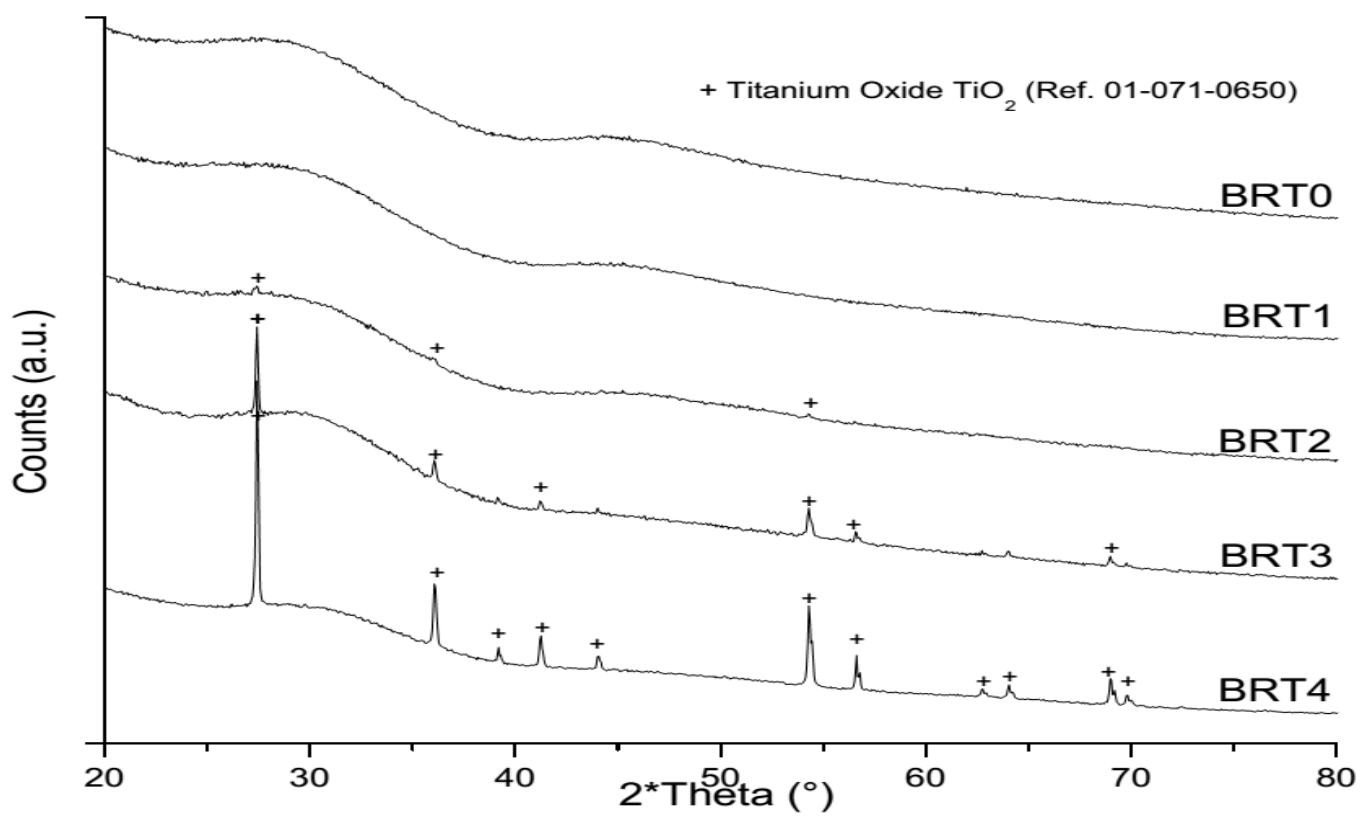

Figure 3.2. XRD patterns for borate-based glass series.

\subsubsection{Particle size analysis (PSA)}

Upon grinding and sieving each glass the average particle size was assessed using PSA. As observed for the silica-based glass in Table 3.2, the mean particle size ranges between $3 \mu \mathrm{m}-6$ $\mu \mathrm{m}$. The borate glasses have a mean particle size of around $9 \mu \mathrm{m}$.

Table 3.2. Particle size distribution for silica-based and borate-based glass series.

\begin{tabular}{|c|c|c|c|c|c|}
\cline { 2 - 6 } \multicolumn{1}{c|}{} & $\begin{array}{c}\text { Mean } \\
(\boldsymbol{\mu m})\end{array}$ & $\begin{array}{c}\text { S.D. } \\
(\boldsymbol{\mu m})\end{array}$ & $\begin{array}{c}\mathbf{d 1 0} \\
(\boldsymbol{\mu m})\end{array}$ & $\begin{array}{c}\mathbf{d 5 0} \\
(\boldsymbol{\mu m})\end{array}$ & $\begin{array}{c}\mathbf{d 9 0} \\
(\boldsymbol{\mu m})\end{array}$ \\
\hline SRT0 & 5.3 & 4.0 & 2.1 & 3.2 & 9.8 \\
\hline SRT1 & 3.5 & 1.7 & 2.2 & 3.1 & 5.7 \\
\hline SRT2 & 4.8 & 3.1 & 2.1 & 2.7 & 8.9 \\
\hline SRT3 & 3.2 & 1.6 & 2.1 & 2.8 & 4.7 \\
\hline SRT4 & 3.3 & 1.6 & 2.1 & 2.8 & 5.1 \\
\hline BRT0 & 10.1 & 4.2 & 6.5 & 8.6 & 15.2 \\
\hline BRT1 & 9.1 & 3.3 & 6.4 & 7.9 & 13.7 \\
\hline BRT2 & 9.3 & 3.4 & 6.4 & 8.3 & 14.5 \\
\hline BRT3 & 9.7 & 3.7 & 6.3 & 8.5 & 15.2 \\
\hline BRT4 & 9.2 & 3.4 & 6.3 & 7.9 & 14.2 \\
\hline
\end{tabular}




\subsubsection{Differential scanning calorimetry (DSC)}

To determine the glass transition $\left(\mathrm{T}_{\mathrm{g}}\right)$ and crystallization $\left(\mathrm{T}_{\mathrm{x}}\right)$ temperatures for each glass, DSC was employed and results are shown on Table 3.3. A decrease in $T_{g}$ for the silica-based glass series occurred with an increase in $\mathrm{TiO}_{2}$ at the expense of $\mathrm{SiO}_{2}$ up to $5 \mathrm{~mol} \%$. However, further increase in the amount of $\mathrm{TiO}_{2}$ up to $20 \mathrm{~mol} \%$ resulted in an increase in $\mathrm{T}_{\mathrm{g}}$. In terms of $\mathrm{T}_{\mathrm{x}}$, increasing $\mathrm{TiO}_{2}$ from $0 \mathrm{~mol} \%$ up to $10 \mathrm{~mol} \%$ translated into a decrease in $\mathrm{T}_{\mathrm{x}}$, with subsequent increase as $\mathrm{TiO}_{2}$ increased to $20 \mathrm{~mol} \%$. For the borate-based glass series, $\mathrm{T}_{\mathrm{g}}$ ranged between $520{ }^{\circ} \mathrm{C}$ and $530{ }^{\circ} \mathrm{C}$, with no significant changes with the addition of $\mathrm{TiO}_{2}$. BRT0 $(0$ mol $\% \mathrm{TiO}_{2}$ ) exhibited a $\mathrm{T}_{\mathrm{g}}$ of $521{ }^{\circ} \mathrm{C}$, reaching a maximum at $5 \mathrm{~mol} \% \mathrm{TiO}_{2}$ at $530{ }^{\circ} \mathrm{C}$ and a minimum at $10 \mathrm{~mol} \% \mathrm{TiO}_{2}$ at $520{ }^{\circ} \mathrm{C} . \mathrm{T}_{\mathrm{x}}$ was significantly impacted by the addition of $\mathrm{TiO}_{2}$. The lowest $\mathrm{T}_{\mathrm{x}}$ was achieved for control BRT0 at $603{ }^{\circ} \mathrm{C}$, increasing with addition of $\mathrm{TiO}_{2}$ up to 10 mol $\%$ at $670{ }^{\circ} \mathrm{C}$, then decreasing with addition of $\mathrm{TiO}_{2}$, reaching $625^{\circ} \mathrm{C}$ at $20 \mathrm{~mol} \% \mathrm{TiO}_{2}$.

Table 3.3. DSC results for silica and borate-based glass series.

\begin{tabular}{|l|c|c|c|}
\cline { 2 - 4 } \multicolumn{1}{c|}{} & $\mathbf{T}_{\mathbf{g}}\left({ }^{\circ} \mathbf{C}\right)$ & $\mathbf{T}_{\mathbf{x}}\left({ }^{\circ} \mathbf{C}\right)$ & $\Delta \mathbf{T}\left({ }^{\circ} \mathbf{C}\right)$ \\
\hline SRT0 & 619 & 735 & 116 \\
\hline SRT1 & 592 & 670 & 78 \\
\hline SRT2 & 596 & 650 & 54 \\
\hline SRT3 & 610 & 705 & 95 \\
\hline SRT4 & 636 & 710 & 74 \\
\hline
\end{tabular}

\begin{tabular}{|l|c|c|c|}
\cline { 2 - 4 } \multicolumn{1}{c|}{} & $\mathbf{T}_{\mathbf{g}}\left({ }^{\circ} \mathbf{C}\right)$ & $\mathbf{T}_{\mathbf{x}}\left({ }^{\circ} \mathbf{C}\right)$ & $\Delta \mathbf{T}\left({ }^{\circ} \mathbf{C}\right)$ \\
\hline BRT0 & 521 & 603 & 82 \\
\hline BRT1 & 530 & 625 & 95 \\
\hline BRT2 & 520 & 670 & 150 \\
\hline BRT3 & 523 & 633 & 110 \\
\hline BRT4 & 528 & 625 & 97 \\
\hline
\end{tabular}

\subsubsection{Energy dispersive spectroscopy (EDS)}

Table 3.4 and Table 3.5 summarize the element compositions for the silicate- and the borate-based glass series, respectively; EDS traces are shown in Fig. 3.3 for the silica-based series, and in Fig. 3.4 for the borate-based series. For both series, incorporation of titanium into the materials' structure is confirmed, and a reduction in silica (for the silicate-based series), and 
of boron oxide (for the borate-based series) is observed. Silica was also found in the borate-based glasses, which resulted from using silica crucibles for firing these glasses; however, mole percentage is less than $5.0 \%$ (less than $1.5 \%$ weight percentage), so its effect may be negligible.

Table 3.4. Compositional analysis from EDS (mol\%) with standard deviation for the silicatebased glasses. Values in parentheses represent target values.

\begin{tabular}{|c|c|c|c|c|c|}
\hline Reagent & SRT0 & SRT1 & SRT2 & SRT3 & SRT4 \\
\hline TiO $_{2}$ & $0.0 \pm 0.0$ & $4.6 \pm 0.1$ & $9.0 \pm 0.2$ & $13.4 \pm 0.2$ & $22.8 \pm 0.1$ \\
& $(0)$ & $(5)$ & $(10)$ & $(15)$ & $(20)$ \\
\hline \multirow{2}{*}{$\mathbf{S i O}_{2}$} & $47.6 \pm 0.3$ & $43.4 \pm 0.2$ & $41.6 \pm 0.4$ & $37.6 \pm 0.2$ & $37.7 \pm 0.1$ \\
& $(52)$ & $(47)$ & $(42)$ & $(37)$ & $(32)$ \\
\hline $\mathbf{C a O}$ & $12.1 \pm 0.1$ & $12.0 \pm 0.1$ & $11.1 \pm 0.2$ & $11.0 \pm 0.3$ & $14.2 \pm 0.1$ \\
\hline $\mathbf{P}_{2} \mathbf{O}_{5}$ & $(12)$ & $(12)$ & $(12)$ & $(12)$ & $(12)$ \\
\hline \multirow{2}{*}{$\mathbf{N a}_{\mathbf{2}} \mathbf{O}$} & $5.4 \pm 0.1$ & $4.8 \pm 0.1$ & $4.7 \pm 0.1$ & $4.8 \pm 0.1$ & $6.1 \pm 0.1$ \\
& $(6)$ & $(6)$ & $(6)$ & $(6)$ & $(6)$ \\
\hline \multirow{2}{*}{$\mathbf{Z n O}$} & $18.1 \pm 0.2$ & $19.2 \pm 0.2$ & $18.3 \pm 0.2$ & $18.3 \pm 0.2$ & $18.5 \pm 0.1$ \\
\hline & $(14)$ & $(14)$ & $(14)$ & $(14)$ & $(14)$ \\
\hline
\end{tabular}

Table 3.5. Compositional analysis from EDS (mol\%) with standard deviation for the boratebased glasses. Values in parentheses represent target values.

\begin{tabular}{|c|c|c|c|c|c|}
\hline Reagent & BRT0 & BRT1 & BRT2 & BRT3 & BRT4 \\
\hline \multirow{2}{*}{$\mathrm{TiO}_{2}$} & $0.0 \pm 0.0$ & $2.7 \pm 0.1$ & $3.6 \pm 0.2$ & $7.6 \pm 0.3$ & $10.7 \pm 0.2$ \\
\hline & $(0)$ & $(5)$ & (10) & (15) & $(20)$ \\
\hline \multirow{2}{*}{$\mathrm{SiO}_{2}$} & $4.2 \pm 0.2$ & $4.2 \pm 0.1$ & $2.5 \pm 0.1$ & $3.3 \pm 0.2$ & $2.9 \pm 0.1$ \\
\hline & $(0)$ & $(0)$ & $(0)$ & $(0)$ & $(0)$ \\
\hline \multirow{2}{*}{$\mathbf{B}_{2} \mathbf{O}_{3}$} & $66.7 \pm 8.7$ & $60.5 \pm 8.9$ & $71.5 \pm 12.2$ & $59.3 \pm 10.5$ & $53.5 \pm 6.0$ \\
\hline & $(52)$ & $(47)$ & $(42)$ & (37) & (32) \\
\hline \multirow{2}{*}{$\mathrm{CaO}$} & $6.4 \pm 0.3$ & $7.0 \pm 0.3$ & $4.8 \pm 0.3$ & $6.2 \pm 0.2$ & $7.1 \pm 0.1$ \\
\hline & (12) & (12) & $(12)$ & $(12)$ & (12) \\
\hline \multirow{2}{*}{$\mathbf{P}_{2} \mathbf{O}_{5}$} & $2.4 \pm 0.1$ & $3.0 \pm 0.1$ & $2.2 \pm 0.1$ & $3.0 \pm 0.1$ & $3.3 \pm 0.1$ \\
\hline & $(6)$ & $(6)$ & $(6)$ & $(6)$ & (6) \\
\hline \multirow{2}{*}{$\mathrm{Na}_{2} \mathrm{O}$} & $10.0 \pm 0.5$ & $12.2 \pm 0.5$ & $8.7 \pm 0.3$ & $10.8 \pm 0.4$ & $12.3 \pm 0.4$ \\
\hline & (14) & (14) & (14) & $(14)$ & (14) \\
\hline \multirow{2}{*}{ ZnO } & $10.3 \pm 0.4$ & $10.5 \pm 0.4$ & $6.6 \pm 0.2$ & $9.8 \pm 0.4$ & $10.3 \pm 0.3$ \\
\hline & $(16)$ & (16) & (16) & (16) & (16) \\
\hline
\end{tabular}




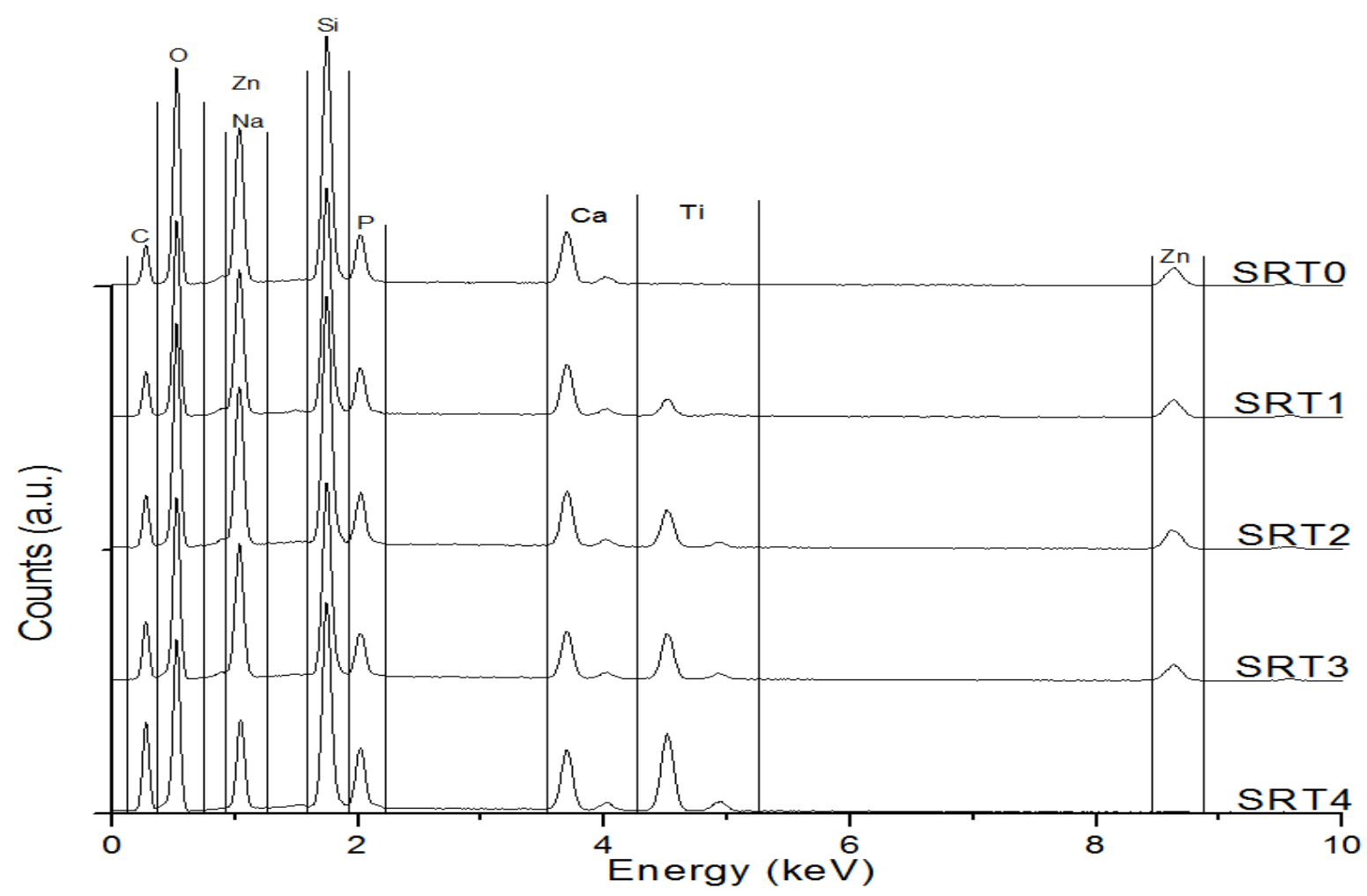

Figure 3.3. EDS traces for silica-based series.

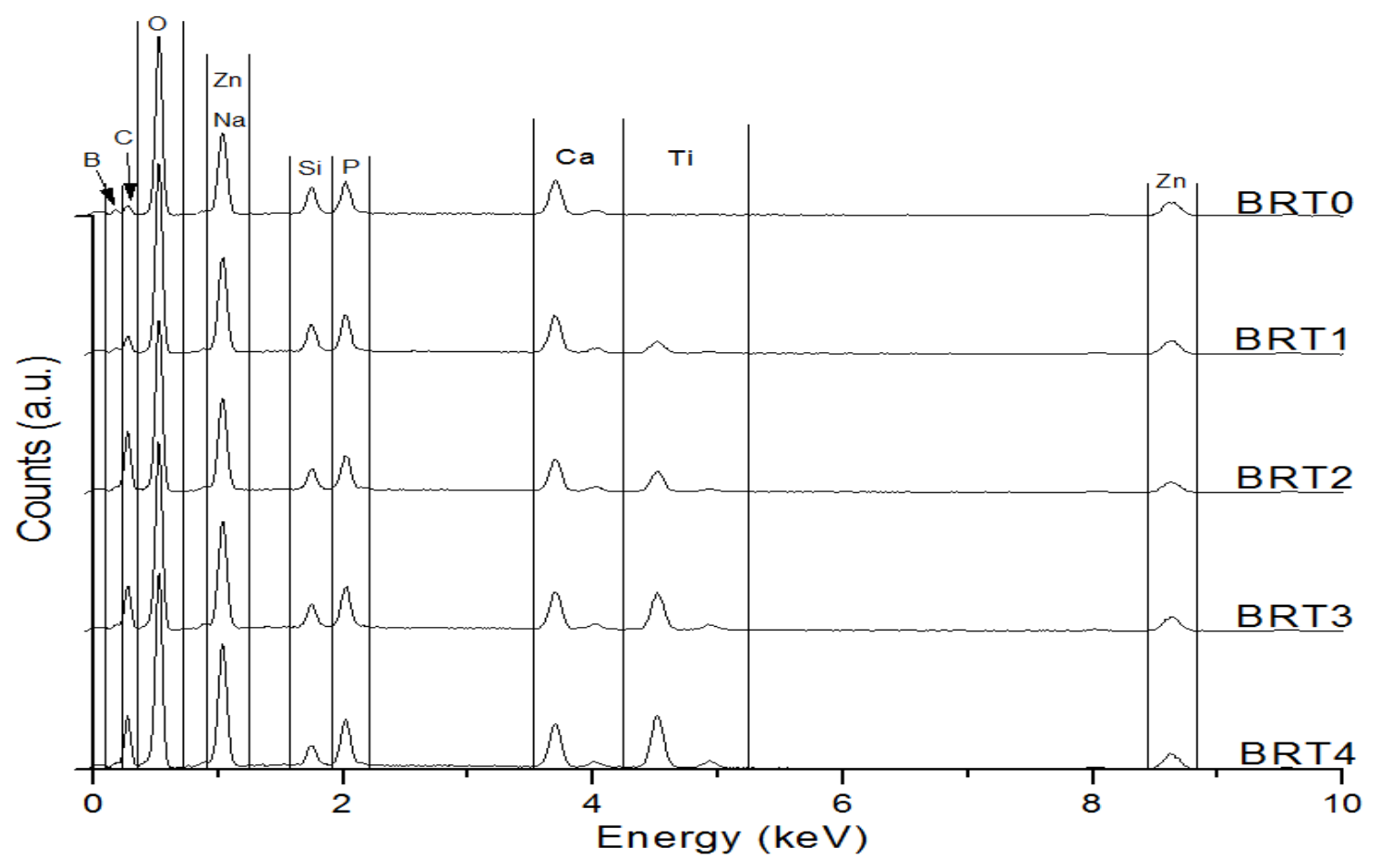

Figure 3.4. EDS traces for borate-based series. 


\subsubsection{Fourier transform infrared (FTIR) spectroscopy}

Absorbance spectra for the silica-based and borate-based glass series are shown in Fig. 3.5 and Fig. 3.6, respectively. From the absorbance spectra for the silica-based series, three peaks were observed, $\sim 772 \mathrm{~cm}^{-1}, \sim 928 \mathrm{~cm}^{-1}$ and $\sim 991 \mathrm{~cm}^{-1}$. The $772 \mathrm{~cm}^{-1}$ band, belonging to $\mathrm{Si}-\mathrm{O}-\mathrm{Si}$ bending bond [82], remained visible up until the addition of $15 \mathrm{~mol} \% \mathrm{TiO}_{2}$ (SRT3), fading for 20 mol\% $\mathrm{TiO}_{2}$ glass (SRT4), with the $991 \mathrm{~cm}^{-1}$ band, belonging to $\mathrm{Si}-\mathrm{O}-\mathrm{Si}$ stretched bond [82], present. This band was also identified for SRT0 and SRT1, and at a lower wavenumber $\left(963 \mathrm{~cm}^{-}\right.$ ${ }^{1}$ ) for SRT3. Bond $\mathrm{Si}-\mathrm{O}-\mathrm{NBO}$, centered around $928 \mathrm{~cm}^{-1}$ [82], showed no significant shift with the addition of $\mathrm{TiO}_{2}$. A summary of the infrared (IR) assignments is listed in Table 3.6. For the borate-based series, bands were encountered near $696 \mathrm{~cm}^{-1}, 770 \mathrm{~cm}^{-1}, 916 \mathrm{~cm}^{-1}, 1010 \mathrm{~cm}^{-1}, 1248$ $\mathrm{cm}^{-1}$ and $1345 \mathrm{~cm}^{-1}$ (refer to Table 3.6 for the IR assignment). Peaks at $696 \mathrm{~cm}^{-1}$ and $770 \mathrm{~cm}^{-1}$ indicate the presence of $\mathrm{B}-\mathrm{O}-\mathrm{B}$ bending bond [83], with absorbance intensity decreasing consistently decreasing with the additional of $\mathrm{TiO}_{2}$. The peak at $916 \mathrm{~cm}^{-1}$, belonging to stretching bond $\mathrm{B}-\mathrm{O}$ in diborate groups [83], maintained absorbance levels with the increase in the content of $\mathrm{TiO}_{2}$, with slight shifts for BRT1 and BRT2, and significant shifts for BRT3 (to $859 \mathrm{~cm}^{-1}$ ) and BRT4 (to $900 \mathrm{~cm}^{-1}$ ), compositions which exhibited the crystallization of $\mathrm{TiO}_{2}$. 
Table 3.6. Infrared (IR) peak assignment for silica-based and borate-based glass spectra.

\begin{tabular}{|c|c|c|}
\hline Wavenumber $\left(\mathrm{cm}^{-1}\right)$ & IR Assignment & Reference \\
\hline$\sim 771$ & $\mathrm{Si}-\mathrm{O}-\mathrm{Si}$ bond-bending & \multirow{3}{*}[82]{} \\
\hline$\sim 928$ & $\mathrm{Si}-\mathrm{O}-\mathrm{NBO}$ & \\
\hline$\sim 991$ & $\mathrm{Si}-\mathrm{O}-\mathrm{Si}$ bond-stretching & \\
\hline$\sim 696, \sim 770$ & B-O-B bond-bending vibrations & \multirow{5}{*}{$\begin{array}{l}\quad[83] \\
\varnothing \text { represents } \\
\text { oxygen atom } \\
\text { bridging two } \\
\text { boron atoms. }\end{array}$} \\
\hline$\sim 916$ & $\begin{array}{l}\mathrm{B}-\mathrm{O} \text { bond-stretching vibrations in } \mathrm{BO}_{4} \text { units from diborate } \\
\text { groups }\end{array}$ & \\
\hline$\sim 1010$ & $\begin{array}{l}\mathrm{B}-\varnothing \text { bond-stretching vibrations of } \mathrm{B}_{4}^{-} \text {tetrahedra from } \\
\text { tri-, tetra- and pentaborate groups }\end{array}$ & \\
\hline$\sim 1248$ & $\begin{array}{l}\text { Asymmetric stretching vibration of } \mathrm{B}-\mathrm{O} \text { bonds from } \\
\text { orthoborate groups }\end{array}$ & \\
\hline$\sim 1345$ & $\begin{array}{l}\text { Asymmetric stretching modes of borate triangles } \mathrm{B}_{3} \text { and } \\
\mathrm{B} \emptyset_{2} \mathrm{O}-\mathrm{NBO}\end{array}$ & \\
\hline
\end{tabular}

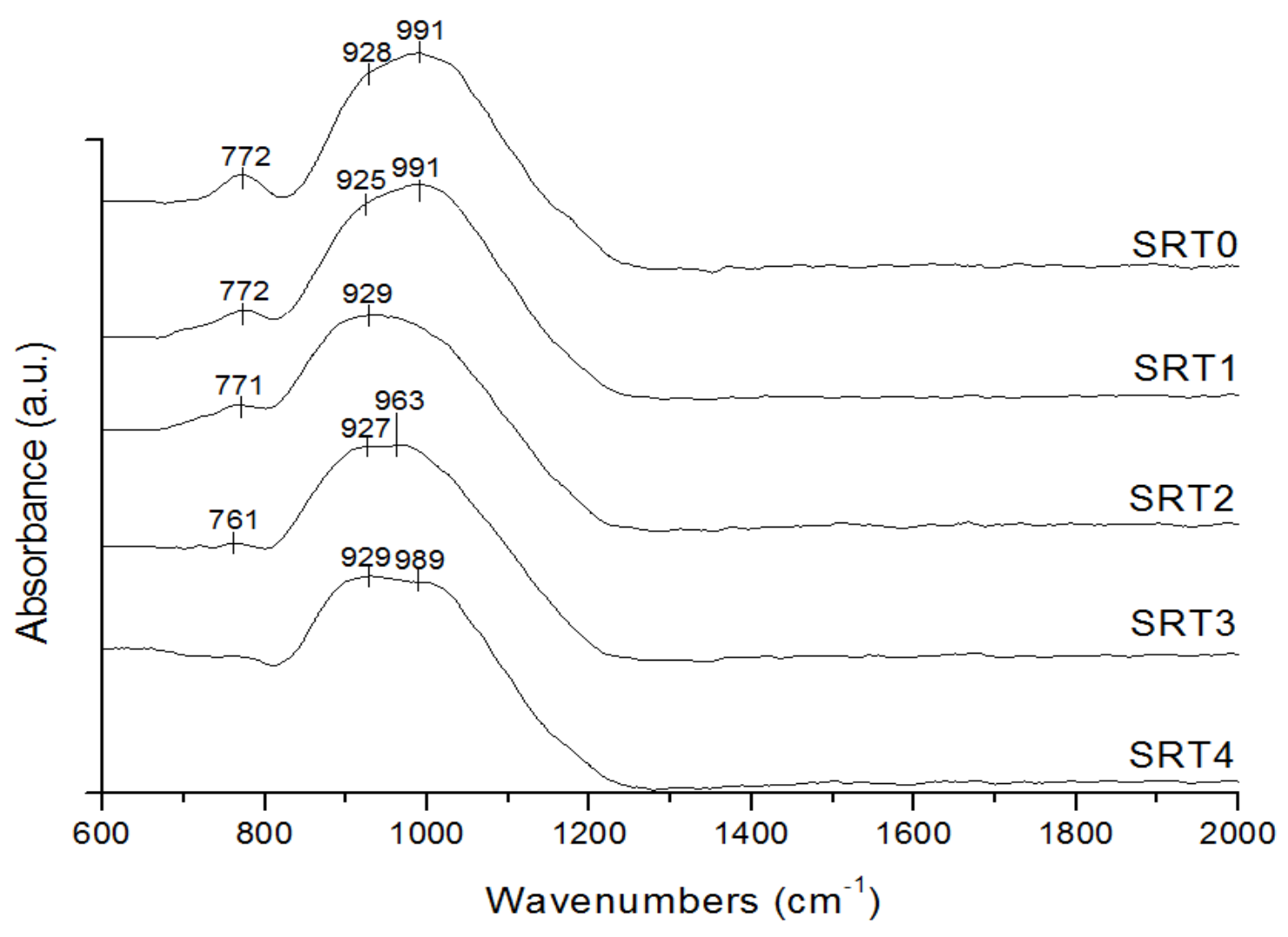

Figure 3.5. FTIR Transmittance spectra for silica-based glasses. 


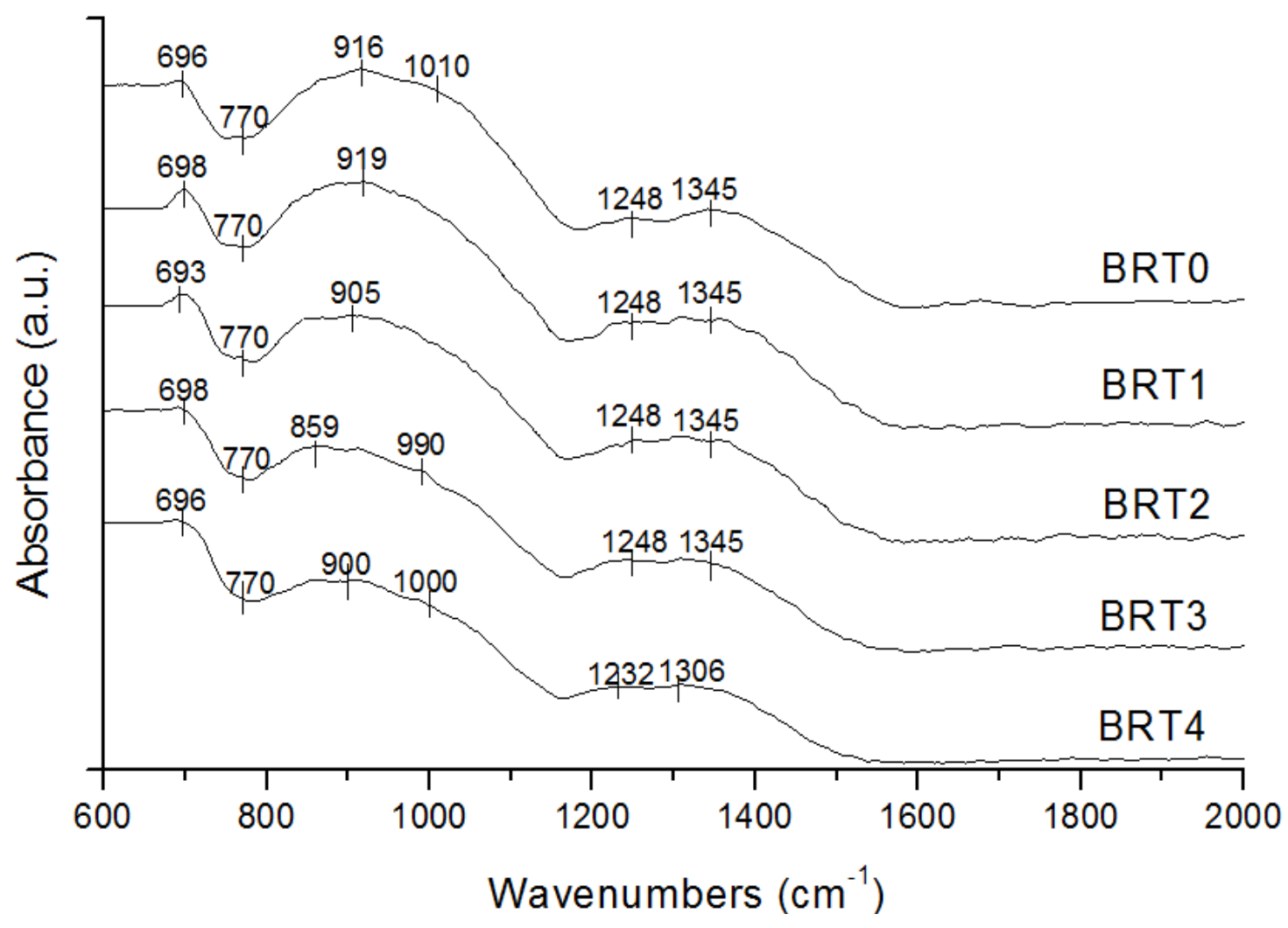

Figure 3.6. FTIR Transmittance spectra for borate-based glasses.

\subsubsection{Magic-angle spinning- Nuclear magnetic resonance spectroscopy}

\section{(MAS-NMR)}

${ }^{29} \mathrm{Si}$ and ${ }^{31} \mathrm{P}$ NMR spectra for the silica-based series are shown in Fig. 3.7 and Fig. 3.8, respectively; ${ }^{11} \mathrm{~B}$ and ${ }^{31} \mathrm{P}$ NMR spectra for the borate-based glass series are shown in Fig. 3.9 and Fig. 3.10, respectively. A consistent increase in chemical shift for ${ }^{29} \mathrm{Si}$, from $-93.67 \mathrm{ppm}\left(\mathrm{Q}^{4}\right)$ [84] for SRT0 at $0 \mathrm{~mol} \% \mathrm{TiO}_{2}$, is observed with the addition of $\mathrm{TiO}_{2}$ up to $15 \mathrm{~mol} \% \mathrm{TiO}_{2}$, with a significant decrease at $20 \mathrm{~mol} \%$. Two peaks, $\sim 4.26 \mathrm{ppm}$ and $\sim 2.60 \mathrm{ppm}\left(\mathrm{Q}^{0}\right.$ and $\mathrm{Q}^{1}$, respectively) [84], are observed in the ${ }^{31} \mathrm{P}$ spectra for the silica-based glass series for $\mathrm{TiO}_{2}$ content at 0,5 and $20 \mathrm{~mol} \%$, whereas a single peak is observed at 10 and $15 \mathrm{~mol} \%$. ${ }^{11} \mathrm{~B}$ NMR 
exhibited three peaks, $\sim 13.61 \mathrm{ppm}, \sim 8.93 \mathrm{ppm}$ and $\sim 0.43 \mathrm{ppm}$, corresponding to $\mathrm{Q}^{3}$ structures in the form of symmetric $\mathrm{BO}_{3}$, asymmetric $\mathrm{BO}_{3}$, and $\mathrm{Q}^{4}$ structures in the form of $\mathrm{BO}_{4}$ species, respectively [85], with chemical shifts increasing with the addition of $\mathrm{TiO}_{2}$ up to $10 \mathrm{~mol} \%$, with BRT2 peaking at $\sim 14.05 \mathrm{ppm}, \sim 9.51 \mathrm{ppm}$ and $\sim 0.87 \mathrm{ppm}$, respectively; however, further addition of $\mathrm{TiO}_{2}$ and the presence of crystal phase $\mathrm{TiO}_{2}$ resulted in a decrease in chemical shift to $\sim 13.76 \mathrm{ppm}, \sim 9.07 \mathrm{ppm}$ and $\sim 0.58 \mathrm{ppm}$, respectively, at $15 \mathrm{~mol} \%$. At $20 \mathrm{~mol} \%$, and with greater crystallinity intensities, the chemical shift shifted to $\sim 14.05 \mathrm{ppm}, \sim 9.51 \mathrm{ppm}$ and $\sim 0.73 \mathrm{ppm}$. For the borate-based glass series, the ${ }^{31} \mathrm{P}$ NMR spectra exhibits a single peak, $44.82 \mathrm{ppm}\left(\mathrm{Q}^{0}\right)\left[{ }^{84}\right]$, for all compositions, with the chemical at the peak decreasing with the addition of $\mathrm{TiO}_{2}$ from 0 to $10 \mathrm{~mol} \%$, then increasing at 15 and $20 \mathrm{~mol} \%$.

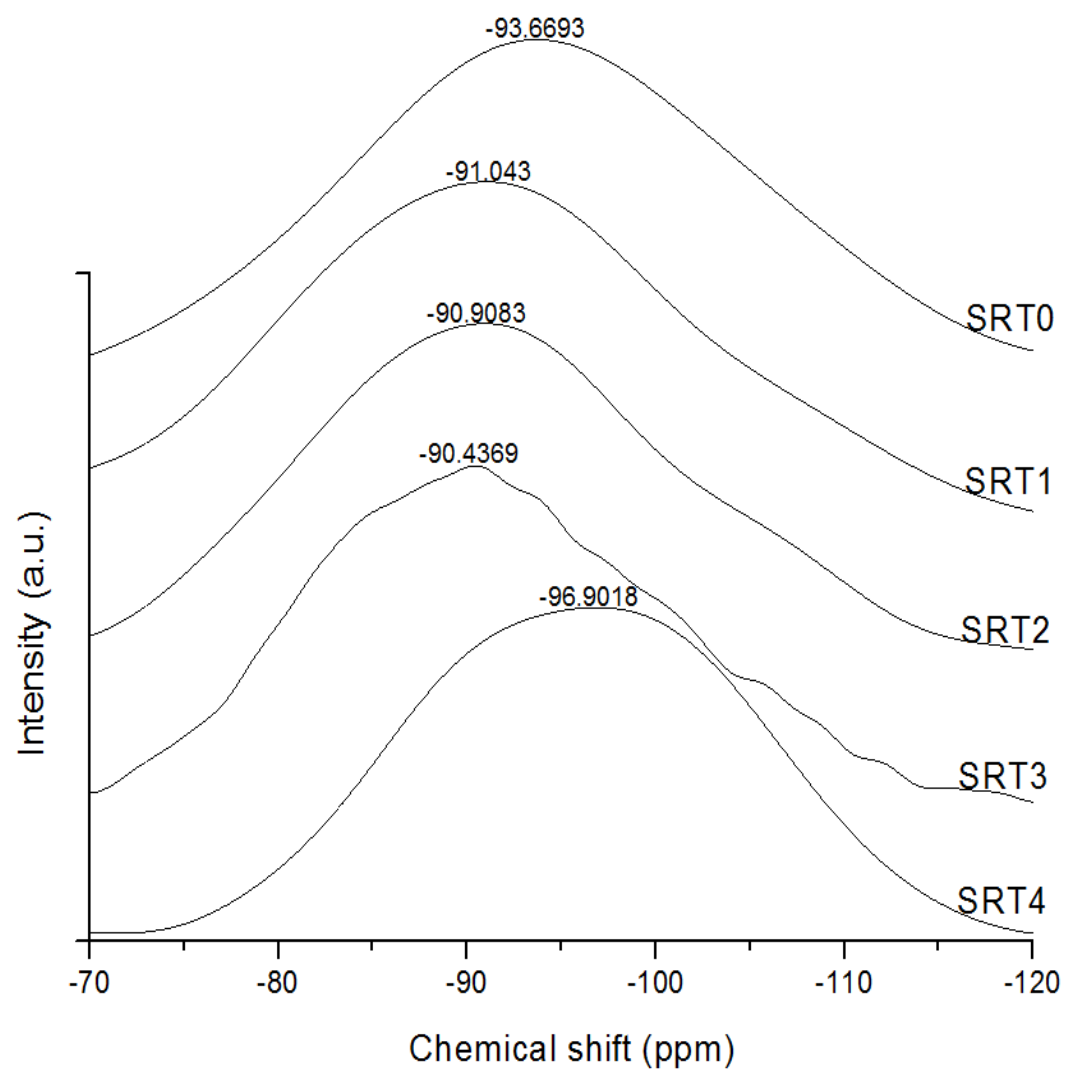

Figure 3.7. ${ }^{29} \mathrm{Si}$ Chemical shift for the silica-based glass series. 


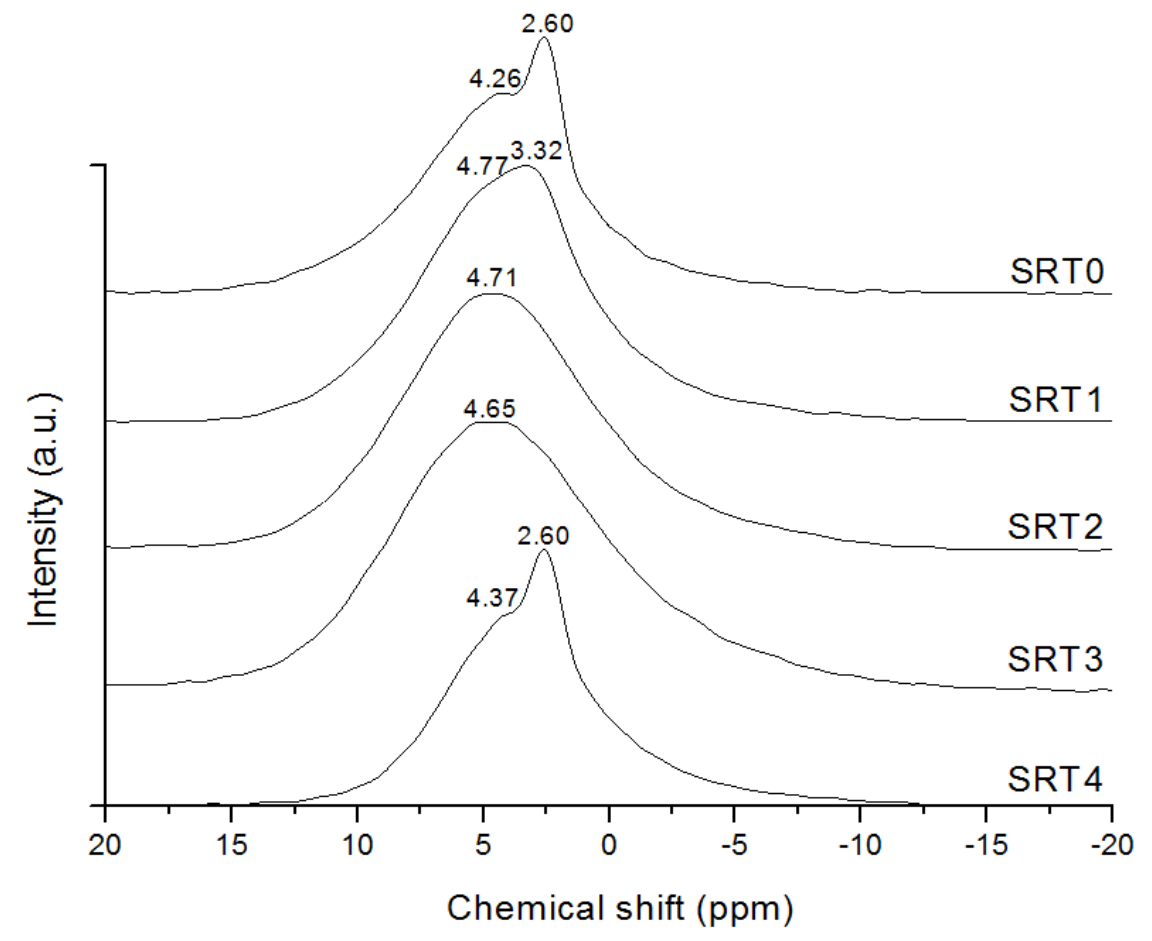

Figure 3.8. ${ }^{31} \mathrm{P}$ Chemical shift for the silica-based glass series.

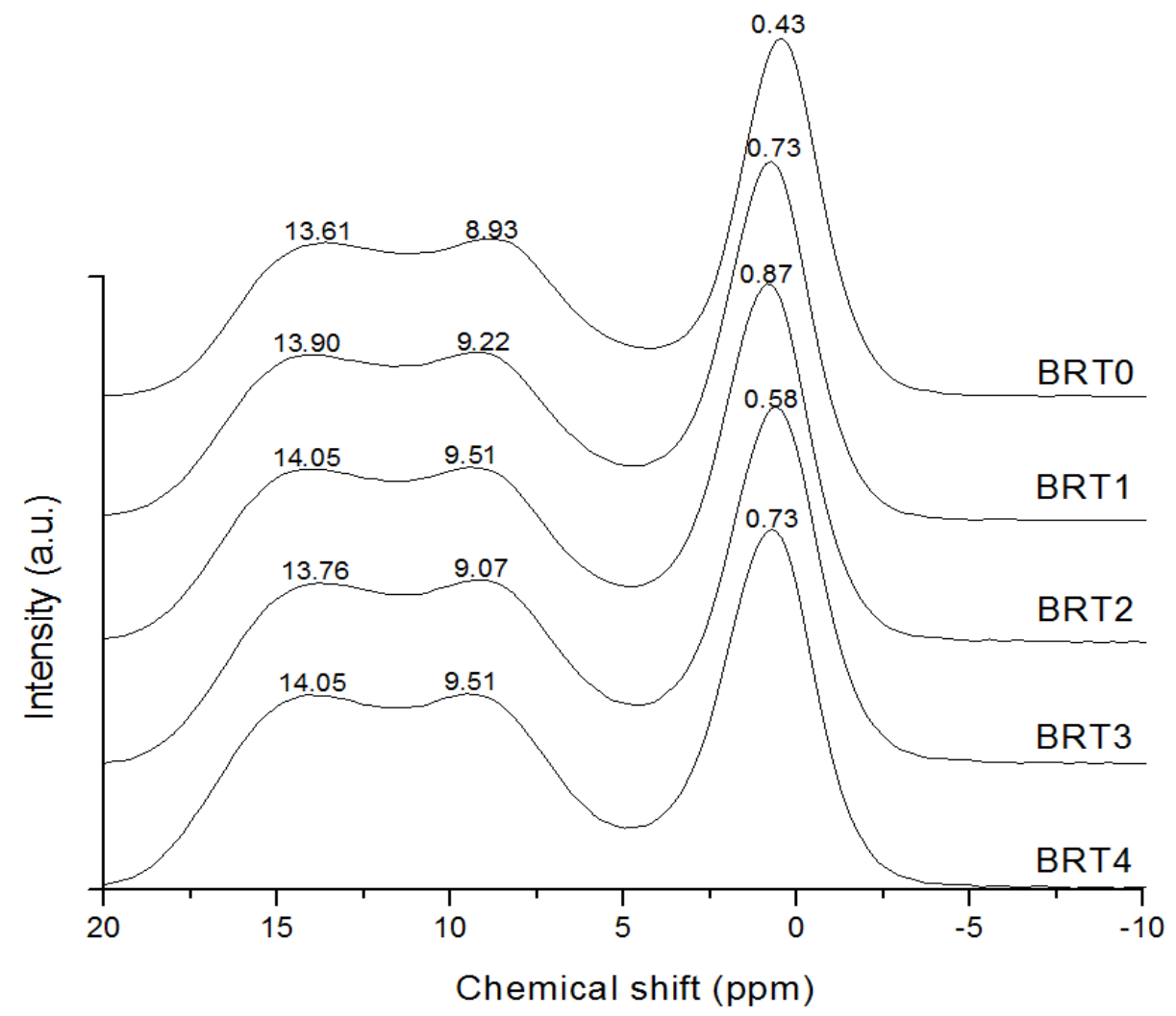

Figure 3.9. ${ }^{11} \mathrm{~B}$ Chemical shift for the borate-based glass series. 


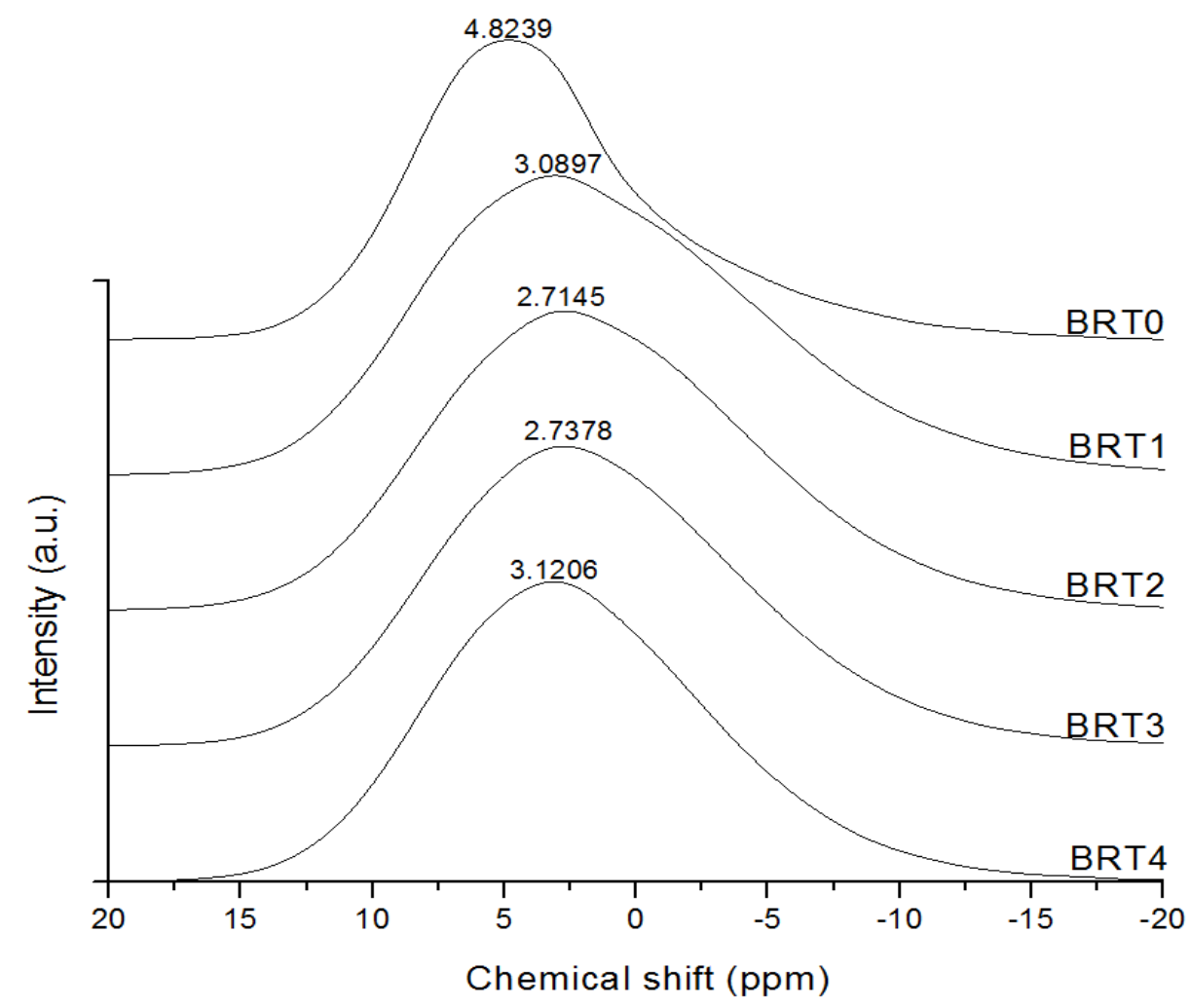

Figure 3.10. ${ }^{31} \mathrm{P}$ Chemical shift for the borate-based glass series.

\subsection{Discussion}

With respect to the silica-based series, amorphicity remained for glass SRT3, which contains $15 \mathrm{~mol} \%$ of $\mathrm{TiO}_{2}$, evidenced by the amorphous hump and lack of sharp peaks found in the XRD traces; whereas partial crystallinity (i.e., the amorphous hump remained visible in the background of the XRD traces, as exhibited by SRT3) was found for glasses SRT0, SRT1, SRT2 and SRT4, containing 0, 5, 10 and $20 \mathrm{~mol} \% \mathrm{TiO}_{2}$, respectively. XRD traces were compared to the ICDD database, and identified as Sodium Calcium Phosphate Silicate $\mathrm{Na}_{2} \mathrm{Ca}_{4}\left(\mathrm{PO}_{4}\right) \mathrm{SiO}_{4}(\mathrm{Ref}$. 00-033-1229) in all cases. ${ }^{31} \mathrm{P}$ NMR for the partially crystallized glasses exhibited two peaks ( 4.26 ppm and $\sim 2.60 \mathrm{ppm}$ ), with the exception of SRT2, which may be attributed to low intensity crystal peaks compared to SRT0, SRT1 and SRT4; amorphous glass SRT3 presented 
only one peak ( $4.71 \mathrm{ppm})$. The presence of the Sodium Calcium Phosphate Silicate phase may explain the occurrence on the second peak $(\sim 2.60 \mathrm{ppm})$ for the crystalline materials, accounting for $\mathrm{Q}^{1}$ tetrahedron (pyrophosphate) in $\mathrm{Na}_{2} \mathrm{Ca}_{4}\left(\mathrm{PO}_{4}\right) \mathrm{SiO}_{4}$, whereas the peak $\sim 4.26 \mathrm{ppm}$ and $\sim 4.71$ ppm indicates the presence of orthophosphate $\left(\mathrm{Q}^{0}\right.$ tetrahedron) [84], supporting the statement that $\mathrm{P}_{2} \mathrm{O}_{5}$ would enter the glass network as a network modifier, rather than as a network former [80]. ${ }^{29} \mathrm{Si}$ NMR peak was located at $-93.67 \mathrm{ppm}$ for $\mathrm{SRT0}\left(\mathrm{Q}^{4}\right)$, increasing as $\mathrm{TiO}_{2}$ is added up to $15 \mathrm{~mol} \%$ to $-90.44 \mathrm{ppm}$, then decreasing to $-96.90 \mathrm{ppm}$ for SRT4 at $20 \mathrm{~mol} \%$. Considering the crystal peak intensities, the decreased chemical shift in ${ }^{29} \mathrm{Si}$ is observed with increased intensity, suggesting that phase $\mathrm{Na}_{2} \mathrm{Ca}_{4}\left(\mathrm{PO}_{4}\right) \mathrm{SiO}_{4}$ promoted the formation of $\mathrm{Q}^{4}$ structures in the glasses.

As for the borate-based series, no crystallization occurred in glasses with up to $10 \mathrm{~mol} \%$ $\mathrm{TiO}_{2}$, i.e., BRT0 and BRT1. Partial crystal phase of Titanium Oxide $\mathrm{TiO}_{2}$ (Ref. 01-071-0650) was found in BRT2, BRT3 and BRT4, indicating a possible saturation point for the addition of $\mathrm{TiO}_{2}$ to the control glass BRT0. Studies have been performed to determine the effect of crystallinity on glass solubility and ion release [86], which points toward fully amorphous glasses providing better solubility and ion release profiles compared to crystalline materials. As coating materials, degradation behavior of these glasses is important to bacterial inhibition and osseointegration; therefore, further studies on the degradation of these partially crystallized materials would confirm how effective these materials are in releasing ions into the body and would help quantify the effect of partial crystallinity on the properties of these particular glasses. Compared to the SRT results, ${ }^{31} \mathrm{P}$ for the BRT series presented only one peak for all glasses, centered at $4.82 \mathrm{ppm}$ for BRT0, corresponding to orthophosphate $\mathrm{PO}_{4}{ }^{-3}\left(\mathrm{Q}^{0}\right.$ tetrahedron) [84], decreasing with the addition of $\mathrm{TiO}_{2}$ up to $10 \mathrm{~mol} \%$, with $\mathrm{BRT} 2$ exhibiting a peak at $2.71 \mathrm{ppm}$; however, the presence of crystallinity translated into an increase to $2.74 \mathrm{ppm}$ for BRT3, and 
further to $3.12 \mathrm{ppm}$ for BRT4, correlating the increase in chemical shift with the increase in crystallinity intensity. ${ }^{11} \mathrm{~B}$ NMR exhibited three peaks, $\sim 13.61 \mathrm{ppm}, \sim 8.93 \mathrm{ppm}$ and $\sim 0.43 \mathrm{ppm}$, corresponding to $\mathrm{Q}^{3}$ structures in the form of symmetric $\mathrm{BO}_{3}$, asymmetric $\mathrm{BO}_{3}$, and $\mathrm{Q}^{4}$ structures in the form of $\mathrm{BO}_{4}$ species, respectively [85]; furthermore, it was observed from FTIR the presence of different boron-to-oxygen bonds, as shown in Table 3.6. It may be argued that the presence of $\mathrm{TiO}_{2}$ crystals perturbed stretching bond $\mathrm{B}-\mathrm{O}$ in diborate groups, but favoring these bonds for tri-, tetra- and pentaborate groups, as the peak at $1010 \mathrm{~cm}^{-1}$ is only observed for the control BRT0, then also in BRT3 and BRT4, with minor shifts to $990 \mathrm{~cm}^{-1}$ and $1000 \mathrm{~cm}^{-1}$, respectively. The maxima around $1248 \mathrm{~cm}^{-1}$ and $1345 \mathrm{~cm}^{-1}$, belonging to asymmetric stretching of $\mathrm{B}-\mathrm{O}$ bonds, remained unchanged up until $15 \mathrm{~mol} \% \mathrm{TiO}_{2}$, but experienced a shift to $1232 \mathrm{~cm}^{-1}$ and $1306 \mathrm{~cm}^{-1}$ for BRT4, respectively, which may be attributed to the presence of crystal phase $\mathrm{TiO}_{2}$ at higher concentration compared to BRT3. Provided the absence of IR peaks pertaining to bonds of titanium, it suggests $\mathrm{TiO}_{2}$ behavior as a network modifier, rather than a network former, for both silica-based and borate-based glasses.

It was found that as $\mathrm{TiO}_{6}{ }^{2-}$ enters the glass network for the proposed materials, a decrease of NC below 2 is expected, which by definition favors bioactivity, with $\mathrm{Zn}^{+2}$ contributing as well to the decrease in NC. NBO disrupt the glass network by depolymerizing Si-O-Si and B-O-B [74, 87], which facilities ion release from the glass network, increasing bioactivity [88], suggesting that $\mathrm{TiO}_{2}$ entered the glass network as modifier $\mathrm{TiO}_{6}{ }^{2-}$, rather than as a former, allows for better bioactivity.

In evaluating the suitability of the bioactive glasses for coating, the processing window $(\Delta \mathrm{T})$ is defined by the range between $\mathrm{T}_{\mathrm{x}}$ and $\mathrm{T}_{\mathrm{g}}$; a larger processing window is more desirable as it allows for a wider range of temperatures in which to process the glass [46]. The smallest 
processing window for the SRT series, $54^{\circ} \mathrm{C}$, occurred for SRT2, whereas the maximum processing window, $116^{\circ} \mathrm{C}$, occurred for SRT0. Greater processing windows were found for the BRT series, with the smallest one (BRT0) at $82^{\circ} \mathrm{C}$ and the largest one (BRT2) at $150^{\circ} \mathrm{C}$. Crystallization temperatures for both glass series are, however, below the $\beta$ transus temperature for commercially pure (cp) $\mathrm{Ti}\left(882 \pm 2^{\circ} \mathrm{C}\right)$ and $\mathrm{Ti} 6 \mathrm{Al} 4 \mathrm{~V}\left(995^{\circ} \mathrm{C}\right.$ to $\left.1010^{\circ} \mathrm{C}\right)$ [69], two preferred metals for implant applications; therefore, in coating titanium with these glasses, no $\alpha$ to $\beta$ transformation will occur, preserving the oxidation resistance in alpha phases compared to beta phases. With the increase in $\mathrm{TiO}_{2}$ in the silica-based series, a decrease was observed in the processing window $\Delta \mathrm{T}$ up to $10 \mathrm{~mol} \%$, with an increase with further increase in $\mathrm{TiO}_{2}$. Increasing $\mathrm{TiO}_{2}$ beyond $10 \mathrm{~mol} \%$ directly translated into an increase in $\mathrm{T}_{\mathrm{g}}$ and $\mathrm{T}_{\mathrm{x}}$, with the absence of crystal peaks in SRT3 resulting in a greater $\Delta \mathrm{T}$, attributed to higher energy required to promote the formation of new crystal structures within the glassy material, thus increasing $\mathrm{T}_{\mathrm{g}}$. For the borate-based series, at 10 mol\% maximum $\mathrm{T}_{\mathrm{x}}$ was achieved, where low crystal peak intensities are first encountered for this series; the addition of $\mathrm{TiO}_{2}$ beyond this point increased peak intensities, which translated into decreased $T_{x}$ (and subsequently decreased $\Delta T$ ). It may be suggested that the presence of crystal phase $\mathrm{TiO}_{2}$ favored crystallization, hence reducing $\mathrm{T}_{\mathrm{x}}$ as $\mathrm{TiO}_{2}$ was increased beyond $10 \mathrm{~mol} \%$ in the borate-based series.

\subsection{Chapter Summary}

Incorporation of $\mathrm{TiO}_{2}$ to silica-based and borate-based glasses was achieved through standard melt-quenching glass synthesis processes. MAS-NMR proved that $\mathrm{P}_{2} \mathrm{O}_{5}$ acted as a network modifier for both glass series by evidencing only $\mathrm{Q}^{0}$ structures (and $\mathrm{Q}^{1}$ structures for the silica-based glasses with crystal structures), whereas FTIR proved that $\mathrm{TiO}_{2}$ acted as a network 
modifier by lack of peaks assignable to titanium bonding. Upon characterization, the two glass series are expected to have potential as coatings on metals owing to the favorable network connectivity calculations, inferring that the glasses will degrade in-situ and release ions at the site of implantation. Additionally, thermal behavior of these glasses provided for processing windows which make them suitable for enameling metallic implants, with the borate-based series exhibiting greater processing windows over the silica-based series.

Further studies will provide additional insight on the advantages and disadvantages of employing borate-based glasses for coating applications in contrast to silica-based glasses, expanding the range of applications of bioactive materials. The biocompatibility and bioactivity of the glasses will be studied in the next chapter. Though both glass series exhibited thermal, structural and compositional characteristics making them suitable materials for coating applications, it was observed that zinc oxide may not have been properly incorporated into SRT4, as this formulation required higher firing temperatures and may not have fully melted. Since zinc oxide is the antibacterial component in these glass series, and that characteristic is fundamental to achieve the objectives of this dissertation, glass SRT4 (and subsequently, BRT4) was removed from further evaluation. 
4. Biocompatibility Behavior of Titanium-containing Bioactive Glasses for Metallic Implant

Coating: Solubility, Cytotoxicity and Antibacterial Analysis 
The work contained in this chapter [89] has been submitted for publication as follows:

Rodriguez, O., Stone, W., Papini, M., Schemitsch, E.H., Zalzal, P., Waldman, S. and Towler, M.R., 2016. Biocompatibility Behavior of Titanium-containing Bioactive Glasses for Metallic Implant Coating: Solubility, Cytotoxicity and Antibacterial Analysis, Journal of NonCrystalline Solids (under review).

\subsection{Introduction}

The results of Chapter 3 demonstrated the successful incorporation of titanium dioxide into the glass structure of silica-based and borate-based glasses, and that these compositions exhibited characteristics that make them suitable for coating applications while preventing bacterial proliferation. For example, the glasses exhibited large enameling processing windows, glass transition and crystallization temperatures below beta transus temperature for titanium and its alloys, and the incorporation of antibacterial reagent zinc oxide in these glasses was confirmed. However, glass SRT4 did not successfully incorporate zinc oxide. Therefore, the work in this chapter does not consider glass SRT4 and, consequently, BRT4.

This chapter evaluates the characteristics of the two glass series, a silica-based and a borate-based, in terms of their degradative behavior (including solubility and ion release profiles), cytotoxicity, and in vitro antibacterial capabilities. For the latter studies, inhibition zones will be measured in media containing Staphylococcus epidermidis and Escherichia coli. 


\subsection{Methods}

\subsubsection{Sample preparation}

Glass preparation for this work was done as per Section 2.2, and discs were prepared as per Section 2.3. For this work, glass compositions were evaluated from both series up to 15 mol\% incorporated $\mathrm{TiO}_{2}$.

\subsubsection{Solubility analysis}

Three glass discs $(n=3)$ for each glass composition were placed in separate containers filled with $25 \mathrm{~mL}$ of deionized water, and incubated at $37^{\circ} \mathrm{C}$ for 1,7 and 30 days. The discs were weighted prior to incubation, and re-weighed after each incubation period; the percentage difference from the initial mass of the disc was then computed as a function of time, as follows:

$$
\% m_{l(t)}=\left|\frac{m_{0}-m_{(t)}}{m_{0}}\right| 100 \%
$$

where $\% m_{l(t)}$ is the percentage of mass loss, $m_{0}$ is the mass at time zero (before incubation) and $m_{(t)}$ is the mass at time $t$ (where $t=1,7$ and 30 days).

\subsubsection{Ion release through Atomic Absorption Spectroscopy (AAS)}

Samples for ion release profiles were prepared as described in Section 4.2.2 and measured using Atomic Absorption Spectroscopy (AAS), model PinAAcle 500 Flame Atomic Absorption Spectrometer (PerkinElmer, Waltham, MA, USA). AAS calibration standards for titanium and zinc ions at concentrations of 0.00 (blank sample), 0.50, 1.00, 5.00 and $10.00 \mathrm{ppm}$ were prepared from stock solutions on a gravimetric basis. At 1, 7 and 30 days, samples were 
tested, with the AAS measuring absorbance levels, which were automatically translated into concentration levels by the Syngistix Touch software (PerkinElmer, Waltham, MA, USA) based on the ion calibration curves.

\subsection{4. pH change}

Samples $(n=3)$ for $\mathrm{pH}$ change were prepared as described in Section 4.2.2. At 1, 7 and 30 days, samples were tested using an Omega PHH222 pH meter (Omega, Laval, QC, Canada) and compared to reference samples at $t=0$ days to determine how $\mathrm{pH}$ varied in the presence of the glass discs.

\subsubsection{In vitro antibacterial analysis}

The antimicrobial properties of the SRT and BRT glass discs were evaluated on agar plates against prokaryotic species Escherichia coli (E.coli) and Staphylococcus epidermidis (S. epidermidis) against bacterial lawns, spread on Tryptic Soy Agar (TSA) (3 g/L Tryptic Soy Broth, $15 \mathrm{~g} / \mathrm{L}$ agar). All chemicals were purchased from Fisher Scientific (Ottawa, ON, Canada). Bacterial cultures were grown to an exponential phase $(12-16 \mathrm{hr})$, diluted in Physiological Saline Solution $(9 \mathrm{~g} / \mathrm{L} \mathrm{NaCl})$ to $10^{6}$ cells $/ \mathrm{mL}$ and spread onto TSA. Antimicrobial properties were quantified on the bacteria by measuring and comparing the zones of growth inhibition. One disc (prepared as described in Section 4.2.2) of each glass was added to each bacterial plate (4 discs per plate, evenly spaced on the lawn). Each plate had a single microbial species, and each species was repeated in triplicate for statistical comparisons. The diameters of the bacterial inhibition zones were measured at 1, 7 and 30 days, and the means and standard deviations of triplicate samples were compared with the post-hoc Tukey analysis of variance. 


\subsubsection{Cytotoxicity study}

Bone metabolic activity assays were conducted to determine in vitro bioactivity of the glasses. Pre-osteoblastic MC3T3-E1 cells (ATCC CRL-2593, ATCC, Manassas, VA, USA) from passage 3-5 were used for this study and were maintained in aMEM media supplemented with $10 \%$ FBS and $1 \%(2 \mathrm{mM})$ L-glutamine (Cambrex, MD, USA) within a cell culture incubator at $37^{\circ} \mathrm{C} / 5 \% \mathrm{CO}_{2} / 95 \%$ air atmosphere. Cells were seeded into 24 well plates at a density of 5,000 cells $/ \mathrm{cm}^{2}$ and incubated for $24 \mathrm{hr}$ prior to testing. Culture media $(1 \mathrm{ml})$ was then further supplemented with $100 \mu 1$ of liquid extract (from the solubility samples at 30 days for all glasses; $n=3$ per sample well) and then incubated for $24 \mathrm{hr}$ at $37^{\circ} \mathrm{C} / 5 \% \mathrm{CO}_{2}$. The MTT was added in an amount equal to $10 \%$ of the culture medium volume/well. The cultures were then re-incubated for a further $2 \mathrm{hr}\left(37^{\circ} \mathrm{C} / 5 \% \mathrm{CO}_{2}\right)$ after which they were removed from the incubator and the resultant formazan crystals dissolved by adding an amount of MTT Solubilization Solution $(10 \%$ Triton $\mathrm{x}-100$ in Acidic Isopropanol $(0.1 \mathrm{n} \mathrm{HCI}))$ equal to the original culture medium volume. Once the crystals were fully dissolved, the absorbance was measured at a wavelength of $570 \mathrm{~nm}$. Cells seeded (at the same density) on tissue culture plastic $(n=3)$ were used as controls.

\subsubsection{Statistical methods}

One-way analysis of variance (ANOVA) was employed to analyze the data to determine significance in mean difference across the gathered data when $p<0.05$. Post-hoc Tukey and Dunnett tests were used on MiniTab 17 (MiniTab Inc., State College, PA, USA). The Tukey test assumes equal variance in the data sets being analyzed to determine the significance in mean difference across all factors (i.e., all glasses in both series); the Dunnett test also assumes equal variance in the data, and it is employed when a control group is used to compare against the data 
sets. Results from the solubility analysis, $\mathrm{pH}$ change studies, AAS measurements and in vitro antibacterial studies were analyzed using post-hoc Tukey; cytotoxicity results were analyzed using post-hoc Dunnett.

\subsection{Results}

\subsubsection{Solubility analysis}

Evaluation of the mass loss at different incubation periods was undertaken, with results shown in Fig. 4.1 for the SRT glass series, and Fig. 4.2 for the BRT glass series. As a function of incubation period, it is observed that mass loss steadily increased from day 1 to day 30 , with SRT1 and BRT0 experiencing the greatest amount of degradation within their respective series. Borate-based glasses exhibited much higher degradation behavior as opposed to the silica-based counterparts, which was expected as borate-based glasses are known to degrade faster than silica-based glasses due to their lower chemical durability [90]; additionally, crystallinity in the silica-based glasses may only account for the reduced solubility of these glasses. As a function of incubation period, for the SRT series, only SRT0 and SRT3 exhibited a significant increase in solubility between 1 and 30 days (vs. all other SRT glasses), and SRT0 and SRT3 between 1 and 7 days and between 7 and 30 days did not exhibit a significant difference in solubility; for the BRT series, all weight changes for all glasses were statistically different, except for BRT0 and BRT2 between 1 and 7 days. As a function of the amount of $\mathrm{TiO}_{2}$, a reduction in solubility is observed as the amount of $\mathrm{TiO}_{2}$ is increased to $15 \mathrm{~mol} \%$ for the silica-based glasses. Similarly, for the borate-based glasses, a decrease in solubility is observed, but only up to $10 \mathrm{~mol} \% \mathrm{TiO}_{2}$, with a significant increase for BRT3 $\left(15 \mathrm{~mol} \%\right.$ incorporated $\left.\mathrm{TiO}_{2}\right)$. 


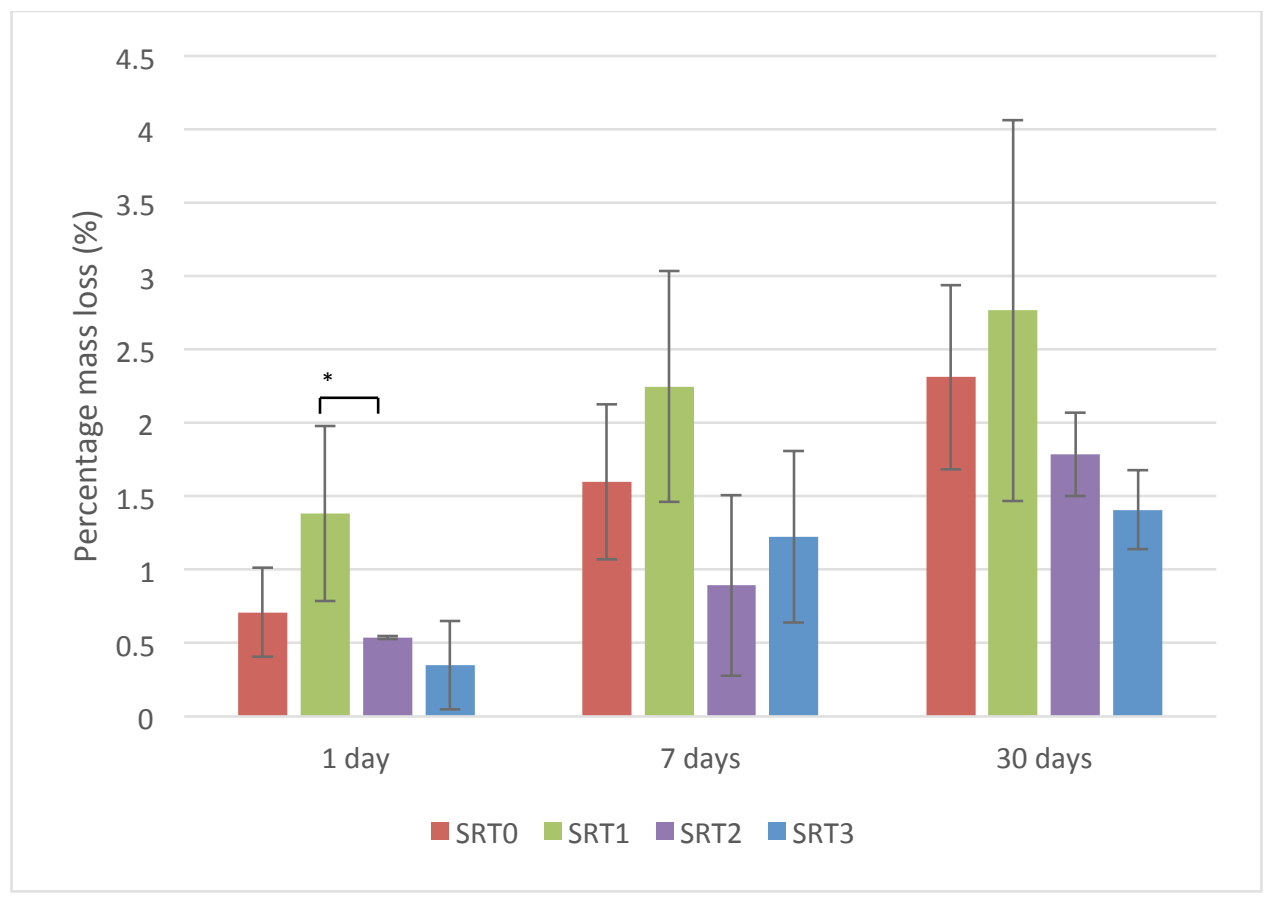

Figure 4.1. Solubility study for SRT glass series $(n=3)$. Scatter bars indicate one standard deviation from the mean. Stars and bars show statistical significance $(p<0.05)$.

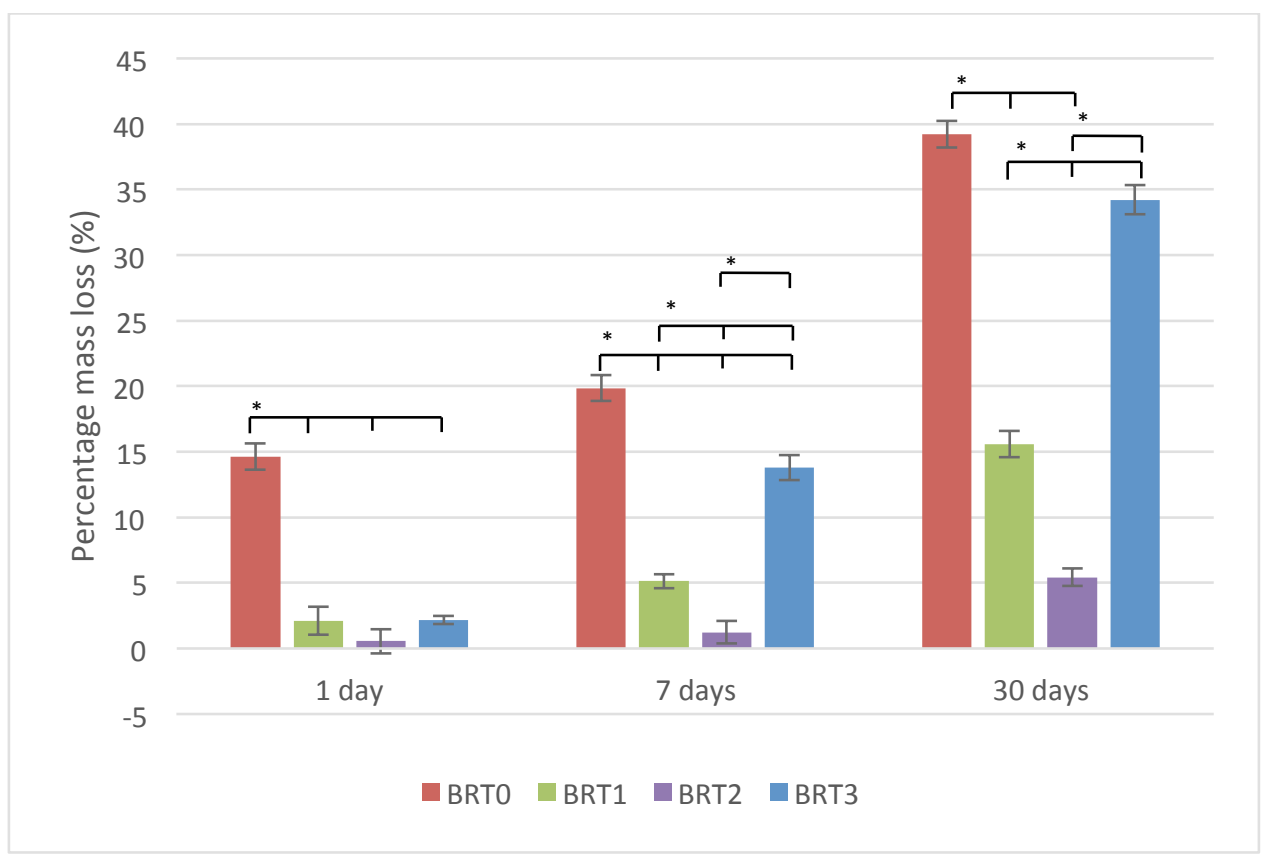

Figure 4.2. Solubility study for BRT glass series $(n=3)$. Scatter bars indicate one standard deviation from the mean. Stars and bars show statistical significance $(p<0.05)$. 


\subsubsection{Ion release through Atomic Absorption Spectroscopy (AAS)}

$\mathrm{Zn}^{2+}$ release for the SRT series is shown in Fig. 4.3, while results for the BRT glass series are shown in Fig. 4.4; $\mathrm{Ti}^{4+}$ release is shown in Fig. 4.5 and Fig. 4.6 for the SRT and BRT glass series, respectively. For both glass series, the inclusion of $\mathrm{TiO}_{2}$ up to $10 \mathrm{~mol} \%$ resulted in a significant drop in the concentration of $\mathrm{Zn}^{2+}$ released; however, at $15 \mathrm{~mol} \%$ an increase in $\mathrm{Zn}^{2+}$ release was observed. In terms of incubation time, a significant increase in $\mathrm{Zn}^{2+}$ is observed for both glass series at all incubation times, except for SRT2 between 1 and 7 days. With respect to $\mathrm{Ti}^{4+}$ release, for the SRT series an increase in release is observed, which may be associated with a decrease in crystallinity for this series as $\mathrm{TiO}_{2}$ is increased (SRT3 is amorphous, while SRT1 and SRT2 exhibit crystallinity) [77]; $\mathrm{Ti}^{4+}$ release in the BRT glasses increased with $\mathrm{TiO}_{2}$ content incorporated into the glass, with a decrease observed for BRT3, glass which exhibited a secondary phase of $\mathrm{TiO}_{2}$ in $\mathrm{XRD}$ [77] explaining the decrease in $\mathrm{Ti}^{4+}$ release. As a function of incubation time, all glasses exhibited statistically different $\mathrm{Ti}^{4+}$ concentrations at each time.

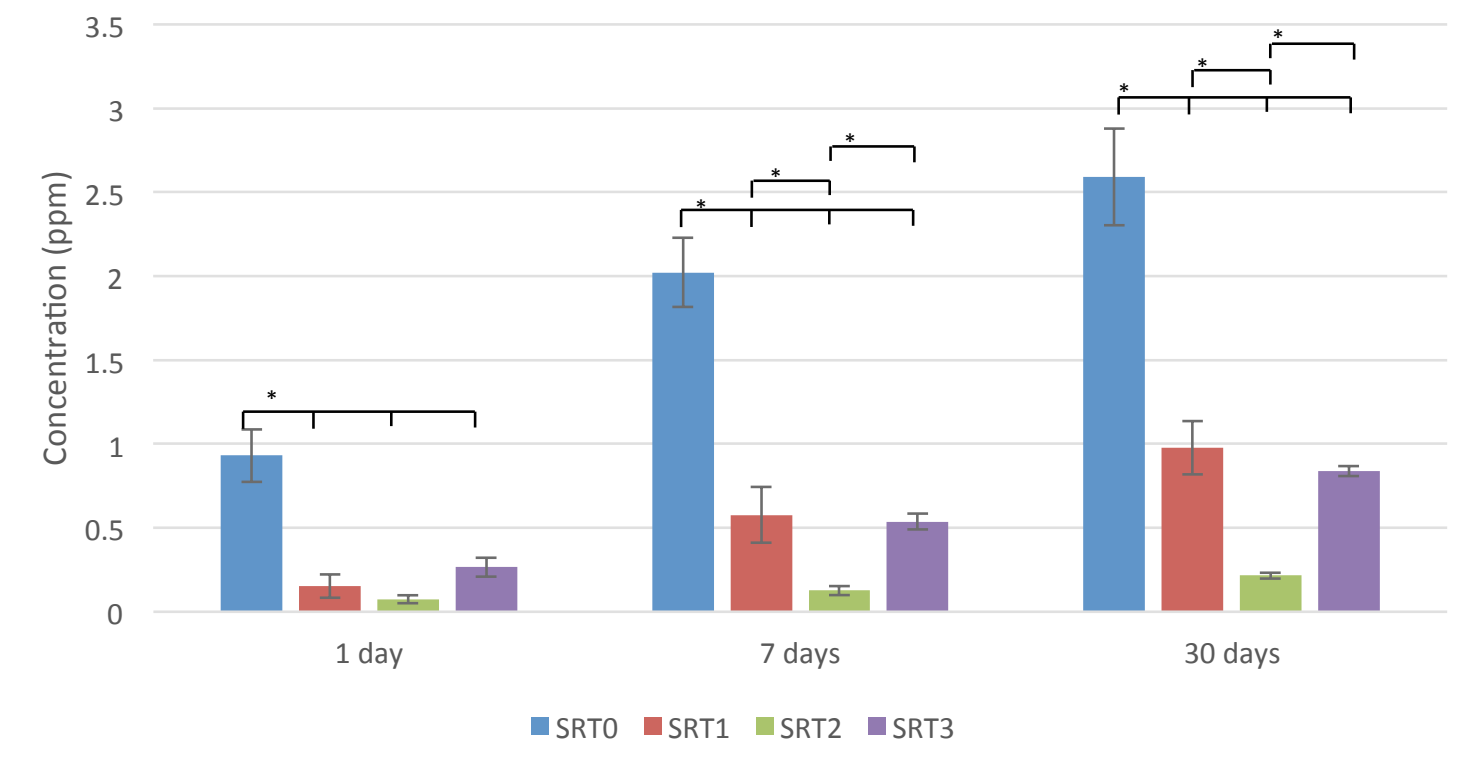

Figure 4.3. $\mathrm{Zn}^{2+}$ release from SRT glass series $(n=3)$. Scatter bars indicate one standard deviation from the mean. Stars and bars show statistical significance $(p<0.05)$. 


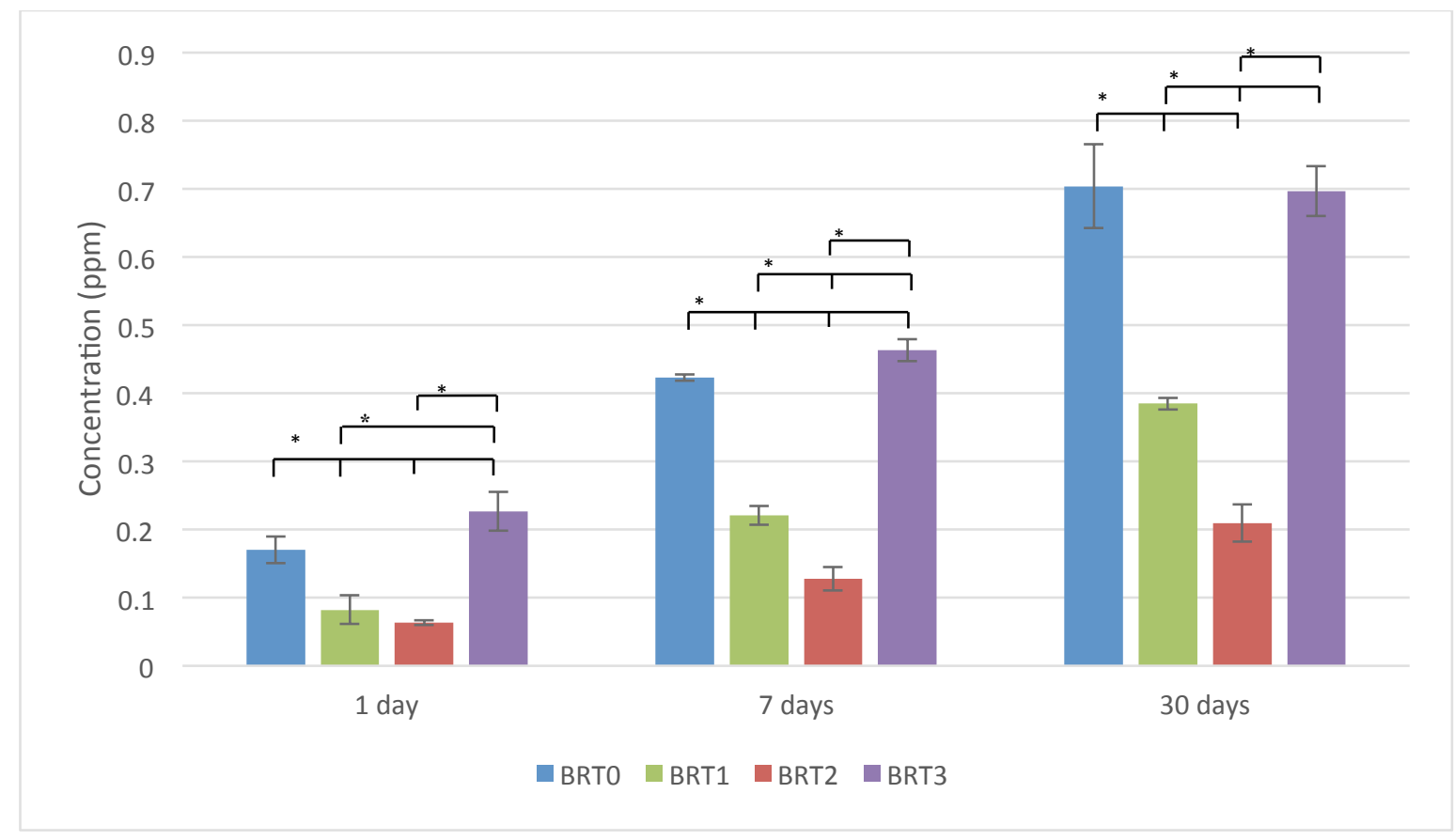

Figure 4.4. $\mathrm{Zn}^{2+}$ release from BRT glass series $(n=3)$. Scatter bars indicate one standard deviation from the mean. Stars and bars show statistical significance $(p<0.05)$.

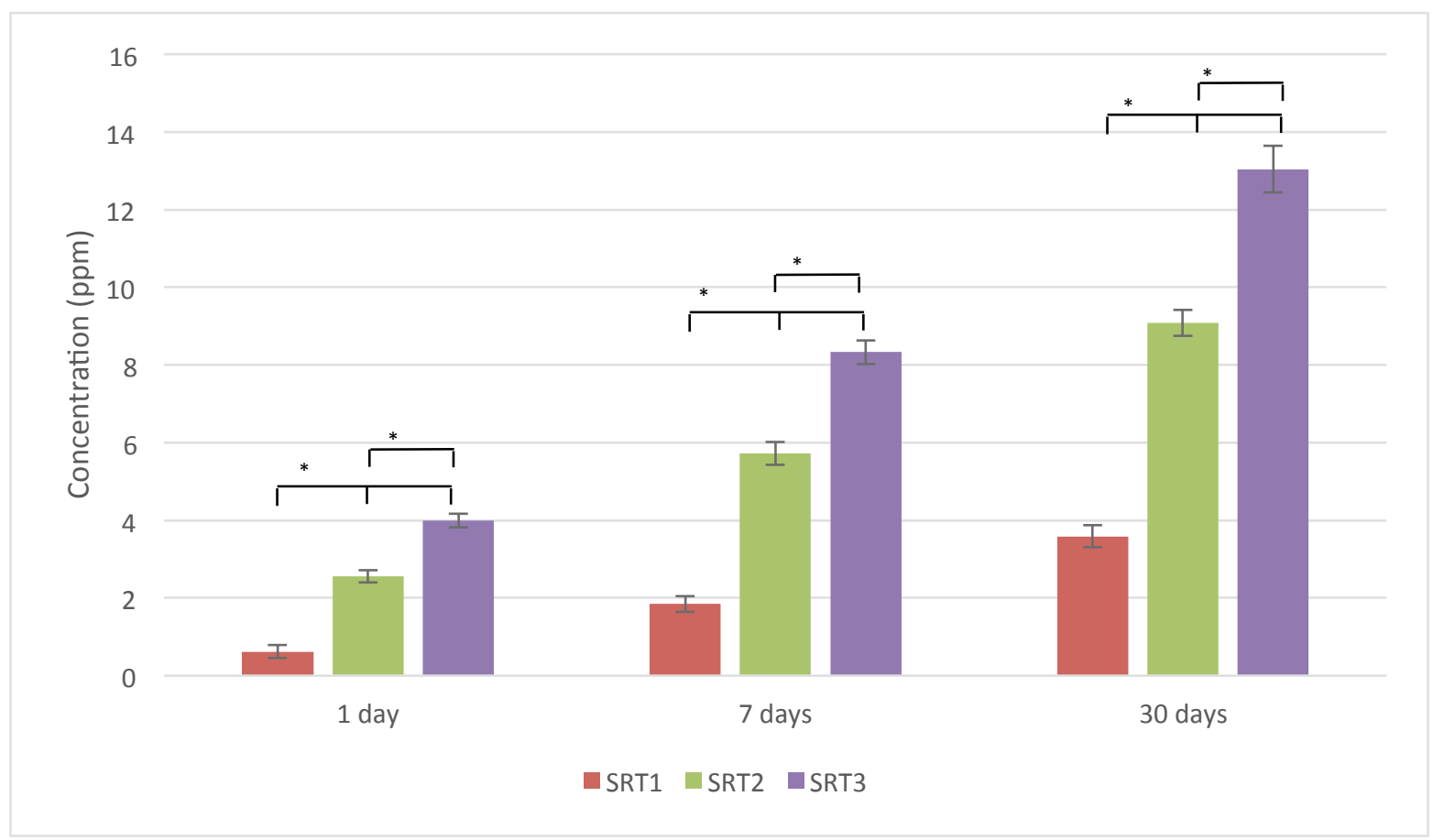

Figure 4.5. $\mathrm{Ti}^{4+}$ release from SRT glass series $(n=3)$. Scatter bars indicate one standard deviation from the mean. Stars and bars show statistical significance $(p<0.05)$. 


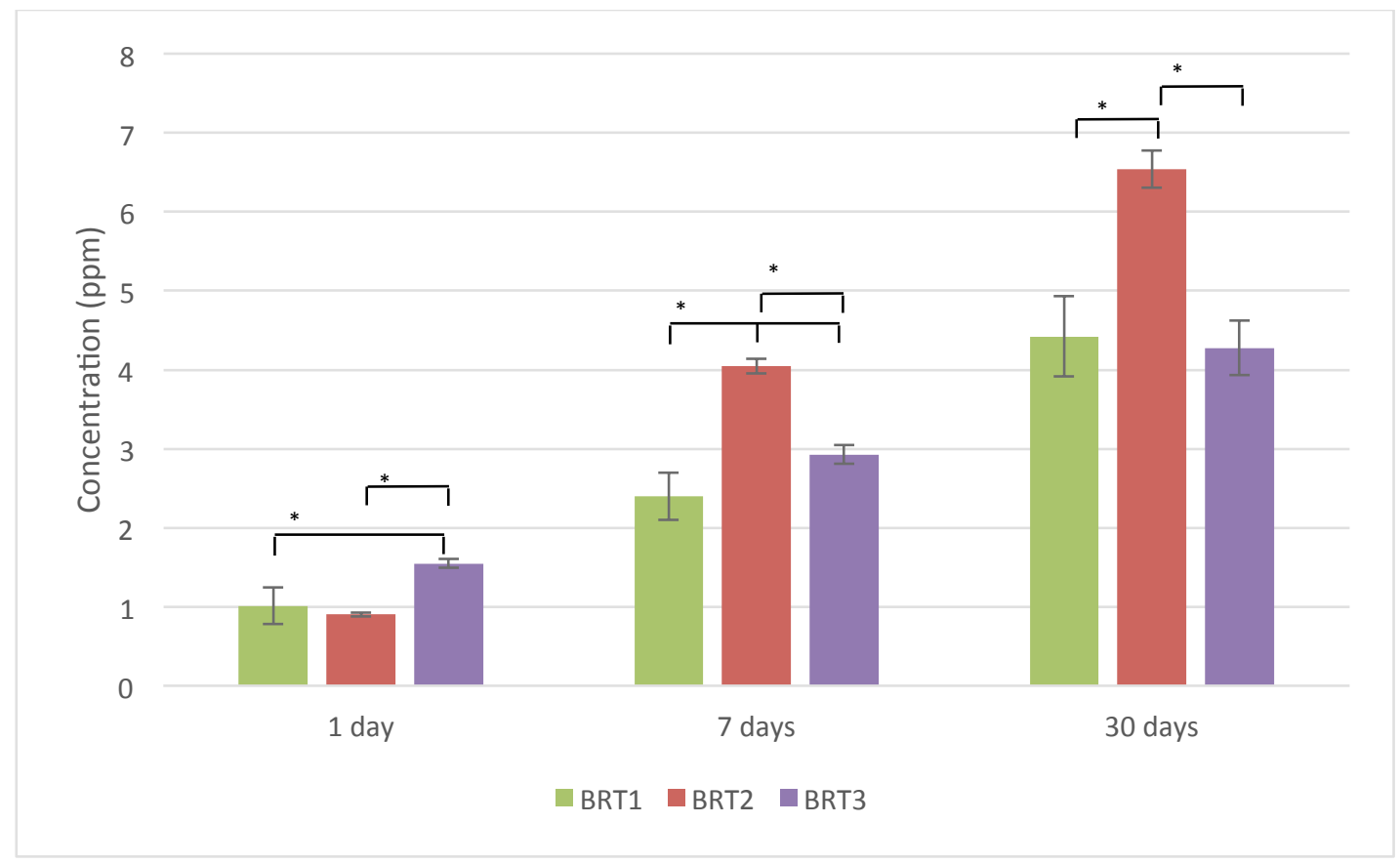

Figure 4.6. $\mathrm{Ti}^{4+}$ release from BRT glass series $(n=3)$. Scatter bars indicate one standard deviation from the mean. Stars and bars show statistical significance $(p<0.05)$.

\subsection{3. pH Change}

Changes in the $\mathrm{pH}$ of deionized water were evaluated for the SRT and BRT glasses, with results shown in Fig. 4.7 and Fig. 4.8, respectively. After 30-days incubation, no significant difference is observed as a function of the amount of $\mathrm{TiO}_{2}$ incorporated for the SRT series, with the SRT glasses averaging a $\mathrm{pH}$ of 7.90; due to the small standard deviations in the measurements for the BRT series, only the $\mathrm{pH}$ at 30 days for BRT0 and BRT3 are not significantly different. $\mathrm{pH}$ changes due to exposure to BRT glasses ranged between 8.67 and 8.85 . 


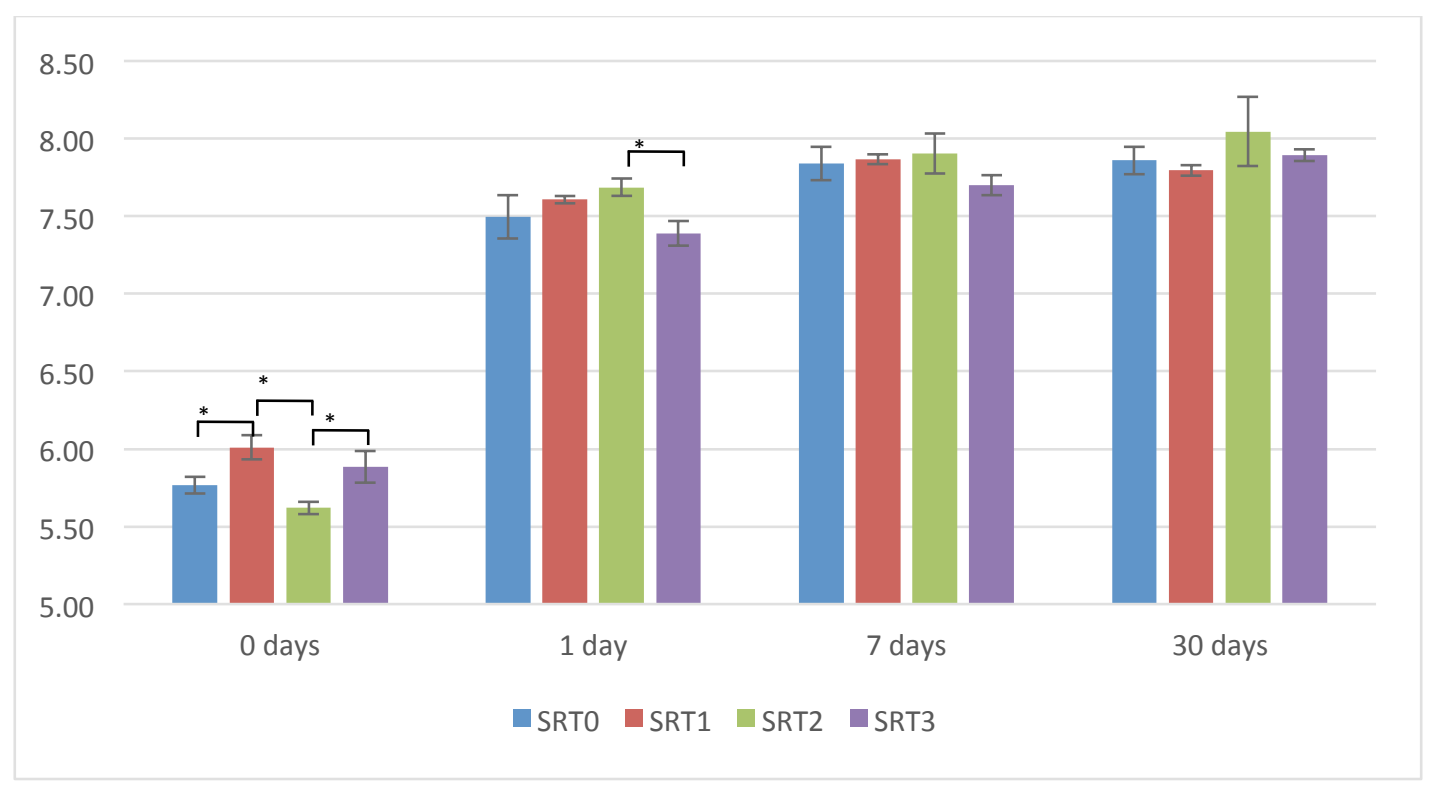

Figure 4.7. $\mathrm{pH}$ Measurements for SRT glass series $(n=3)$. Scatter bars indicate one standard deviation from the mean. Stars and bars show statistical significance $(p<0.05)$.

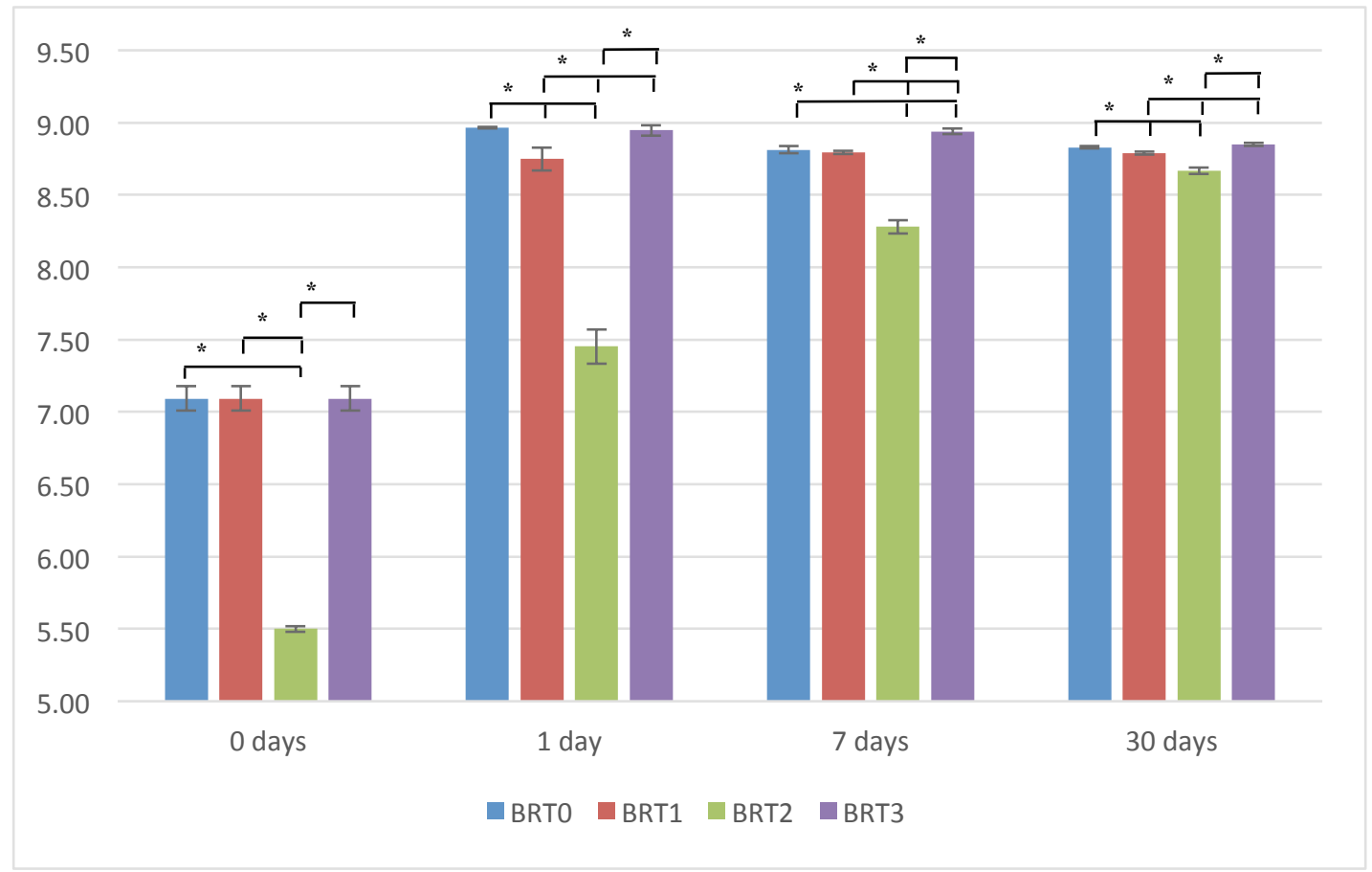

Figure 4.8. $\mathrm{pH}$ Measurements for BRT glass series $(n=3)$. Scatter bars indicate one standard deviation from the mean. Stars and bars show statistical significance $(p<0.05)$. 


\subsubsection{In vitro antibacterial analysis}

Inhibition zones were measured for cultures of S. epidermidis and E. coli after 1, 7 and 30 days of incubation with SRT and BRT glass discs. Results are shown in Fig. 4.9 and Fig. 4.10 for S. epidermidis inhibition by the SRT and BRT glasses, respectively, and in Fig. 4.11 for $E$. coli inhibition by the BRT glasses. No inhibition zones were observed in the E. coli cultures, with the exception of BRT0, which showed a small zone after 1 day, but with the presence of bacteria in-growth in the zone, indicating resistance of the E. coli bacteria to the antibacterial effect of BRT0. Regarding S. epidermidis, the SRT glasses exhibited inhibition zones that remained constant as a function of incubation time (with the exception of SRT1, which started exhibiting antibacterial activity after 7 days, and SRT0 significantly increased from day 1 to day 7). Greater inhibition zones were observed for the BRT glasses, namely BRT0 and BRT3, with BRT0 proving to be the best antibiotic glass from both glass series. BRT1 and BRT2 exhibited no inhibition zone. Statistically, for S. epidermidis, all SRT glasses are significantly equivalent, whereas for the BRT glasses only BRT1 and BRT2 (both glasses which exhibited no antibacterial behavior) are significantly equivalent. 


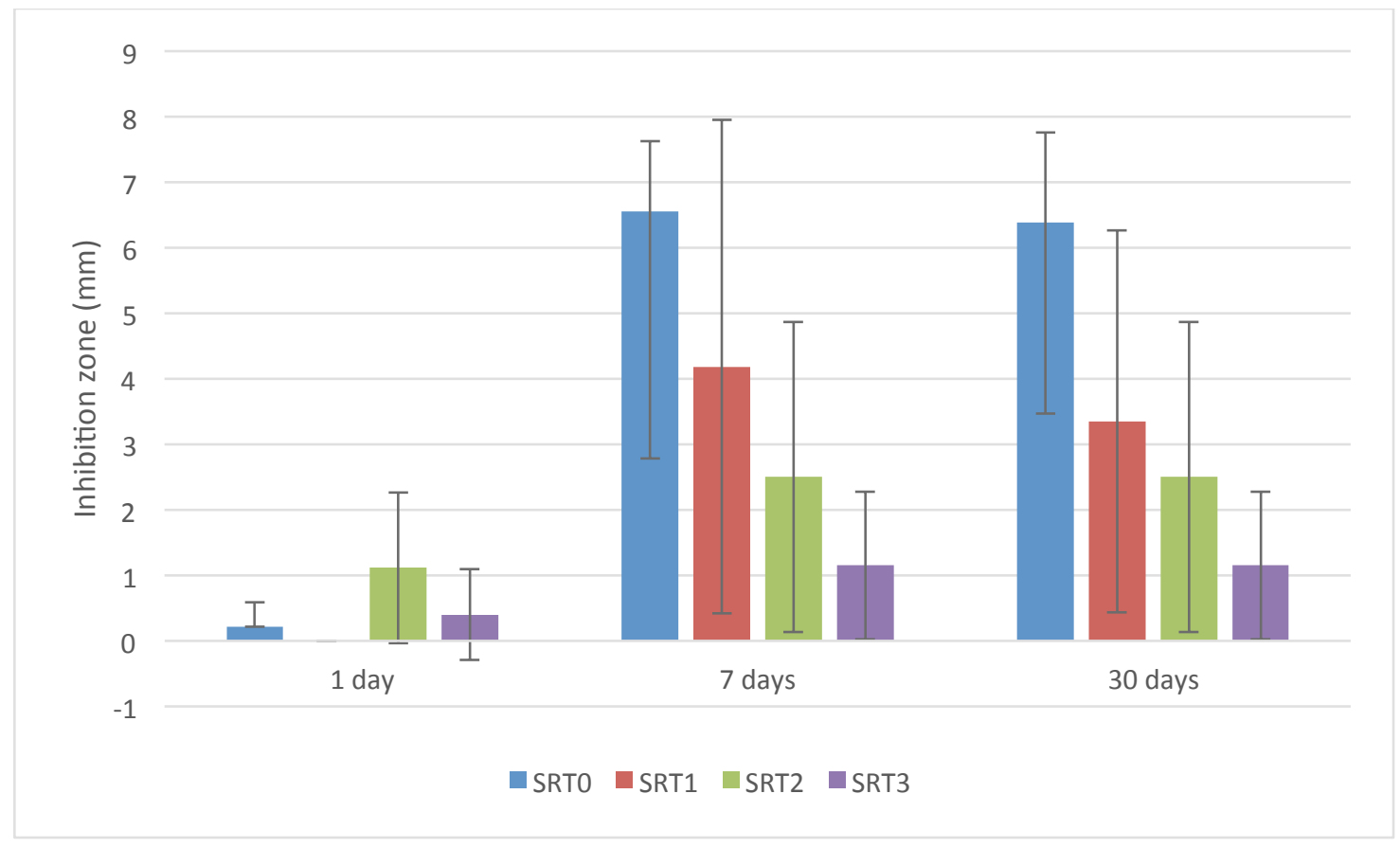

Figure 4.9. Inhibition zones (in $\mathrm{mm}$ ) for $S$. epidermidis for SRT glasses $(n=3)$. Scatter bars indicate one standard deviation from the mean. No significant difference was found at each time incubation time $(p<0.05)$.

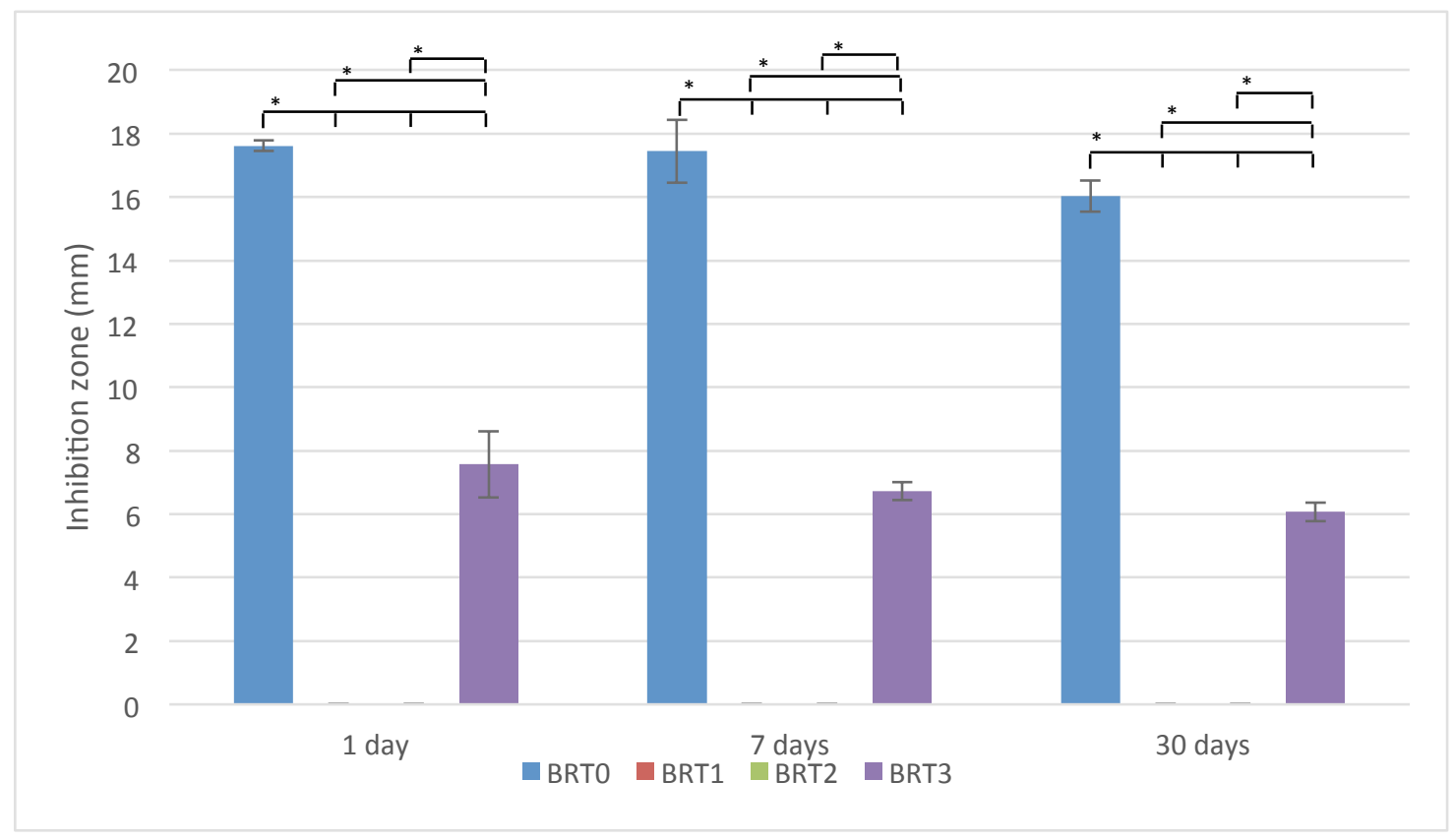

Figure 4.10. Inhibition zones (in $\mathrm{mm}$ ) for $S$. epidermidis for BRT glasses $(n=3)$. Scatter bars indicate one standard deviation from the mean. Stars and bars show statistical significance $(p<$ $0.05)$. 


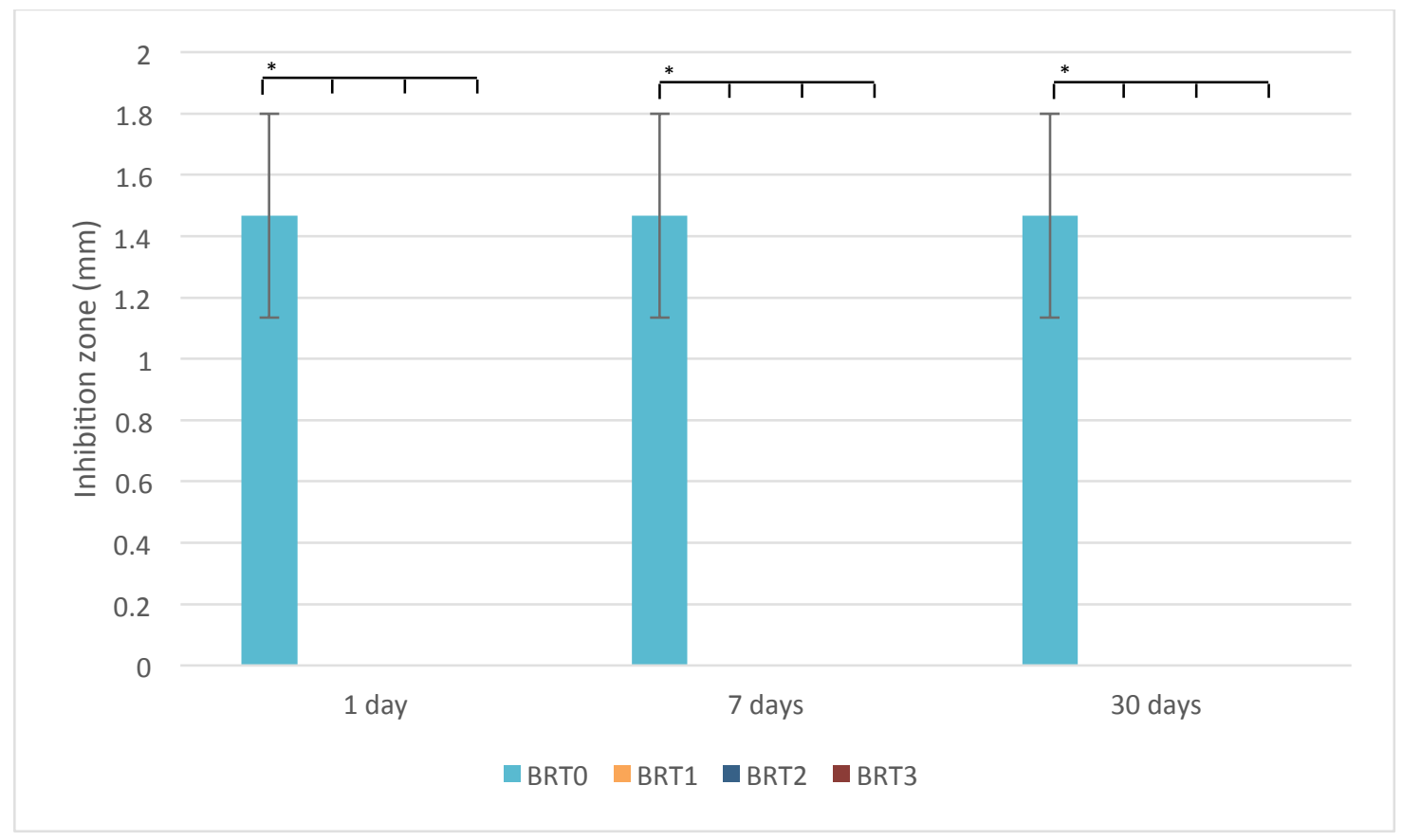

Figure 4.11. Inhibition zones (in $\mathrm{mm})$ for $E$. coli for BRT glasses $(n=3)$. Scatter bars indicate one standard deviation from the mean. Stars and bars show statistical significance $(p<0.05)$.

\subsubsection{Cytotoxicity studies}

Cell viability was assessed through an MTT assay for cytotoxicity, with results reported in Fig. 4.12. Overall, a decrease in absorbance was observed for all glasses when compared with the control, indicating a decrease in proliferation in the presence of the glasses; nonetheless, glasses SRT1, SRT3 and BRT2 were found to be statistically equivalent to the controls. Contrasting the SRT and BRT series, the performance of both series could be described as similar, with SRT3 (10 mol\% incorporated $\mathrm{TiO}_{2}$ ) exhibiting higher proliferation opposed to the other glasses; however, all glasses were statistically equal in terms of cell viability among themselves. 


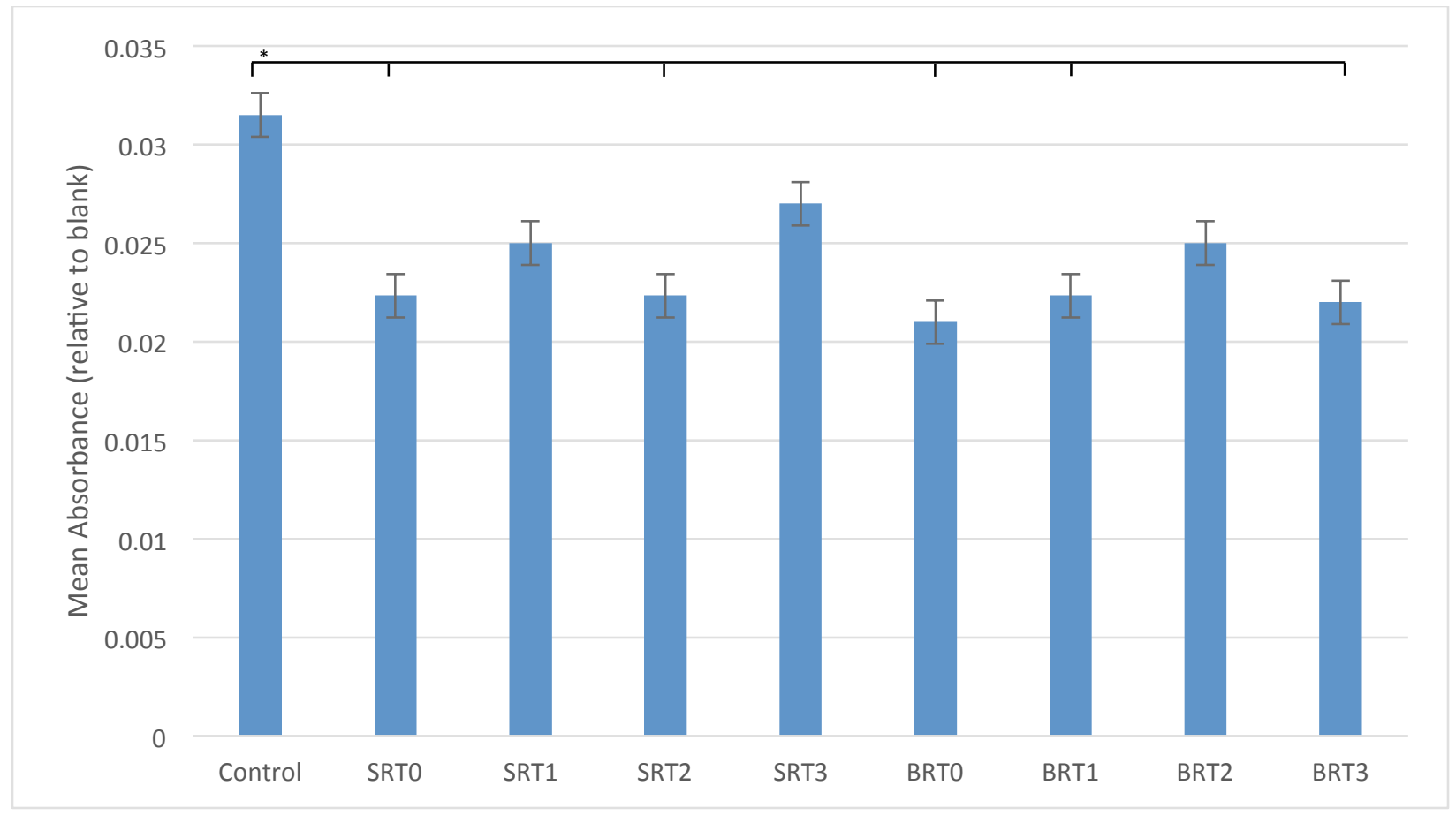

Figure 4.12. MTT cytotoxicity assay results $(n=3)$. Scatter bars indicate one standard deviation from the mean. Stars and bars show statistical significance $(p<0.05)$.

\subsection{Discussion}

From Fig. 4.1 and Fig. 4.2, it can be observed that the inclusion of $\mathrm{TiO}_{2}$ in both the silicabased and the borate-based glass structures resulted in a decrease in solubility. For the silicabased glasses, at 30 days, decreasing solubility with increasing $\mathrm{TiO}_{2}$ content to up to $15 \mathrm{~mol} \%$ can be observed, whereas for the borate-based glasses this trend is observed only up to $10 \mathrm{~mol} \%$ $\mathrm{TiO}_{2}$. BRT3 exhibited degradation behavior comparable to that of the control BRT0, which may be attributed to $\mathrm{TiO}_{2}$ in BRT3 partially existing as a separate phase from the glass phase [77], which may explain the increased solubility of these particular glass samples. In terms of overall solubility, the borate-based glasses exhibited higher solubility compared to the silica-based glasses, which was expected since borate-based glasses have been shown to degrade faster than their silica-based counterparts due to their lower chemical durability [91, 92], making them 
suitable for applications where faster dissolution of the coating is required. Degradation is also confirmed through AAS, which recorded larger quantities of $\mathrm{Zn}^{2+}$ and $\mathrm{Ti}^{4+}$ released from the control glasses (SRT0 and BRT0) as opposed to their titanium-containing counterparts. Boratebased structures allow for the release of the modifier ions more readily than silicate-based structures. Moreover, for BRT3, an increase in degradation is observed when compared to BRT2, the amount of $\mathrm{Ti}^{4+}$ released did not follow this trend, which, again, is to be attributed to the occurrence of $\mathrm{TiO}_{2}$ as a separate phase in the glass, a phase which, due to its crystallinity, does not allow for titanium to be released.

As expected, exposure of the glass samples to deionized water resulted in an increase in $\mathrm{pH}$ of the environment due to the release of ions altering the acidity of the media. With the greater dissolution of the BRT series, $\mathrm{pH}$ was observed to increase more than in the SRT series; however, at 30 days, it can be seen that the $\mathrm{pH}$ of the media for all BRT glasses reached a maximum of 8.85 . For the SRT series, which exhibited much lower solubility, the $\mathrm{pH}$ reached a maximum of 8.05 for SRT2 after 30 days incubating. A higher $\mathrm{pH}$ raise in borate-based glasses compared to silica-based glasses has been previously reported [61]; furthermore, the substitution of $\mathrm{SiO}_{2}$ with $\mathrm{TiO}_{2}$ did not significantly affect the $\mathrm{pH}$ levels, and substitution of $\mathrm{B}_{2} \mathrm{O}_{3}$ with $\mathrm{TiO}_{2}$ did not result in a substantial change in $\mathrm{pH}$ levels after 30 days.

As an antibacterial agent, the amounts of $\mathrm{Zn}^{2+}$ released, as measured by AAS at day 1 , are linked to the larger bacterial inhibition zones in BRT0 and BRT3 in the BRT series and SRT0 in the SRT series for Gram-positive bacteria S. epidermidis, with the BRT series significantly outranking the SRT series. Additionally, the SRT glasses that exhibited antibacterial behavior also showed signs of bacterial recolonization, evidencing the weak antibacterial nature of these glasses. The proliferation of Gram-negative bacteria $E$. coli was not 
significantly affected by the presence of any of the glasses. Gram-positive bacterial growth is more likely to be inhibited when compared to Gram-negative bacterial growth given that Gramnegative bacteria have a layer of lipopolysaccharide (LPS) molecules, not present in Grampositive bacteria, acting as an impermeable layer to the antibacterial effects of $\mathrm{Zn}^{2+}[93$, 94]. It has been shown that, for the same concentration of zinc ions from zinc nanoparticles, inhibition zones for Gram-negative bacteria are 16-33\% smaller than those of Gram-positive bacteria [95]. In fact, glass BRT0, which showed greater inhibition zones in the presence of gram-positive bacteria S. epidermidis, was the only glass composition in this study that exhibited an inhibition zone for Gram-negative E. coli. In the light of these results, it would be expected that BRT0 would exhibit antibacterial behavior when tested in vivo, tackling the issue of bacterial infection at the site of prosthetic implantation $[14,15,16]$. Further time-dependent tests in liquid or biofilm systems are necessary to corroborate these antibacterial results in scenarios closer to in vivo environments. When tested to determine the cell viability capacity of the glasses, it was determined that all glasses slowed down the proliferation of MC3T3-E1 osteoblasts, though per ISO10993-5:2009 this reduction is considered as nontoxic [96]. This reduced proliferation was unexpected, as the levels of $\mathrm{Zn}^{2+}$ were not found to be toxic [97], indicating potential toxicity of the borate ion $\left(\mathrm{BO}_{3}\right)^{3-}$ for the BRT glasses, which has been found to occur in vitro in boratebased glasses [98], while this toxicity has not been reported under dynamic testing conditions [99]. Furthermore, inhibition of cell proliferation for both glasses may be explained by a faster release of sodium (alkali ion) over calcium (alkaline ion) $[76,100,101]$, linked to the glass compositions possessing a higher $\mathrm{Na}_{2} \mathrm{O}$ than $\mathrm{CaO}(14 \mathrm{~mol} \%$ vs. $12 \mathrm{~mol} \%)$.

Once an implant is inserted in the human body, two processes start to occur: bacteria attempt to colonize it, while tissue integration from the surroundings occurs; this phenomenon is 
known as "the race for the surface" $[102,103]$. The desirable outcome is that bacterial infection is inhibited, while tissue integration is promoted; the antibacterial results herein presented present BRT0 and BRT3 as potential candidates to eliminate bacteria at the implantation site, with their superior antibacterial conditions potentially allowing for bone cells to attach and proliferate around the implant in vivo.

\subsection{Chapter Summary}

Silica-based and borate-based glass series have been evaluated to assess their antibacterial, solubility and cytotoxicity characteristics for their potential as coating materials for surgical implants. Overall, the borate-based glasses exhibited significantly superior antibacterial and solubility behavior, with BRT0 and BRT3 (at 0 and $15 \mathrm{~mol} \%$ of $\mathrm{TiO}_{2}$ incorporated, respectively) outperforming the remainder of the glasses. Atomic Absorption Spectroscopy demonstrated the release of $\mathrm{Zn}^{2+}$, which is linked to the antibacterial inhibition observed by these glasses. In vitro cytotoxicity studies were conducted using MC3T3-E1 osteoblasts to evaluate how cell proliferation was affected by the proposed glasses, with results indicating a decrease in proliferation, which may be attributed to the presence of $\left(\mathrm{BO}_{3}\right)^{3-}$ in the borate-based glasses, and a faster release of sodium ion over calcium ion in both glass series, factors which are known to slow cell proliferation in vitro. Nonetheless, in vivo studies will be required to evaluate the effect of a dynamic environment on the cytotoxicity and antibacterial inhibitory characteristics of these glasses.

The evaluation of the mechanical properties of these glass series and their behavior used as coatings on metals will be discussed in the next chapter, focusing on the strain energy release rates, hardness and coefficients of thermal expansion. Through the biocompatibility and 
bioactivity evaluation, borate-based glasses proved superior to the silica-based glasses, with BRT0 and BRT3 outperforming the other glasses in the series. BRT1 and BRT2 exhibited similar behaviors; however, BRT2 exhibited the lowest solubility after 30 days in the boratebased glass series and no antibacterial activity. For this reason, BRT2 (and subsequently SRT2) will not be in the scope of evaluation of the following chapter. 
5. Silica-based and Borate-based, Titanium-containing Bioactive Coatings Characterization: strain energy release rate, residual stresses, hardness and thermal expansion 
The work contained in this chapter [104] has been submitted for publication as follows:

Rodriguez, O., Matinmanesh, A., Papini, M., Schemitsch, E.H., Zalzal, P., Clarkin, O. and Towler, M.R., 2016. Silica-based and Borate-based, Titania-containing Bioactive Coatings Characterization: strain energy release rate, residual stresses, hardness and thermal expansion, Journal of Functional Biomaterials, 7(4), pp.32.

\subsection{Introduction}

The results of Chapter 4 demonstrated the superior degradation and antibacterial behavior for the borate-based glasses, specifically for BRT0 and BRT3. Glasses BRT2 and SRT2 did not show any significant in vitro cytotoxicity or antibacterial behavior compared to the remaining glasses, with both glasses exhibiting the lowest degradation behavior within their respective series and no antibacterial properties. Since biocompatibility and bioactivity are required for the proposed coatings to battle the drawbacks from DSA, then the work in this chapter does not consider glasses BRT2 and SRT2, alongside SRT4 and BRT4, which were already removed from further evaluation.

In this chapter, both glass series will be evaluated to determine their coefficient of thermal expansion (CTE) and its effect on the residual stresses and strains post-coating, their critical strain energy release rate in mode I (opening) of the coating/substrate system through double-cantilever beam (DCB) specimens and of the bulk glass through Vickers indentation, and their bulk hardness. 


\subsection{Methods}

\subsubsection{Samples preparation}

Glass preparation for this work was done as per Section 2.2; discs were prepared as per Section 2.3; and sample coating were prepared as per Section 2.4, all procedures outlined in Chapter 2. For this work, glass compositions were evaluated from both series at 0,5 and 15 mol\% incorporated $\mathrm{TiO}_{2}$.

\subsubsection{Coefficient of thermal expansion (CTE) measurement by Linear Dilatometry}

The CTE of each glass was tested based on current ASTM E228 "Standard Test Method for Linear Thermal Expansion of Solid Materials with a Push-Rod Dilatometer" [105]. Samples $(n=3)$ were prepared following the procedure outlined in Section 2.3, with samples measuring 6 $\mathrm{mm}$ in diameter and $12 \mathrm{~mm}$ in height (by stacking 4 discs), and tested with a Netzsch DIL 402 PC dilatometer (Netzsch Instruments, Burlington, MA, USA). A heating rate of $4^{\circ} \mathrm{C} / \mathrm{min}$ was employed, with testing temperature range from 25 to $300^{\circ} \mathrm{C}$ for the both glass series. Based on the measured lengths and temperature changes, CTE was determined as

$$
\alpha_{m}=\frac{1}{\Delta T} \frac{\Delta L}{L_{0}}
$$


where $\alpha_{m}$ is the mean CTE of the glass, $\Delta T$ is the change in temperature with respect to the initial temperature, $L_{0}$ is the initial length of the test specimen, and $\Delta L$ is the change in length of the sample with respect to the initial length $L_{0}$.

\subsubsection{Residual Stress and Strain Analysis}

Due to the mismatch between CTE of the substrate and of the coating, residual stresses at the interface are induced. Based on the measured CTE as per Section 5.2.2, and based on the cooling profile and temperatures as per Section 2.4, residual strains were computed as

$$
\varepsilon_{\text {res }}=\left(\alpha_{\text {Ti6Al4V }}-\alpha_{\text {glass }}\right)\left(T_{\text {coat }}-T_{i}\right)
$$

where $\varepsilon_{\text {res }}$ is the calculated residual strain, $\alpha_{\text {glass }}$ is the CTE of the glass, $\alpha_{T i 6 A l 4 V}$ is the CTE of the titanium substrate $\left(9.5 \times 10^{-6} /{ }^{\circ} \mathrm{C}\right), T_{\text {coat }}$ is the coating temperature (from Table 2.2), and $T_{i}$ is the room temperature $\left(25^{\circ} \mathrm{C}\right)$. This approach has already been proposed and verified by Oel and Frechette [106]. To determine the residual stresses, Yu et al. [107] proposed the use of EulerBernoulli beam theory on bi-layer materials with different CTEs subjected to thermal loading. The residual stress at the interface experienced by the glass coating is

$$
\sigma_{\text {res_glass }}=\frac{P\left(t_{s}+t_{c}\right)\left(\frac{t_{c}}{2}\right)}{2 I_{c}+\frac{2 E_{S} I_{s}}{E_{c}}}
$$

where

$$
P=\frac{\varepsilon_{\text {res }}}{\frac{1}{E_{C} A_{C}}+\frac{1}{E_{S} A_{S}}+\frac{\left(t_{S}+t_{c}\right)^{2}}{4\left(E_{C} I_{C}+E_{S} I_{S}\right)}}
$$


and $t_{s}$ is the thickness of the titanium substrate $(3.15 \mathrm{~mm}), t_{c}$ is the thickness of the glass coating $(90 \mu \mathrm{m}), I_{s}$ is the second moment of area of the titanium substrate, defined as $I_{s}=\frac{w t_{s}^{3}}{12}$, where $w$ is the width of the titanium substrate and of the glass coating $(11 \mathrm{~mm}), I_{c}$ is the second moment

of area of the glass coating, defined as $I_{c}=\frac{w t_{c}^{3}}{12}, E_{s}$ is the modulus of elasticity of the titanium alloy substrate $(110 \mathrm{GPa}), E_{c}$ is the modulus of elasticity of the glass coating (35 GPa [108]), $A_{s}$ is the cross-sectional area of the titanium substrate, defined as $A_{s}=w t_{s}$, and $A_{c}$ is the crosssectional area of the glass coating, defined as $A_{c}=w t_{c}$.

\subsubsection{Vickers Hardness}

Samples $(n=3)$ for hardness testing were prepared as described in Section 2.3. An HM114 Mitutoyo Testing Machine (Mitutoyo, Mississauga, ON, Canada) was utilized, equipped with a Vickers indenter, and loading the samples with a force of $1 \mathrm{kgf}(9.81 \mathrm{~N})$ for $10 \mathrm{~s}$. The indent diagonals were measured through the integrated optical microscope at 20x.

\subsubsection{Coating Bulk Mode I Strain Energy Release Rate Using Vickers}

\section{Indentation}

The mode I strain energy release rate of the bulk glasses was measured by indenting glass $\operatorname{discs}(n=3$ per glass composition), prepared as per Section 2.3 and indented similarly to the process described in 5.2.4. A schematic depiction of the indent is shown in Fig. 5.1. According to Anstis et al. [54], the indentation load needs to be large enough to create an indent pattern that is well-defined and cracks that are longer than the indent diameter $(2 a)$, yet shorter than one tenth of the thickness of the sample (300 $\mu \mathrm{m}$ in this case) to avoid interactions with the lower free 
surface of the specimen. The indentation load is considered too large if it breaks the sample or causes a chipping on the sample's surface [54].

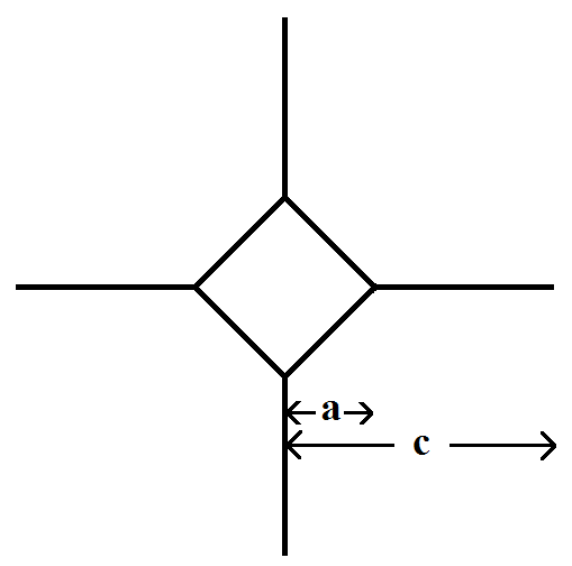

Figure 5.1. Schematic depiction of the cracks emanating from a Vickers indent. $a$ is the half of the diameter length of the dent, and $c$ is the crack length measured from the center of the indent.

By trial and error, the appropriate indentation load to meet the aforementioned force criteria was found to be $3 \mathrm{kgf}(29.43 \mathrm{~N})$. This indentation load was applied using a Macro indenter HM-114 Mitutoyo Testing Machine (Mitutoyo, Mississauga, ON, Canada) normal to the surface of the glass for the duration of $10 \mathrm{~s}$. The length of the crack was measured through scanning electron microscope (SEM) using a JEOL JSM-6380LV SEM (JEOL, Peabody, MA, USA). The mode I critical strain energy release rate of the bulk glass was found using the equation below $[109,110]$ :

$$
G_{I C}=\frac{\alpha^{2} P^{2}}{H c^{3}}
$$

where $P$ is the applied load, $H$ is hardness of the glass (as measured per Section 5.2.4), $c$ is the length of the surface trace of the half penny crack measured from the center of the indent, and $\alpha$ is the calibration constant $\alpha=0.016 \pm 0.004$ [54]. Equation 5.5 is derived for plane stress. 
Even though the current application does not completely satisfy the plane stress condition, Eq. 5.5 can still be used as an approximation of $G_{I C}$ given that the thickness of the discs is less than half of their diameter.

\subsubsection{Coating/Substrate System Mode I Strain Energy Release Rate}

The mode I critical strain energy release rate $\left(G_{I C}\right)$ of the coating on the substrate was evaluated following the procedure outlined by Matinmanesh et al. [70]. Typical sample dimensions for the bilayer double-cantilever beam (DCB) specimen are shown in Fig. 5.2. Three samples per glass composition were tested, with at least two measurements obtained per sample. Coated samples prepared as described in Section 2.4 were used to make the test specimens, then an epoxy layer (J-B Weld 8265-S Cold Weld Compound, Sulphur Springs, TX, USA) was deposited to cover the glass and attach the second titanium alloy substrate. Specimens were loaded using a STM United Tensile Tester (United Testing Systems, Inc., Huntington Beach, CA, USA) using a $500-\mathrm{N}$ load cell at a rate of $0.5 \mathrm{~mm} / \mathrm{min}$; then based on the recorded loads, the mode I critical strain energy release rate $G_{I C}$ was calculated as

$$
G_{I C}=\frac{12 L^{2} a^{2}}{E_{S} w^{2} t_{S}^{3}}
$$

where $L$ refers to the load to start crack, $a$ is the crack length, $E_{s}$ to the tensile modulus of the substrate $(110 \mathrm{GPa}), w$ to the specimen width $(11 \mathrm{~mm})$, and $t_{s}$ is the thickness of the substrate $(3.15 \mathrm{~mm})$. 


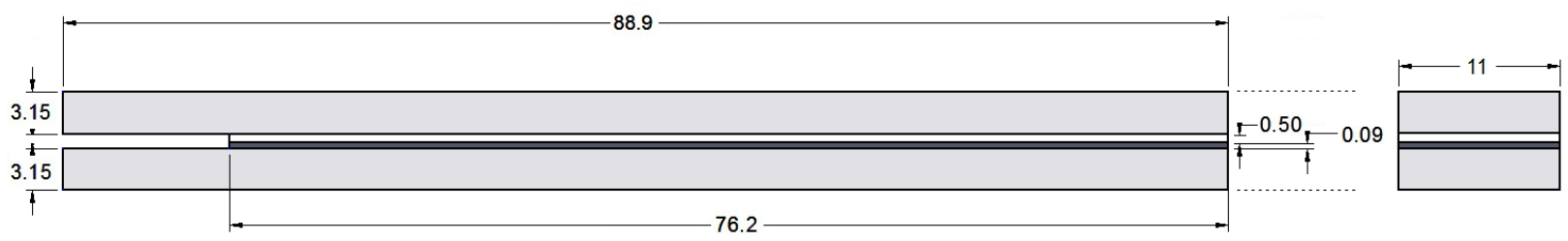

Figure 5.2. Bilayer double cantilever beam specimens. All units in millimeters. Gray materials represent the titanium alloy substrates, black material represents the glass, and white material represents the epoxy.

\subsubsection{Statistical methods}

The results of all the measurements were expressed as means with experimental scatter expressed as a standard deviation. Additionally, one-way analysis of variance (ANOVA) was employed to analyze the data to determine significance in mean difference across the gathered data when $p<0.05$. Post-hoc Tukey test was used on MiniTab 17 (MiniTab Inc., State College, PA, USA). The Tukey test assumes equal variance in the data sets being analyzed to determine the significance in mean difference across all factors (i.e. all glasses in both series).

\subsection{Results}

\subsubsection{Coefficient of thermal expansion (CTE) measurement by Linear}

\section{Dilatometry}

Results from the measurement of the CTE are plotted in Fig. 5.3. The CTE of the silicabased glasses were found to be consistently greater than the CTE of Ti6Al4V, with the percentage difference ranging between $11.1 \%$ and $24.0 \%$, whereas the CTE for the borate-based glasses were found to be below the CTE of Ti6Al4V with smaller percentage difference, ranging between 4.1 and 5.8\%. In statistical terms, the CTE for all borate-based glasses were found to be equivalent; the CTE for SRT0 and SRT1 were also found to be equivalent. 


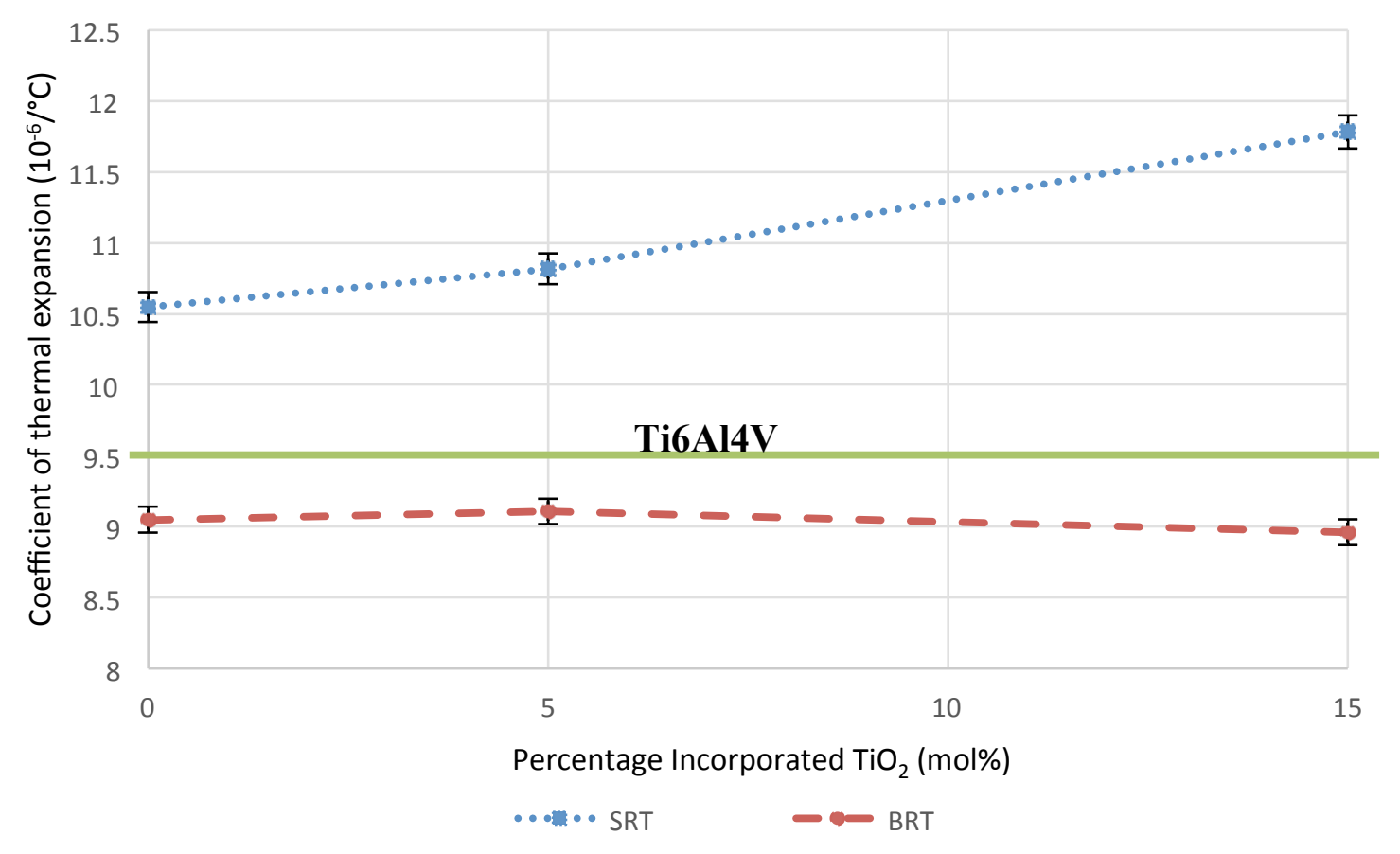

Figure 5.3. CTE for the SRT and BRT glasses, plotted along with the CTE of Ti6Al4V as reference $(n=3)$. Scatter bars indicate one standard deviation from the mean.

\subsubsection{Residual Stress and Strain Analysis}

Residual strains results (Eq. 5.2) are shown in Fig. 5.4, where it can be seen that, in terms of the magnitude, greater strains were experienced when the silica-based coatings were employed, compared to the borate-based ones. This is due to higher CTE mismatch between the silica-based glasses and the titanium substrate, especially for the case of SRT3 (15 mol\% incorporated $\mathrm{TiO}_{2}$ ). Residual stress magnitudes in the glass coating (Fig. 5.5) at the interfacial site (Eq. 5.3) follow a similar trend as the residual strains, with borate-based glasses exhibiting compressive residual stresses and silica-based glasses exhibiting tensile residual stresses. 


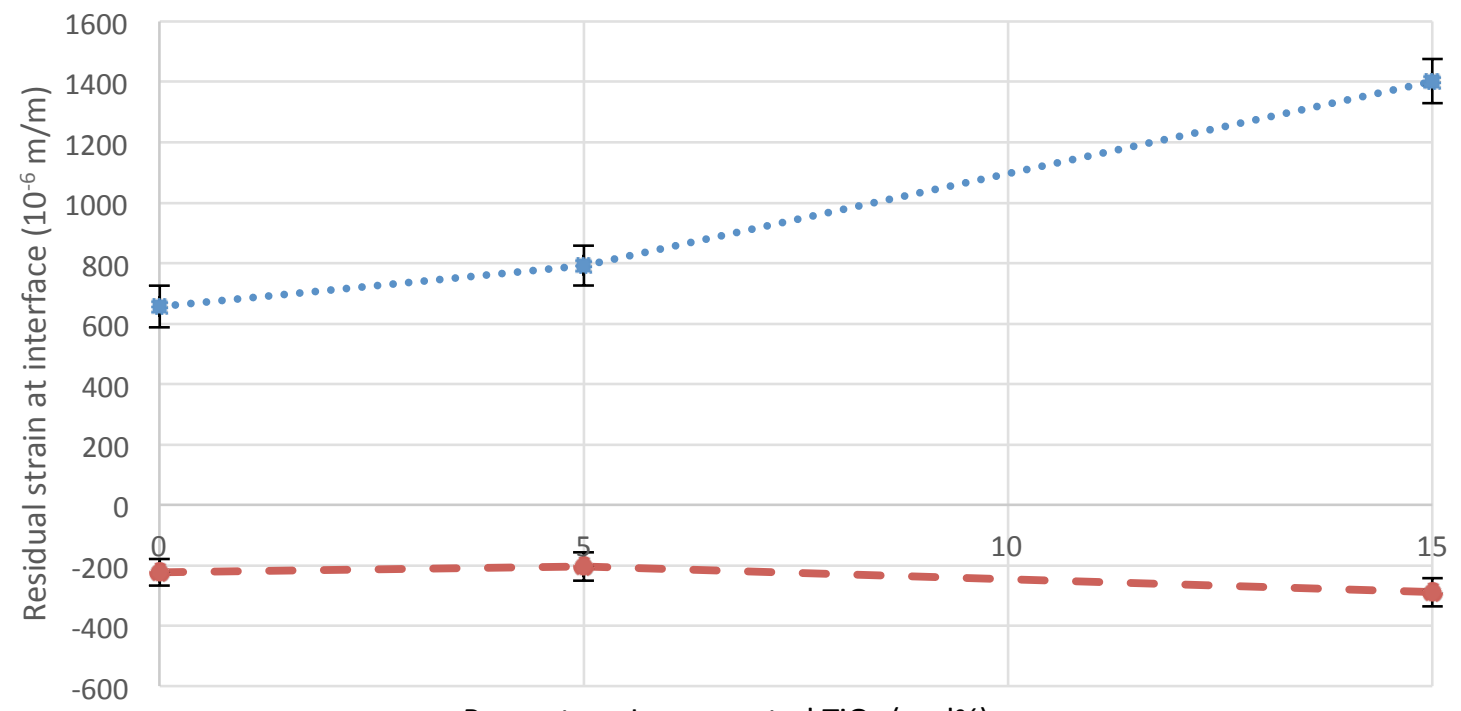

Percentage Incorporated $\mathrm{TiO}_{2}$ (mol\%)

$\cdots$ O O

Figure 5.4. Residual strain at the substrate/coating interface using the SRT and BRT glasses as coating $(n=3)$. Scatter bars indicate one standard deviation from the mean.

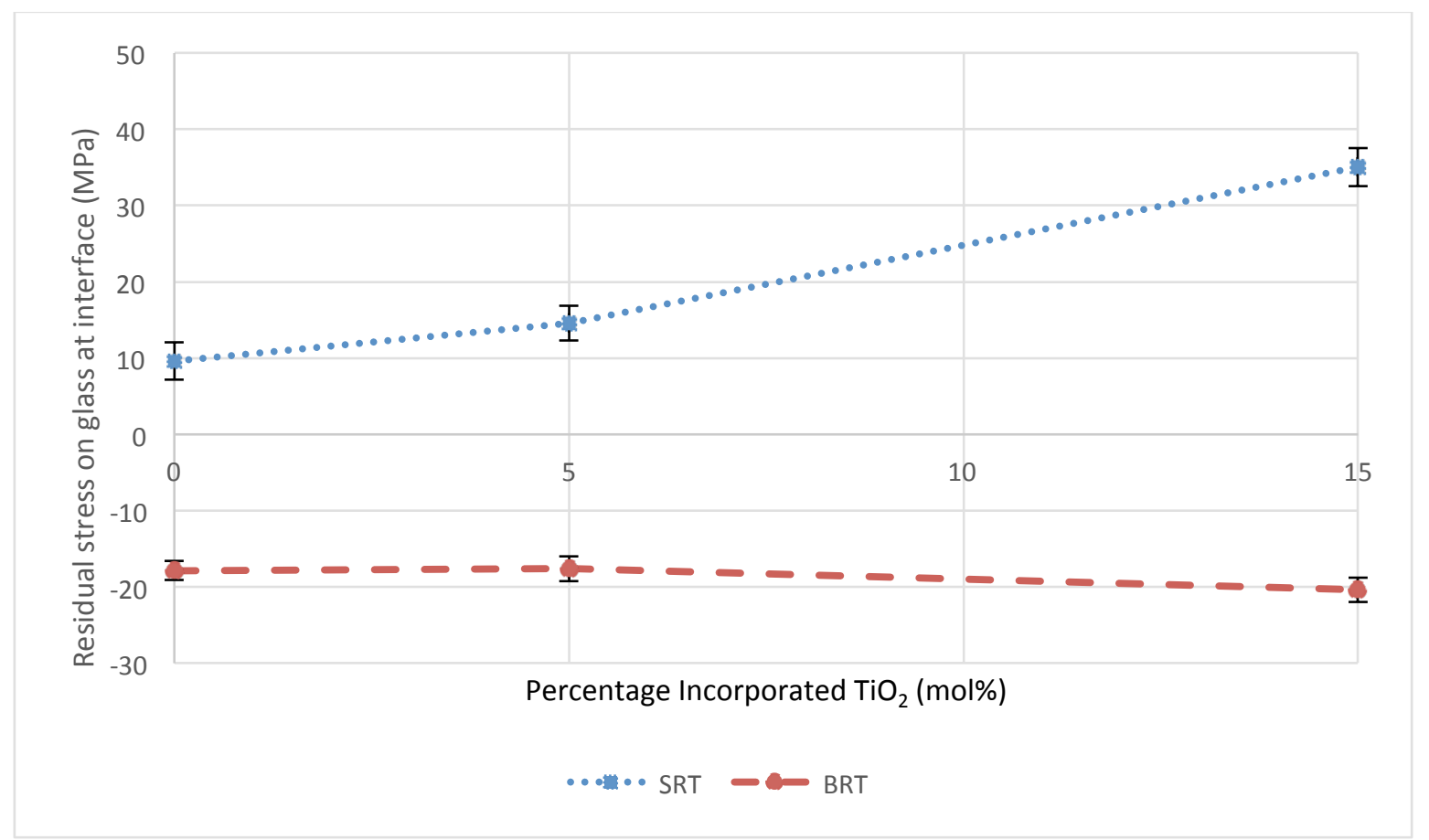

Figure 5.5. Residual stresses experienced in the glass coating at the coating/substrate interface using the SRT and BRT glasses as coating $(n=3)$. Scatter bars indicate one standard deviation from the mean. 


\subsubsection{Vickers Hardness}

A substitution of $\mathrm{SiO}_{2}$ for $\mathrm{B}_{2} \mathrm{O}_{3}$ resulted in an increase in the Vickers hardness of the glass, as shown in Fig. 5.6, statistically significant at 5 and $15 \mathrm{~mol} \%$ of incorporated $\mathrm{TiO}_{2}$. The incorporation of $\mathrm{TiO}_{2}$, however, did not significantly affect the hardness for the BRT glass series; for the SRT glass series, the addition of $\mathrm{TiO}_{2}$ to $5 \mathrm{~mol} \%$ decreased the hardness, but further addition did not significantly decrease it.

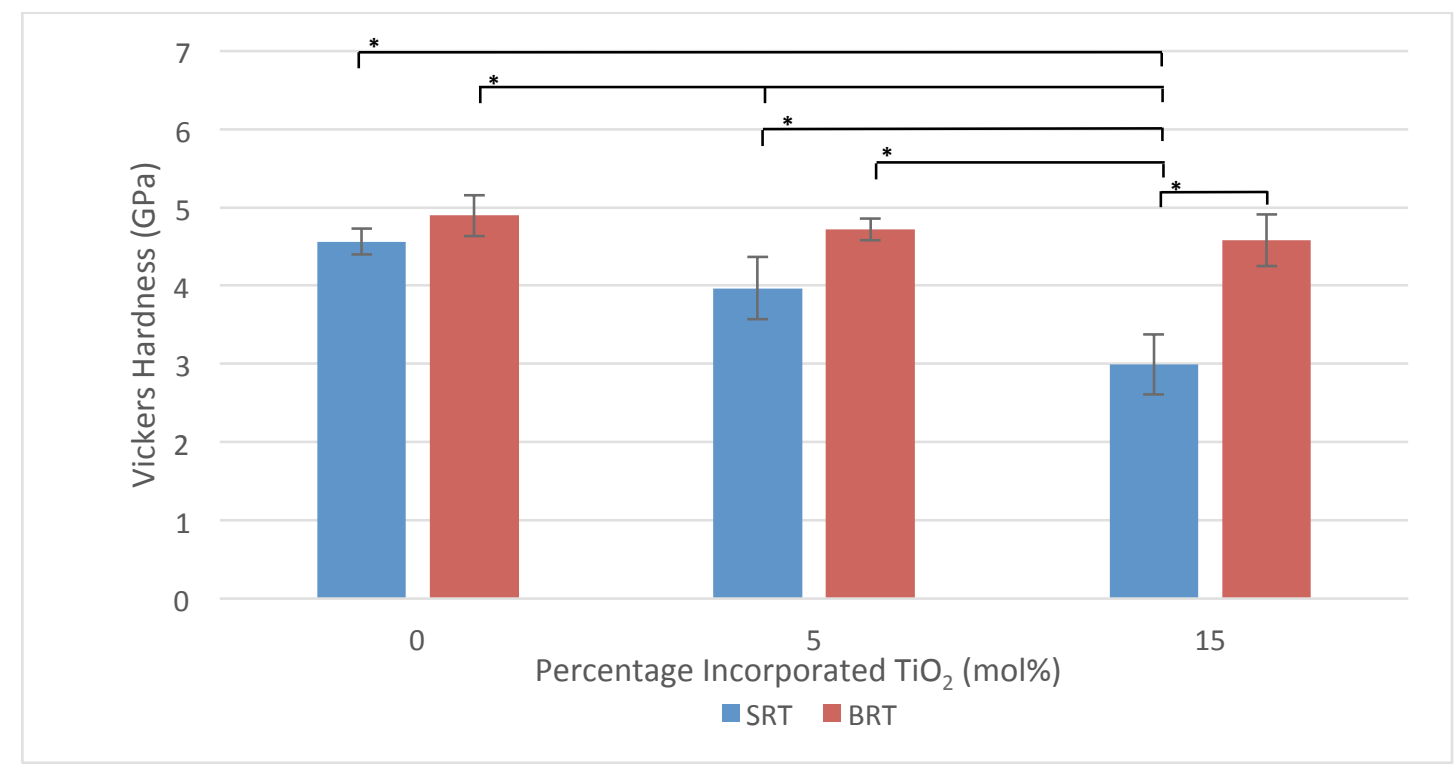

Figure 5.6. Vickers hardness for the SRT and BRT glasses $(n=3)$. Scatter bars indicate one standard deviation from the mean. Stars and bars show statistical significance $(p<0.05)$.

\subsubsection{Bulk Mode I Critical Strain Energy Release Rate Using Vickers Indentation}

The Vickers indentation test was performed to measure the bulk mode I critical strain energy release rate (Eq. 5.5), and the results are shown in Fig. 5.7. A sample of the SEM image for SRT0 showing the indent and the cracks emanating from it is presented in Fig. 5.8. Figure 5.7 
also presents as reference points the data obtained from the literature for the mode I critical strain energy release rate of fused silica based glass $\left(99.995 \% \mathrm{SiO}_{2}\right)$ and Pyrex (heat resistant borosilicate glass). Based on previous studies, the fracture toughness $K_{I C}$ and modulus of elasticity $E_{c}$ of fused silica glass and Pyrex are $0.80 \mathrm{MPa} \cdot \mathrm{m}^{1 / 2}[111], 0.63 \mathrm{MPa} \cdot \mathrm{m}^{1 / 2}[112]$ and 72 GPa [111], $67 \mathrm{GPa}$ [113], respectively. The following equation [109], valid for plane stress condition, was used to convert these $K_{I C}$ and $E_{c}$ values to the $G_{I C}$ in Fig. 5.7 , yielding $8.9 \mathrm{~J} / \mathrm{m}^{2}$ for fused silica and $5.9 \mathrm{~J} / \mathrm{m}^{2}$ for Pyrex.

$$
G_{I C}=\frac{K_{I C}^{2}}{E_{C}}
$$

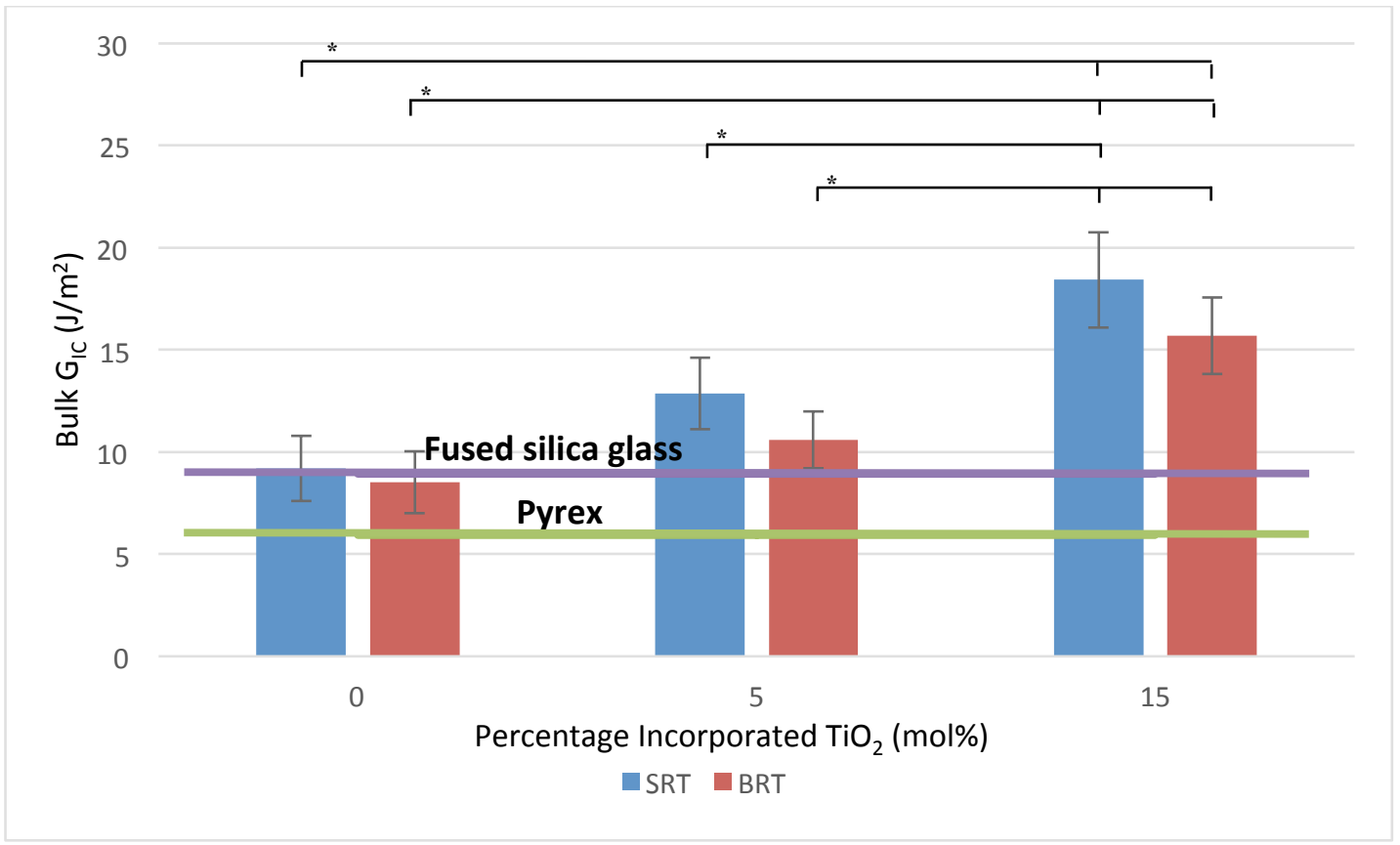

Figure 5.7. Bulk Mode I critical strain energy release rates for the SRT and BRT glasses $(n=3)$. The $\mathrm{G}_{\mathrm{IC}}$ values for Fused silica glass and Pyrex obtained from the literature $[111,112]$ are also shown for reference. Scatter bars indicate one standard deviation from the mean. Stars and bars show statistical significance $(p<0.05)$. 


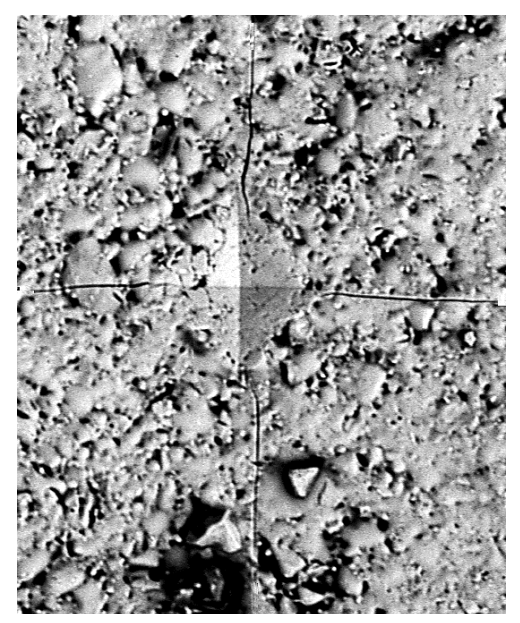

Figure 5.8. SEM of a Vickers indent on SRT0 with the emanating cracks. The average half diameter and crack length are $54.8 \mu \mathrm{m}$ and $187.9 \mu \mathrm{m}$, respectively.

\subsubsection{Coating/ Substrate System Mode I Critical Strain Energy Release Rate}

The mode I critical strain energy release rates for the coating/substrate system for both glass series are shown in Fig. 5.9. Systems made with borate-based glasses exhibited higher critical strain energy release rates in mode I opposed to the silica-based coatings, with the exception of SRT1 and BRT1 (5 mol\% incorporated $\left.\mathrm{TiO}_{2}\right)$, which were statistically equivalent $(p$ $<0.05)$. As a function of percentage of $\mathrm{TiO}_{2}$ incorporated, for the silica-based series, there is no significant difference in the critical strain energy release rate between 0 and $5 \mathrm{~mol} \%$ incorporated $\mathrm{TiO}_{2}$ and between 5 and $15 \mathrm{~mol} \%$ incorporated $\mathrm{TiO}_{2}$; however, statistical difference is observed between 0 and $15 \mathrm{~mol} \%$ incorporated $\mathrm{TiO}_{2}$. Similarly, for systems made with the borate-based series, there is no significant increase $(p<0.05)$ in critical strain energy release rate between 0 and $5 \mathrm{~mol} \%$ incorporated $\mathrm{TiO}_{2}$, whereas a significant increase is found between 0 and $15 \mathrm{~mol} \%$ incorporated $\mathrm{TiO}_{2}$, and between 5 and $15 \mathrm{~mol} \%$ incorporated $\mathrm{TiO}_{2}$. 


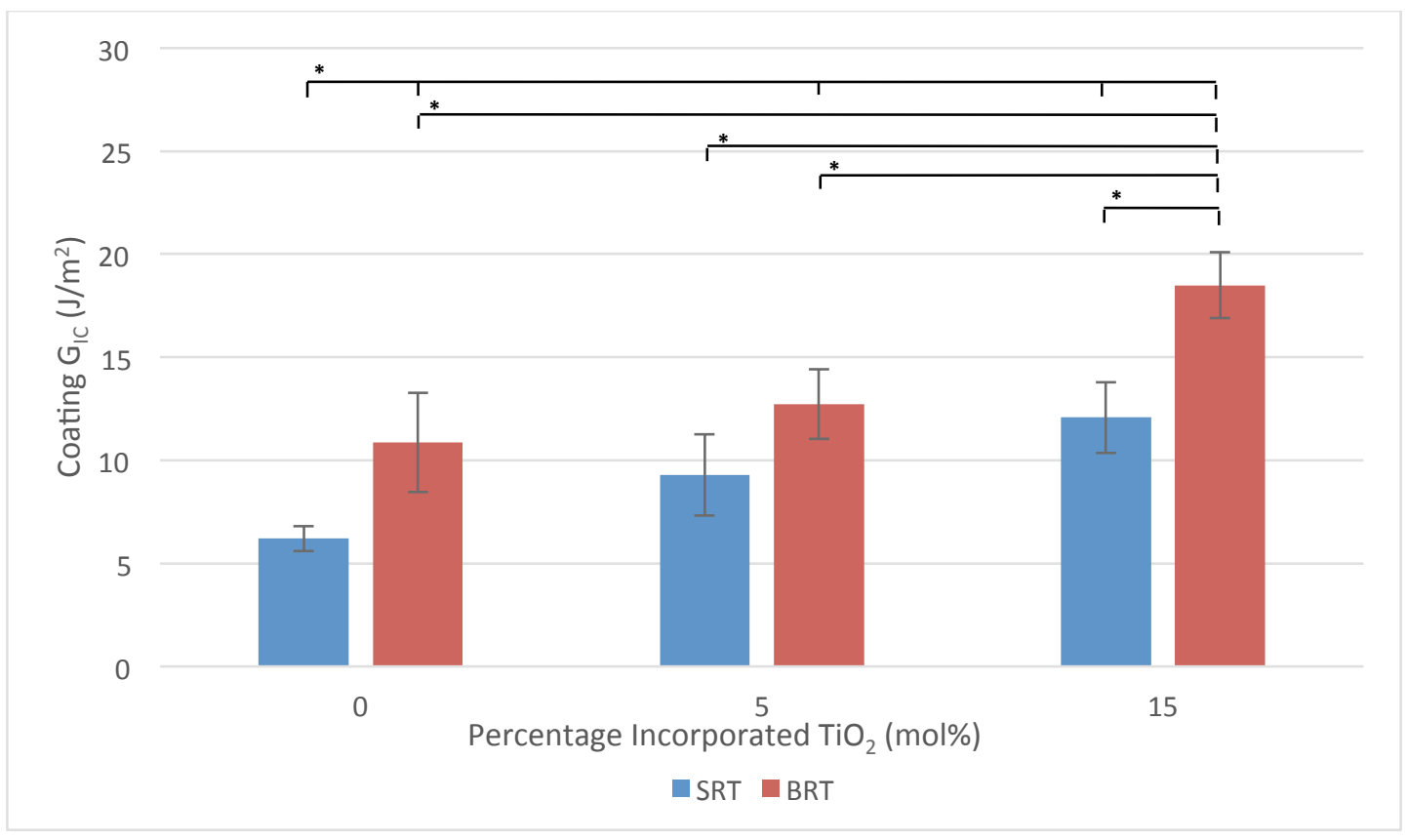

Figure 5.9. Mode I critical strain energy release rates for the coating/substrate systems with SRT and BRT glasses ( $n=3$ /sample, 3 samples per glass). Scatter bars indicate one standard deviation from the mean. Stars and bars show statistical significance $(p<0.05)$.

\subsection{Discussion}

The CTE results confirmed that the borate-based glasses possessed CTEs comparable to that of Ti6Al4V, evidenced by the reduced percentage difference of the CTEs between the borate-based glasses and Ti6Al4V, compared to the silica-based glasses. However, the CTE for the proposed silica-based glasses was significantly lower than what has been reported for other similar glasses (e.g. CTE of Bioglass ${ }^{\circledR} 45 \mathrm{~S} 5$ has been reported to be $15.1 \times 10^{-6} /{ }^{\circ} \mathrm{C}$ over the range from $200-400^{\circ} \mathrm{C}[52]$ ), indicating that the proposed silicate formulations would provide better adhesion to the metallic substrate compared to other silica-based glasses since these novel silicate glasses would induce tensile residual stresses of lower magnitude when used as coatings compared to Bioglass ${ }^{\circledR}$ 45S5. Hence they would offer better resistance to crack growth. Since the addition of $\mathrm{TiO}_{2}$ increased $\mathrm{CTE}$, then the control silicate formulation should be analyzed to 
understand the causes behind the reduced CTE. Compared to 45S5, SRT0 contains a higher molar percentage of $\mathrm{SiO}_{2}$ and contains $\mathrm{ZnO}$ at $16 \mathrm{~mol} \%$, whereas $45 \mathrm{~S} 5$ does not include $\mathrm{ZnO}$. Higher $\mathrm{SiO}_{2}$ content is known to decrease CTE of silica-based glasses [45], which explains how substituting $\mathrm{SiO}_{2}$ for $\mathrm{TiO}_{2}$ in the SRT glasses translated into an increase in the CTE. Furthermore, $\mathrm{ZnO}$ increase (or inclusion, in this case) has been proven to decrease the CTE of silica-based glasses [114], explaining the reduced CTE of SRT0 compared to 45S5.

Since the CTEs of the borate-based glasses are lower than that of the substrate, the difference in shrinkage caused the glass coating to experience compressive residual stresses. Compressive residual stresses are beneficial, acting to prevent cracks from propagating, thus requiring higher stresses to cause coating failure $[115,116,117]$. On the other hand, the CTE of the silica-based glasses induced tensile residual stresses, promoting the growth of cracks under loading $[115,118]$.

As shown in Fig. 5.7, the measured bulk $G_{I C}$ of the control glass of the silica-based series, SRT0, was found to be comparable to that of fused silica glass. However, as the percentage of $\mathrm{TiO}_{2}$ in the silica-based glass series was increased, the mean $G_{I C}$ value increased, with significant differences $(p<0.05)$ observed between the SRT0 and SRT3 $\left(15 \mathrm{~mol} \%\right.$ incorporated $\left.\mathrm{TiO}_{2}\right)$. There is limited literature available on the mode I critical strain energy release rate (or fracture toughness) of bioactive glasses, specifically on the effect of the inclusion of $\mathrm{TiO}_{2}$ at the expense of the backbone component. The authors hypothesize that the observed increase in the bulk $G_{I C}$ as the amount of $\mathrm{TiO}_{2}$ increased can be attributed to the presence of $\mathrm{Ti}^{4+}$ ions. Incorporation of such ions have been shown to strengthen glass systems and to improve their mechanical properties [119], due to their small ionic radius and high electrical charge [120] that tends to strengthen the bonds in the glass. The bulk $G_{I C}$ of the control glass in the borate series, BRT0, 
was found not to be significantly different $(p<0.05)$ from that of SRT0; however, the bulk $G_{I C}$ of the remaining borate-based glasses were lower than their counterpart in the silica-based series. This is not surprising, as previous studies on boro-silicate glasses have shown that the incorporation of $\mathrm{B}_{2} \mathrm{O}_{3}$ at the expense of $\mathrm{SiO}_{2}$ can decrease the fracture toughness (directly related to $G_{I C}$ through Eq. 5.7) $[121,122]$. Furthermore, similar to silica-based series, the incorporation of $\mathrm{TiO}_{2}$ in the borate series glasses increased the fracture toughness.

In terms of the $G_{I C}$ of the coating/substrate system, the presently used DCB testing method was first published by Matinmanesh et al. [70], establishing the $G_{I C}$ for SRT0-based systems at $6.20 \pm 0.60 \mathrm{~J} / \mathrm{m}^{2}$. The current work expanded on these findings, determining that an increase in $\mathrm{TiO}_{2}$ content resulted in an increase in critical strain energy release rate, peaking at $12.08 \pm 1.72 \mathrm{~J} / \mathrm{m}^{2}$ for the silica-based coatings, and $18.50 \pm 1.60 \mathrm{~J} / \mathrm{m}^{2}$ for the borate-based coatings. This work supports the previous findings that titanium in the glass coating enhances chemical bonding to the titanium substrate [68], resulting in a larger measured $G_{I C}$ for the SRT3 and BRT3 systems, both with $15 \mathrm{~mol} \%$ of $\mathrm{TiO}_{2}$ incorporated. Additionally, the trends of the $G_{I C}$ for the bulk glass and the coating/substrate system are similar, i.e., an increase in incorporated $\mathrm{TiO}_{2}$ translated into an increase in $G_{I C}$. This is similar to the work of Li et al. [123], who studied the effect of the incorporation of strontium oxide into borate-based glass coatings applied to Ti6Al4V substrates, and found that $G_{I C}$ increased as the amount of strontium oxide increased.

The residual stress in the SRT0 coating using the measured values of the CTE was estimated to be $9.6 \pm 2.4 \mathrm{MPa}$ (Section 3.2). This is consistent (no significant difference, $p<$ 0.05) with the $8.6 \pm 1.0 \mathrm{MPa}$ value found by Matinmanesh et al. [70] for the same SRT0 coating/substrate system using measurements of the radius of curvature of the coated assembly. 
Comparing the presented $G_{I C}$ values in Fig. 5.7 with those in Fig. 5.9 revealed that the glasses in the silica-based series have higher critical strain energy release rates in bulk form compared to when applied to the coating/substrate. On the contrary, in the borate based series, the $G_{I C}$ was higher for the coating/substrate system. This effect may be attributed to the nature of the residual stresses that are created during the coating process, i.e., tensile in silica-based systems and compressive in borate-based systems (Section 5.3.2), with compressive residual stresses providing additional resistance to crack growth.

The bulk hardness of the silica-based glass series decreased as the amount of $\mathrm{TiO}_{2}$ incorporated into the glasses increased, while, in statistical terms, the hardness of the borate-

based glasses did not significantly change $(p<0.05)$ with the addition of $\mathrm{TiO}_{2}$. The hardness of the borate-based glasses however, was significantly higher than the silica-based equivalent glasses at 5 and $15 \mathrm{~mol} \%$ incorporated $\mathrm{TiO}_{2}$. The decrease in hardness with increasing incorporation of $\mathrm{TiO}_{2}$ is consistent with the observed increase in fracture toughness, which is inversely proportional to the hardness of the glass (Eq. 5.5).

\subsection{Chapter Summary}

The mechanical properties of the silicate-based and borate-based glasses were determined relevant to their use as coatings on metals. It was observed that borate-based glasses exhibited CTEs that were closer to the substrate's (Ti6A14V) CTE, a common alloy used in medical implants; this translated into higher mode I critical strain energy release rates for the boratebased glasses and compressive residual stresses and strains at the coating/substrate interface, outperforming the silicate-based glasses counterpart. An increase in the content of $\mathrm{TiO}_{2}$ in the glasses resulted in an increase in the mode I critical strain energy release rate for both the bulk 
glass and for the coating/substrate system. Borate-based glass BRT3, with $15 \mathrm{~mol} \% \mathrm{TiO}_{2}$ incorporated, exhibited superior properties overall compared to the other proposed glasses in this work, as well as Bioglass ${ }^{\circledR}$ 45S5 and Pyrex. 
6. Conclusions and Future Work 


\subsection{Conclusions}

A silica-based and a borate-based glass series, with increasing amounts of titanium dioxide incorporated, were proposed, processed and evaluated as coatings for metallic implants. The borate-based glasses exhibited improved performance over the silica-based glasses during the biocompatibility and mechanical testing phases of this dissertation. Overall, it was observed that:

- $T_{g}$ of the borate-based glasses was not influenced by the incorporation of titanium dioxide, whereas the crystallization temperature of these glasses was impacted, resulting in greater enameling processing windows compared to the silica-based glasses.

- Higher dissolution rates of the borate-based glasses were linked to the greater inhibition zones resulting against $S$. epidermidis and E. coli bacteria, measured in vitro, with the antibacterial behavior being achieved due to the presence of zinc oxide in these glasses.

- Both glass series were found to be nontoxic in vitro to pre-osteoblastic MC3T3-E1 cells, with the silica and borate-based glass series performing similarly, regardless of the content of titanium dioxide.

- The coefficients of thermal expansion of the borate-based glasses were lower than that of the titanium alloy Ti6Al4V, resulting in compressive residual stresses being induced in the glass when employed as a coating, improving its resistance to crack growth under loading.

- Higher contents of titanium dioxide in the glasses was correlated to higher critical strain energy release rates in mode I for the coating/substrate systems for both glass series due 
to stronger coating-to-substrate bonding facilitated by the $\mathrm{Ti}^{4+}$ ions present in the glasses.

Based on these findings, BRT3 (borate-based glass with 15 mol\% incorporated titanium dioxide) exhibited overall superior performance in terms of its bioactivity, biocompatibility, and mechanical properties compared to the rest of the proposed glasses, making it suitable as a coating for Ti6Al4V implants. Coating Ti6A14V with BRT3 is expected to provide for a barrier against bacterial growth, to provide improved mechanical attachment to the substrate, and to promote the proliferation of cells around the implantation site.

\subsection{Novel Contributions}

Novel silica-based and borate-based glasses incorporating titanium dioxide were formulated to tackle the drawbacks of the prosthetic direct skeletal attachment method, namely, bacterial infection, implant failure and risk of bone fracture. Evidence that these drawbacks were addressed is offered by the superior antibacterial behavior, high degradation rates, and improved adhesion to metallic substrates reported in this dissertation.

The dissertation also expanded on the limited literature available around the strength of bioactive glasses. A new method was co-developed by the author to measure the mode I critical strain energy release rate $\left(G_{I C}\right)$ of a bioactive glass coating. The measured $G_{I C}$ values for the proposed silica-based glasses were higher than those previously reported in the literature for similar glasses; moreover, substituting $\mathrm{SiO}_{2}$ for $\mathrm{B}_{2} \mathrm{O}_{3}$, and incorporating titanium dioxide, further improved $G_{I C}$.

DSA patients who would receive an implant coated with BRT3 glass could experience improved healing and accelerated osseointegration over patients receiving uncoated implants. 
They will not only be at less risk of bacterial infection at the site of implantation that might require further surgery or implant removal, but the improved strain energy release rate would also allow them to be more confident in their everyday activities.

\subsection{Future Work}

Though substantial work has been done in vitro to evaluate the glasses and their applicability as coatings, additional tests are required before the proposed bioactive glass can be implemented and tested in human beings. These tests include, but are not limited, to:

- Degradation studies using simulated bodily fluids (SBF): As an alternative to degradation in deionized water, SBF can be employed since it more closely matches the composition and $\mathrm{pH}$ level of human blood plasma. The effect of SBF could be assessed by determining if a layer of hydroxyapatite (HA) forms around the glass samples, layer which forms part of the inorganic phase of bone and indicates the possibility of glass bonding to bone.

- Degradation studies using coated samples: To replicate a scenario that is closer to the real-life application, titanium alloy substrates should be coated with the bioactive glass, then the constructs should undergo degradation using a similar procedure as that used in Chapter 4. After each incubation period, liquid extracts would be removed and tested using AAS to determine the amount of zinc and titanium ions released in these scenarios. Additionally, the coated substrates would be removed and air-dried, then prepared and tested to determine the $G_{I C}$ using the methods of Chapter 5 .

- In vitro cell proliferation on coated samples: To expand on the results obtained in vitro using preosteoblastic MC3T3-E1, these cells should be seeded on top of a coated 
sample, and its proliferation should be evaluated then. This would provide information on the effect of the coated surface (roughness, porosity) on the proliferation of MC3T3E1 cells.

- Additional mechanical characterization: To complement the $G_{I C}$, testing in mode II (inplane shear) should be performed since the implantation procedure is likely to induce shear forces on the coating.

- In vivo animal studies: At this point, all the experiments have been performed under controlled laboratory conditions. To more closely simulate the conditions within the human body, coated samples should be implanted in small animals to determine the performance of the glass coating in a dynamic setting. In vivo studies offer the advantage of a dynamic testing environment that allows investigation of how the glass simultaneously inhibits bacterial growth, and promotes bone formation in a living organism. A Sprague Dawley comminuted fracture rat module could be used to evaluate the in vivo effects of the coatings on the bone and bone re-growth. Under general anesthesia, a $0.8-\mathrm{mm} \mathrm{K}$-wire would be inserted into the medullary canal of the tibia. Four weeks post-fracture, harvested tibiae would then be subjected to microcomputed tomography for 3D architectural analysis along Van Kossa (quantify mineralization) and Masson's Trichrome (distinguish cells from surrounding tissue) pathology. 


\section{References}


[1] M. Pitkin, " Design features of implants for direct skeletal attachment of limb prostheses," Journal of Biomedical Materials Research Part A, vol. 101, no. 11, pp. 3339-3348, 2013.

[2] K. Hagberg, E. Haggstrom, M. Uden and R. Branemark, "Socket versus bone-anchored trans-femoral prostheses: hip range of motion and sitting comfort," Prosthetics and Orthotics International, vol. 29, no. 2, pp. 153-163, 2005.

[3] D. G. Shurr, J. W. Michael and T. M. Cook, Prosthetics and Orthotics, East Norwalk: Prentice Hall, 2002.

[4] J. Hughes, "Biomechanics of the through-knee prosthesis," Prosthetics and Orthotics International, vol. 7, no. 2, pp. 96-99, 1983.

[5] M. Zhang and C. Roberts, "Comparison of computational analysis with clinical measurement of stresses on below-knee residual limb in a prosthetic socket," Medical Engineering \& Physics, vol. 22, no. 9, pp. 607-612, 2000.

[6] M. Tanaka, Y. Akazawa, A. Nakagawa and I. Kitayama, "Identification of pressure distribution at the socket interface of an above-knee prosthesis," Advances in Engineering Software, vol. 28, no. 6, pp. 379-384, 1997.

[7] C. M. Schuch and C. H. Pritham, "Current transfemoral sockets," Clinical Orthopaedics and Related Research, vol. 361, pp. 48-54, 1999.

[8] L. A. Frossard, R. Tranberg, E. Haggstrom, M. Pearcy and R. Branemark, "Load on osseointegrated fixation of a transfemoral amputee during a fall: loading, descent, impact and recovery analysis.," Prosthetics and Orthotics International, vol. 34, no. 1, pp. 85-97, 2010.

[9] C. J. Pendegrass, A. E. Goodship and G. W. Blunn, "Development of a soft tissue seal around bone-anchored transcutaneous amputation prostheses," Biomaterials, vol. 27, no. 23, pp. 4183-4191, 2006. 
[10] A. P. T. Association, "Move Forward," 07 February 2014. [Online]. Available: http://www.moveforwardpt.com/symptomsconditionsdetail.aspx?cid=7e9549ef-0bff-4b5088f1-8a8bf4f1e496. [Accessed 110 2015].

[11] R. Hillock, J. Keggi, R. Kennon, E. McPherson, T. Clyburn, D. Brazil and T. McTighe, " A Global Collaboration-Osteointegration Implant (OI) for Transfemoral Amputation Case Report (First Reported Case in US)," Reconstructive Review, vol. 3, no. 2, 2013.

[12] R. Branemark, P. I. Branemark, B. Rydevik and R. R. Myers, "Osseointegration in skeletal reconstruction and rehabilitation: a review," Journal of Rehabilitation Research and Development, vol. 38, no. 2, pp. 175-182, 2001.

[13] P. I. Branemark, B. O. Hansson, R. Adell, U. Breine, J. Lindstrom, O. Hallen and A. Ohman, "Osseointegrated implants in the treatment of the edentulous jaw," Scandinavian Journal of Plastic Reconstruction Surgery, vol. 11, pp. 1-52, 1997.

[14] J. B. Webster, T. Chou, M. Kenly, M. English, T. L. Roberts and R. D. Bloebaum, "Perceptions and acceptance of osseointegration among individuals with lower limb amputations: a prospective survey study," Journal of Prosthetics and Orthotics, vol. 21, no. 4, pp. 215-222, 2009.

[15] J. Sullivan, M. Uden, K. P. Robinson and S. Sooriakumaran, "Rehabilitation of the transfemoral amputee with an osseointegrated prosthesis: The United Kingdom experience," Prosthetics and Orthotics International, vol. 27, no. 2, pp. 114-120, 2003.

[16] J. Tillander, K. Hagberg, L. Hagberg and R. Branemark, "Osseointegrated titanium implants for limb prostheses attachments: infectious complications," Clinical Orthopaedics and Related Research, vol. 468, no. 10, pp. 2781-2788, 2010.

[17] K. A. Drygas, R. Taylor, C. G. Sidebotham, R. R. Hugate and H. McAlexander, "Transcutaneous tibial implants: a surgical procedure for restoring ambulation after amputation of the distal aspect of the tibia in a dog," Veterinary Surgery, vol. 37, no. 4, pp. 322-327, 2008. 
[18] B. J. Farrell, B. I. Prilutsky, R. S. Kistenberg, J. F. Dalton and M. Pitkin, "An animal model to evaluate skin-implant-bone integration and gait with a prosthesis directly attached to the residual limb," Clinical Biomechanics, vol. 29, no. 3, pp. 336-349, 2014.

[19] R. Ghosh and S. Gupta, "Bone remodelling around cementless composite acetabular components: The effects of implant geometry and implant-bone interfacial conditions.," Journal of the Mechanical Behavior of Biomedical Materials, vol. 32, pp. 257-269, 2014.

[20] A. Chaudhari, A. Braem, J. Vleugels, J. A. Martens, I. Naert, M. V. Cardoso and J. Duyck, "Bone tissue response to porous and functionalized titanium and silica based coatings," PloS One, vol. 6, no. 9, p. e24186, 2011.

[21] P. R. Klokkevold, R. D. Nishimura, M. Adachi and A. Caputo, "Osseointegration enhanced by chemical etching of the titanium surface. A torque removal study in the rabbit," Clinical Oral Implants Research, vol. 8, no. 6, pp. 442-447, 1997.

[22] D. Buser, R. K. Schenk, S. Steinemann, J. P. Fiorellini, C. H. Fox and H. Stich, "Influence of surface characteristics on bone integration of titanium implants. A histomorphometric study in miniature pigs," Journal of Biomedical Materials Research, vol. 25, no. 7, pp. 889-902, 1991.

[23] R. J. Furlong and J. F. Osborn, "Fixation of hip prostheses by hydroxyapatite ceramic coatings," Journal of Bone \& Joint Surgery, British Volume, vol. 73, no. 5, pp. 741-745, 1991.

[24] L. I. Havelin, L. B. Engesæter, B. Espehaug, O. Furnes, S. A. Lie and S. E. Vollset, "The Norwegian arthroplasty register: 11 years and 73,000 arthroplasties," Acta Orthopaedica, vol. 71, no. 4, pp. 337-353, 2000.

[25] R. G. Geesink, "Osteoconductive coatings for total joint arthroplasty," Clinical Orthopaedics and Rrelated Research, vol. 395, pp. 53-65, 2002.

[26] C. Logghe, C. H. Van Ossel, W. D'Hoore, H. Ezzedine, G. Wauters and J. J. Haxhe, "Evaluation of chlorhexidine and silver-sulfadiazine impregnated central venous catheters 
for the prevention of bloodstream infection in leukaemic patients: a randomized controlled trial," Journal of Hospital Infection, vol. 37, no. 2, pp. 145-156, 1997.

[27] B. Gottenbos, H. C. van der Mei, F. Klatter, P. Nieuwenhuis and H. J. Busscher, "In vitro and in vivo antimicrobial activity of covalently coupled quaternary ammonium silane coatings on silicone rubber," Biomaterials, vol. 23, no. 6, pp. 1417-1423, 2002.

[28] L. L. Hench, R. J. Splinter, W. C. Allen and T. K. Greenlee, "Bonding mechanisms at the interface of ceramic prosthetic materials," Journal of Biomedical Materials Research, vol. 5, no. 6, pp. 117-141, 1971.

[29] W. Cao and L. L. Hench, "Bioactive materials," Ceramics International, vol. 22, no. 6, pp. 493-507, 1996.

[30] J. R. Jones, L. M. Ehrenfried and L. L. Hench, "Optimising bioactive glass scaffolds for bone tissue engineering," Biomaterials, vol. 27, no. 7, pp. 964-973, 2006.

[31] I. D. Xynos, A. J. Edgar, L. D. Buttery, L. L. Hench and J. M. Polak, "Ionic products of bioactive glass dissolution increase proliferation of human osteoblasts and induce insulinlike growth factor II mRNA expression and protein synthesis," Biochemical and Biophysical Research Communications, vol. 276, no. 2, pp. 461-465, 2000.

[32] I. D. Xynos, M. V. J. Hukkanen, J. J. Batten, L. D. Buttery, L. L. Hench and J. M. Polak, "Bioglass ${ }^{\circledR}$ 45S5 stimulates osteoblast turnover and enhances bone formation in vitro: implications and applications for bone tissue engineering.," Calcified Tissue International, vol. 67 , no. 4, pp. 321-329, 2000.

[33] I. D. Xynos, A. J. Edgar, L. D. Buttery, L. L. Hench and J. M. Polak, "Gene-expression profiling of human osteoblasts following treatment with the ionic products of Bioglass ${ }^{\circledR}$ 45S5 dissolution," Journal of Biomedical Materials Research, vol. 55, no. 2, pp. 151-157, 2001.

[34] A. Asselin, S. Hattar, M. Oboeuf, D. Greenspan, A. Berdal and J. M. Sautier, "The modulation of tissue-specific gene expression in rat nasal chondrocyte cultures by 
bioactive glasses," Biomaterials, vol. 25, no. 25, pp. 5621-5630, 2004.

[35] P. I. Branemark, "Osseointegration and its experimental background," The Journal of Prosthetic Dentistry, vol. 50, no. 3, pp. 399-410, 1983.

[36] G. Welsch, R. Boyer and E. W. Collings, Materials properties handbook: titanium alloys, Materials Park, Ohio: ASM international, 1993, p. 516.

[37] L. Peddi, R. K. Brow and R. F. Brown, "Bioactive borate glass coatings for titanium alloys," Journal of Materials Science: Materials in Medicine, vol. 19, no. 9, pp. 31453152, 2008.

[38] P. R. Klokkevold, R. D. Nishimura, M. Adachi and A. Caputo, "Osseointegration enhanced by chemical etching of the titanium surface. A torque removal study in the rabbit," Clinical Oral Implants Research, vol. 8, no. 6, pp. 442-447, 1997.

[39] G. A. Zarb and A. Schmitt, "Osseointegration and the edentulous predicament. The 10year-old Toronto study," British Dental Journal, vol. 170, no. 12, pp. 439-444, 1991.

[40] G. S. Leventhal, "Titanium, a metal for surgery," The Journal of Bone \& Joint Surgery, vol. 33, no. 2, pp. 473-474, 1951.

[41] P. I. Branemark, "Vital microscopy of bone marrow in rabbit," Scandinavian Journal of Clinical and Laboratory Investigation, vol. 11, p. 1, 1959.

[42] L. Dahlström, " A summary of the work of Torgny Haraldson. Osseoperception and musculo-skeletal function.," The Institute for Applied Biotechnology, pp. 68-85, 1999.

[43] B. Rydevik, "Amputation prostheses and osseoperception in the lower and upper extremity," Quintessence Publishing Co., pp. 175-185, 1997.

[44] M. Chen, W. Li, M. Shen, S. Zhu and F. Wang, " Glass coatings on stainless steels for high-temperature oxidation protection: Mechanisms.," Corrosion Science, vol. 82, pp. 316$327,2014$. 
[45] J. Pavon, E. Jimenez-Pique, M. Anglada, S. Lopez-Esteban, E. Saiz and A. P. Tomsia, "Stress-corrosion cracking by indentation techniques of a glass coating on Ti6Al4V for biomedical applications.," Journal of the European Ceramic Society, vol. 26, no. 7, pp. 1159-1169, 2006.

[46] N. Lotfibakhshaiesh, D. S. Brauer and R. G. Hill, "Bioactive glass engineered coatings for Ti6Al4V alloys: influence of strontium substitution for calcium on sintering behaviour," Journal of Non-Crystalline Solids, vol. 356, no. 44, pp. 2583-2590, 2010.

[47] A. Sola, D. Bellucci and V. Cannillo, "Enamelled coatings produced with low-alkaline bioactive glasses," Surface and Coatings Technology, vol. 248, pp. 1-8, 2014.

[48] M. Mehdipour, A. Afshar and M. Mohebali, " Electrophoretic deposition of bioactive glass coating on 316L stainless steel and electrochemical behavior study," Applied Surface Science, vol. 258, no. 24, pp. 9832-9839, 2012.

[49] J. Schrooten and J. A. Helsen, "Adhesion of bioactive glass coating to Ti6A14V oral implant," Biomaterials, vol. 21, no. 14, pp. 1461-1469, 2000.

[50] T. J. Lardner, J. E. Ritter, M. L. Shiao and M. R. Lin, "Behavior of indentation cracks near free surfaces and interfaces," International Journal of Fracture, vol. 44, no. 2, pp. 133 $143,1990$.

[51] J. M. Gomez-Vega, E. Saiz, A. P. Tomsia, G. W. Marshall and S. J. Marshall, "Bioactive glass coatings with hydroxyapatite and Bioglass ${ }^{\circledR}$ particles on Ti-based implants. 1 . Processing," Biomaterials, vol. 21, no. 2, pp. 105-111, 2000.

[52] S. Lopez-Esteban, E. Saiz, S. Fujino, T. Oku, K. Suganuma and A. P. Tomsia, "Bioactive glass coatings for orthopedic metallic implants," Journal of the European Ceramic Society, vol. 23, no. 15, pp. 2921-2930, 2003.

[53] B. R. Lawn, A. G. Evans and D. B. Marshall, "Elastic/plastic indentation damage in ceramics: the median/radial crack system," Journal of the American Ceramic Society, vol. 
63, no. 9-10, pp. 574-581, 1980.

[54] G. R. Anstis, P. Chantikul, B. R. Lawn and D. B. Marshall, "A critical evaluation of indentation techniques for measuring fracture toughness: I, direct crack measurements," Journal of the American Ceramic Society, vol. 64, no. 9, pp. 533-538, 1981.

[55] G. M. Pharr, "Measurement of mechanical properties by ultra-low load indentation," Materials Science and Engineering: A, vol. 253, no. 1, pp. 151-159, 1998.

[56] T. Fett, Computation of the crack opening displacements for Vickers indentation, FZKA, 2002.

[57] T. Fett, Z. Burghard, A. Zimmermann and F. Aldinger, "Residual stresses and stress intensity factors for vickers indentation cracks in glass derived from COD measurements," Advanced Engineering Materials, vol. 6, no. 11, pp. 914-918, 2004.

[58] T. Fett, A. B. Kounga and J. Rödel, "Stresses and stress intensity factor from COD of Vickers indentation cracks," Journal of Materials Science, vol. 39, no. 6, pp. 2219-2221, 2004.

[59] M. T. Laugier, "New formula for indentation toughness in ceramics," Journal of Materials Science Lletters, vol. 6, no. 3, pp. 355-356, 1987.

[60] D. Boyd, H. Li, D. A. Tanner, M. R. Towler and J. G. Wall, "The antibacterial effects of zinc ion migration from zinc-based glass polyalkenoate cements," Journal of Materials Science: Materials in Medicine, vol. 17, no. 6, pp. 489-494, 2006.

[61] G. Kaur, O. P. Pandey, K. Singh, D. Homa, B. Scott and G. Pickrell, "A review of bioactive glasses: Their structure, properties, fabrication and apatite formation," Journal of Biomedical Materials Research Part A, vol. 102, no. 1, pp. 254-274, 2014.

[62] E. Saiz, M. Goldman, J. M. Gomez-Vega, A. P. Tomsia, G. W. Marshall and S. J. Marshall, "In vitro behavior of silicate glass coatings on Ti6Al4V," Biomaterials, vol. 23, no. 17, pp. 3749-3756, 2002. 
[63] T. P. Flaten, A. C. Alfrey, J. D. Birchall, J. Savory and R. A. Yokel, "Status and future concerns of clinical and environmental aluminum toxicology," Journal of Toxicology and Environmental Health Part A, vol. 48, no. 6, pp. 527-542, 1996.

[64] A. Coughlan, K. Scanlon, B. P. Mahon and M. R. Towler, "Zinc and silver glass polyalkenoate cements: An evaluation of their antibacterial nature," Bio-Medical Materials and Engineering, vol. 20, no. 2, pp. 99-106, 2010.

[65] S. Murphy, A. W. Wren, M. R. Towler and D. Boyd, "The effect of ionic dissolution products of $\mathrm{Ca}-\mathrm{Sr}-\mathrm{Na}-\mathrm{Zn}-\mathrm{Si}$ bioactive glass on in vitro cytocompatibility," Journal of Materials Science: Materials in Medicine, vol. 21, no. 10, pp. 2827-2834, 2010.

[66] J. Foley and A. Blackwell, "Ion release from copper phosphate cement and influence on Streptococcus mutans growth in vitro: a comparative study," Caries Research, vol. 37, no. 6, pp. 416-424, 2002.

[67] R. M. Donlan, "Biofilms: microbial life on surfaces," Emerging Infectious Diseases journal, vol. 8, no. 9, pp. 881-890, 2002.

[68] A. Sola, D. Bellucci, V. Cannillo and A. Cattini, "Bioactive glass coatings: a review," Surface Engineering, vol. 27, no. 8, pp. 560-572, 2011.

[69] G. Welsch, R. Boyer and E. W. Collings (Eds.), Materials properties handbook: titanium alloys, Materials Park: ASM international, 1993.

[70] A. Matinmanesh, O. Rodriguez, M. Towler, P. Zalzal, E. Schemitsch and M. Papini, "Quantitative evaluation of the adhesion of bioactive glasses onto Ti6A14V substrates," Materials \& Design, vol. 97, pp. 213-221, 2016.

[71] R. K. Brow and R. D. Watkins, "Reactions and bonding between glasses and titanium," in (No. SAND-87-0541C; CONF-871207-18). Sandia National Labs., Albuquerque, 1987.

[72] S. K. Saha, H. Jain, J. I. Goldstein, A. C. Miller and R. K. Brow, "Reaction between titanium and B2O3 melt/glass," Physics and Chemistry of Glasses, vol. 39, no. 2, pp. 118- 
$121,1998$.

[73] D. S. Brauer, N. Karpukhina, R. V. Law and R. G. Hill, "Effect of TiO 2 addition on structure, solubility and crystallisation of phosphate invert glasses for biomedical applications," Journal of Non-Crystalline Solids, vol. 356, no. 44, pp. 2626-2633, 2010.

[74] A. W. Wren, F. R. Laffir, A. Kidari and M. R. Towler, "The structural role of titanium in $\mathrm{Ca}-\mathrm{Sr}-\mathrm{Zn}-\mathrm{Si} / \mathrm{Ti}$ glasses for medical applications," Journal of Non-Crystalline Solids, vol. 357, no. 3, pp. 1021-1026, 2011.

[75] A. Hoppe, N. Güldal and A. Boccaccini, "A review of the biological response to ionic dissolution products from bioactive glasses and glass-ceramics," Biomaterials, vol. 32, no. 11, pp. 2757-2774, 2011.

[76] K. Wallace, R. Hill, J. Pembroke, C. Brown and P. Hatton, "Influence of sodium oxide content on bioactive glass properties," Journal of Materials Science: Materials in Medicine, vol. 10, no. 12, pp. 697-701, 1999.

[77] O. Rodriguez, D. Curran, M. Papini, L. Placek, A. Wren, E. Schemitsch, P. Zalzal and M. Towler, "Characterization of silica-based and borate-based, titanium-containing bioactive glasses for coating metallic implants," Journal of Non-Crystalline Solids, vol. 433C, pp. 95-102, 2015.

[78] R. Hill, "An alternative view of the degradation of bioglass," Journal of Materials Science Letters, vol. 15, no. 13, pp. 1122-1125, 1996.

[79] R. G. Hill and D. S. Brauer, "Predicting the bioactivity of glasses using the network connectivity or split network models," Journal of Non-Crystalline Solids, vol. 357, no. 24, pp. 3884-3887, 2011.

[80] M. D. O’Donnell, S. J. Watts, R. V. Law and R. G. Hill, " Effect of P 2 O 5 content in two series of soda lime phosphosilicate glasses on structure and properties-Part I: NMR," Journal of Non-Crystalline Solids, vol. 354, no. 30, pp. 3554-3560, 2008. 
[81] D. S. Brauer, N. Karpukhina, R. V. Law and R. G. Hill, "Structure of fluoride-containing bioactive glasses," Journal of Materials Chemistry, vol. 19, no. 31, pp. 5629-5636, 2009.

[82] J. Serra, P. González, S. Liste, C. Serra, S. Chiussi, B. León, M. Pérez-Amor, H. O. Ylänen and M. Hupa, "FTIR and XPS studies of bioactive silica based glasses," Journal of NonCrystalline Solids, vol. 332, no. 1, pp. 20-27, 2003.

[83] R. Ciceo-Lucacel and I. Ardelean, "FT-IR and Raman study of silver lead borate-based glasses," Journal of Non-Crystalline Solids, vol. 353, no. 18, pp. 2020-2024, 2007.

[84] A. Pedone, T. Charpentier and M. C. Menziani, "The structure of fluoride-containing bioactive glasses: new insights from first-principles calculations and solid state NMR spectroscopy," Journal of Materials Chemistry, vol. 22, no. 25, pp. 12599-12608, 2012.

[85] J. F. Stebbins, P. Zhao and S. Kroeker, "Non-bridging oxygens in borate glasses: characterization by 11 B and 17 O MAS and 3QMAS NMR.," Solid State Muclear Magnetic Resonance, vol. 16, no. 1, pp. 9-19, 2000.

[86] Y. Li, A. Coughlan, F. R. Laffir, D. Pradhan, N. P. Mellott and A. W. Wren, "Investigating the mechanical durability of bioactive glasses as a function of structure, solubility and incubation time.," Journal of Non-Crystalline Solids, vol. 380, pp. 25-34, 2013.

[87] E. I. Kamitsos and G. D. Chryssikos, "Borate glass structure by Raman and infrared spectroscopies," Journal of Molecular Structure, vol. 247, pp. 1-16, 1991.

[88] J. Serra, P. Gonzalez, S. Liste, S. Chiussi, B. Leon, M. Pérez-Amor, H. O. Ylänen and M. Hupa, "Influence of the non-bridging oxygen groups on the bioactivity of silicate glasses," Journal of Materials Science: Materials in Medicine, vol. 13, no. 12, pp. 1221-1225, 2002.

[89] O. Rodriguez, W. Stone, M. Papini, E. H. Schemitsch, P. Zalzal, S. Waldman and M. R. Towler, "Biocompatibility Behavior of Silica-based and Borate-based, Titaniumcontaining Bioactive Glasses: Solubility, Cytotoxicity and Antibacterial Analysis," Journal of Non-Crystalline Solids (under review), 2016. 
[90] A. Yao, D. Wang, W. Huang, Q. Fu, M. Rahaman and D. Day, "In Vitro Bioactive Characteristics of Borate-Based Glasses with Controllable Degradation Behavior," Journal of the American Ceramic Society, vol. 90, no. 1, pp. 303-306, 2007.

[91] M. N. Rahaman, D. E. Day, B. S. Bal, Q. Fu, J. S. B. L. F. Bonewald and A. P. Tomsia, "Bioactive glass in tissue engineering," Acta Biomaterialia, vol. 7, no. 6, pp. 2355-2373, 2011.

[92] A. A. Gorustovich, J. M. P. López, M. B. Guglielmotti and R. L. Cabrini, "Biological performance of boron-modified bioactive glass particles implanted in rat tibia bone marrow.," Biomedical Materials, vol. 1, no. 3, p. 100, 2006.

[93] I. Sondi and B. Salopek-Sondi, "Silver nanoparticles as antimicrobial agent: a case study on E. coli as a model for Gram-negative bacteria," Journal of Colloid and Interface Science, vol. 275, no. 1, pp. 177-182, 2004.

[94] C. McDevitt, A. Ogunniyi, E. Valkov, M. Lawrence, B. Kobe, A. McEwan and J. Paton, "A molecular mechanism for bacterial susceptibility to zinc," PLoS Pathogens, vol. 7, no. 11, p. e1002357, 2011.

[95] A. Azam, A. Ahmed, M. Oves, M. Khan, S. Habib and A. Memic, "Antimicrobial activity of metal oxide nanoparticles against Gram-positive and Gram-negative bacteria: a comparative study," International Journal of Nanomedicine, vol. 7, no. 7, pp. 6003-6009, 2012.

[96] ISO 10993-5, Biological Evaluation of Medical Sevices - Part 5: Tests for in vitro Cytotoxicity, Geneva: International Organization for Standardization, 2009.

[97] V. Aina, A. Perardi, L. Bergandi, G. Malavasi, L. Menabue, C. Morterra and D. Ghigo, "Cytotoxicity of zinc-containing bioactive glasses in contact with human osteoblasts," Chemico-Biological Interactions, vol. 167, no. 3, pp. 207-218, 2007.

[98] R. Brown, M. Rahaman, A. Dwilewicz, W. Huang, D. Day, Y. Li and B. Bal, "Effect of borate glass composition on its conversion to hydroxyapatite and on the proliferation of 
MC3T3-E1 cells," Journal of Biomedical Materials Research Part A, vol. 88, no. 2, pp. 392-400, 2009.

[99] X. Zhang, W. Jia, Y. Gu, W. Xiao, X. Liu, D. Wang, C. Zhang, W. Huang, M. Rahaman, D. Day and N. Zhou, "Teicoplanin-loaded borate bioactive glass implants for treating chronic bone infection in a rabbit tibia osteomyelitis model," Biomaterials, vol. 31, no. 22, pp. 5865-5874, 2010.

[100] I. Kansal, A. Reddy, F. Muñoz, S. Choi, H. Kim, D. Tulyaganov and J. Ferreira, "Structure, biodegradation behavior and cytotoxicity of alkali-containing alkaline-earth phosphosilicate glasses," Materials Science and Engineering: C, vol. 44, pp. 159-165, 2014.

[101] A. Tilocca, "Sodium migration pathways in multicomponent silicate glasses: CarParrinello molecular dynamics simulations," The Journal of Chemical Physics, vol. 133, no. 1, p. $014701,2010$.

[102] A. G. Gristina, "Biomaterial-centered infection: microbial adhesion versus tissue integration," Science, vol. 237, no. 4822, pp. 1588-1595, 1987.

[103] J. Odekerken, T. Welting, J. Arts, G. Walenkamp and P. Emans, "Modern Orthopaedic Implant Coatings - Their Pro’s, Con's and Evaluation Methods," in Modern Surface Engineering Treatments, INTECH, 2013, pp. 45-73.

[104] O. Rodriguez, A. Matinmanesh, M. Papini, E. H. Schemitsch, P. Zalzal, S. Peel, O. Clarkin and M. R. Towler, "Silica-based and Borate-based, Titania-containing Bioactive Coatings Characterization: critical energy release rate, residual stresses, hardness and thermal expansion," Journal of Functional Biomaterials, vol. 7, no. 4, p. 32, 2016.

[105] ASTM Standard E228, 2011, Standard test method for linear thermal expansion of solid materials with a push-rod dilatometer, West Conshohocken, PA: ASTM International, 2011. 
[106] H. J. Oel and V. D. Frechette, "Stress distribution in multiphase systems: I, composites with planar interfaces," Journal of the American Ceramic Society, vol. 50, no. 10, pp. 542$549,1967$.

[107] Y. Yu, I. A. Ashcroft and G. Swallowe, "An experimental investigation of residual stresses in an epoxy-steel laminate," International Journal of Adhesion and Adhesives, vol. 26, no. 7, pp. 511-519, 2006.

[108] T. Kokubo, H. M. Kim and M. Kawashita, "Novel bioactive materials with different mechanical properties," Biomaterials, vol. 24, no. 13, pp. 2161-2175, 2003.

[109] T. L. Anderson, Fracture mechanics: fundamentals and applications, Boca Raton, FL: CRC press, 2005.

[110] J. Kruzic, D. Kim, K. Koester and R. Ritchie, "Indentation techniques for evaluating the fracture toughness of biomaterials and hard tissues," Journal of the Mechanical Behavior of Biomedical Materials, vol. 2, no. 4, pp. 384-395, 2009.

[111] S. M. Wiederhorn, "Fracture surface energy of glass," Journal of the American Ceramic Society, vol. 52, no. 2, pp. 99-105, 1969.

[112] D. S. Harding, W. C. Oliver and G. M. Pharr, "Cracking during nanoindentation and its use in the measurement of fracture toughness," in In MRS Proceedings, 1994.

[113] S. P. Venkateshan, Mechanical measurements, John Wiley \& Sons, 2015.

[114] J. C. Hurt and C. J. Phillips, "Structural Role of Zinc Oxide in Glasses in the System Na2O-ZnO-SiO2," Journal of the American Ceramic Society, vol. 53, no. 5, pp. 269-273, 1970.

[115] W. Elber, "Effects of shot-peening residual stresses on the fracture and crack-growth properties of D6AC steel," In Fracture Toughness and Slow-Stable Cracking, 1974.

[116] V. M. Sglavo, L. Larentis and D. J. Green, "Flaw-Insensitive Ion-Exchanged Glass: I, 
Theoretical Aspects," Journal of the American Ceramic Society, vol. 84, no. 8, pp. 1827$1831,2001$.

[117] R. Bermejo, Y. Torres, A. J. Sanchez-Herencia, C. Baudín, M. Anglada and L. Llanes, "Residual stresses, strength and toughness of laminates with different layer thickness ratios," Acta Materialia, vol. 54, no. 18, pp. 4745-4757, 2006.

[118] J. W. Hutchinson and Z. Suo, "Mixed mode cracking in layered materials," Advances in Applied Mechanics, vol. 29, pp. 63-191, 1991.

[119] J. Clement, G. Avila, M. Navarro, S. Martinez, M. P. Ginebra and J. A. Planell, "Chemical durability and mechanical properties of calcium phosphate glasses with the addition of Fe2O3, TiO2 and ZnO," In Key Engineering Materials, vol. 192, pp. 621-624, 2001.

[120] V. Rajendran, A. G. Devi, M. Azooz and F. H. El-Batal, "Physicochemical studies of phosphate based $\mathrm{P} 2 \mathrm{O} 5-\mathrm{Na} 2 \mathrm{O}-\mathrm{CaO}-\mathrm{TiO} 2$ glasses for biomedical applications," Journal of Non-Crystalline Solids, vol. 353, no. 1, pp. 77-84, 2007.

[121] S. Yoshida, H. Tanaka, T. Hayashi, J. Matsuoka and N. Soga, "Scratch resistance of sodium borosilicate glass," Journal of the Ceramic Society of Japan, vol. 109, no. 1270, pp. 511-515, 2001.

[122] A. K. Seal, P. Chakraborti, N. R. Roy, S. Mukherjee, M. K. Mitra and G. C. Das, "Effect of phase separation on the fracture toughness of $\mathrm{SiO} 2-\mathrm{B} 2 \mathrm{O} 3-\mathrm{Na} 2 \mathrm{O}$ glass," Bulletin of Materials Science, vol. 28, no. 5, pp. 457-460, 2005.

[123] Y. Li, A. Matinmanesh, D. Curran, E. Schemitsch, P. Zalzal, M. Papini, A. Wren and M. Towler, "Characterization and Fracture Property of Different Strontium-containing Boratebased Glass Coatings for Ti6Al4V Substrates," Journal of Non-Crystalline Solids (accepted), 2016.

[124] I. Kashif, A. A. Soliman, H. Farouk and A. M. Sanad, "Effect of titanium addition on crystallization kinetics of lithium borosilicate glass," Journal of Alloys and Compounds, 
vol. 475 , no. 1 , pp. $712-717,2009$.

[125] L. Charles, M. Shaw, J. Olson and M. Wei, "Fabrication and mechanical properties of PLLA/PCL/HA composites via a biomimetic, dip coating, and hot compression procedure," Journal of Materials Science: Materials in Medicine, vol. 21, no. 6, pp. 18451854, 2010. 